\title{
GNREL
}

The North American

Renewable Integration Sturdy? A U.S.Perspective

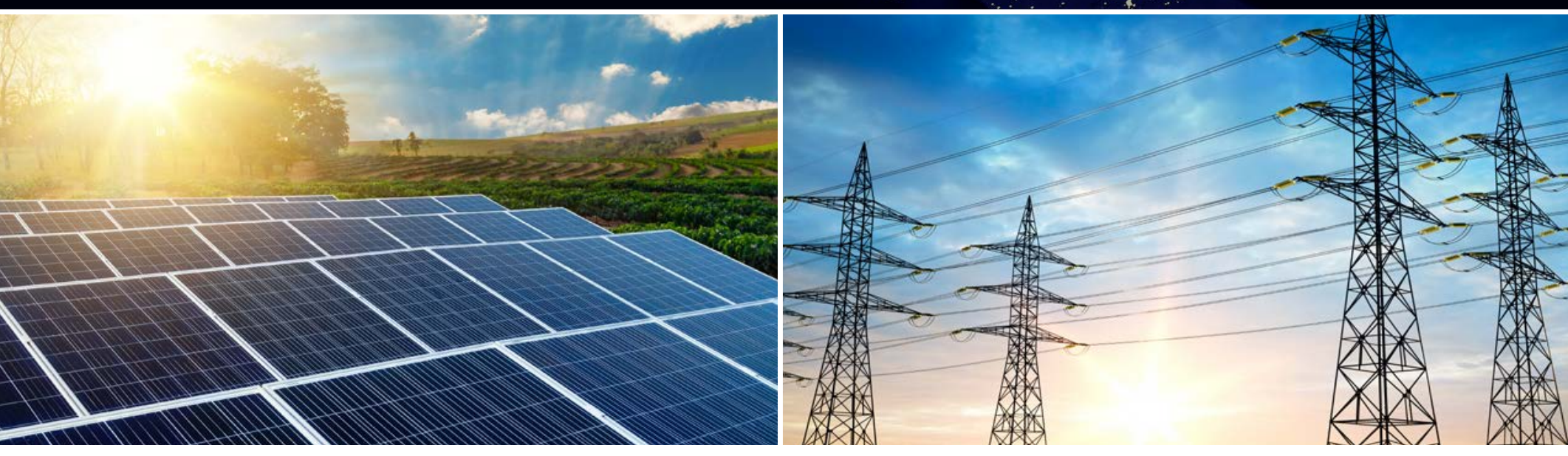

Gregory Brinkman,' Dominique Bain,' Grant Buster,' Caroline Draxl,' Paritosh Das,, Jonathan Ho,'

Eduardo Ibanez, Ryan Jones, ${ }^{3}$ Sam Koebrich,' Sinnott Murphy, Vinayak Narwade, Joshua Novacheck, Avi Purkayastha,' Michael Rossol,' Ben Sigrin,' Gord Stephen,' and Jiazi Zhang'

1 National Renewable Energy Laboratory

${ }^{2}$ GE Energy

${ }^{3}$ Evolved Energy Research 


\title{
GNREL
}

\section{The North American Renewable Integration Study: A U.S. Perspective}

\section{Authors}

Gregory Brinkman, ${ }^{1}$ Dominique Bain, ${ }^{1}$ Grant Buster, ${ }^{1}$ Caroline Draxl, ${ }^{1}$ Paritosh Das, ${ }_{1}$ Jonathan Ho, ${ }_{1}^{1}$ Eduardo Ibanez, ${ }_{1}^{2}$ Ryan Jones, ${ }^{3}$ Sam Koebrich,' Sinnott Murphy, 'Vinayak Narwade,' Joshua Novacheck, ${ }^{1}$ Avi Purkayastha, Michael Rossol, Ben Sigrin,' Gord Stephen,' and Jiazi Zhang'

\author{
${ }^{1}$ National Renewable Energy Laboratory \\ ${ }^{2}$ GE Energy \\ ${ }^{3}$ Evolved Energy Research
}

June 2021

\section{Suggested Citation}

Brinkman, Gregory, Dominique Bain, Grant Buster, Caroline Draxl, Paritosh Das, Jonathan Ho, Eduardo Ibanez, et al. 2021. The North American Renewable Integration Study: A U.S. Perspective. Golden, CO: National Renewable Energy Laboratory. NREL/TP-6A20-79224. https://www.nrel.gov/docs/fy21osti/79224.pdf

NREL is a national laboratory of the U.S. Department of Energy Office of Energy Efficiency and Renewable Energy Operated by the Alliance for Sustainable Energy, LLC

This report is available at no cost from the National Renewable Energy Laboratory (NREL) at www.nrel.gov/publications.

Contract No. DE-AC36-08GO28308
Technical Report NREL/TP-6A20-79224 June 2021

National Renewable Energy Laboratory 15013 Denver West Parkway, Golden, CO 80401 303-275-3000 • www.nrel.gov 
NOTICE

This work was authored in part by the National Renewable Energy Laboratory, operated by Alliance for Sustainable Energy, LLC, for the U.S. Department of Energy (DOE) under Contract No. DE-AC36- 08GO28308. The views expressed in the article do not necessarily represent the views of the DOE or the U.S. Government. Primary funding for the U.S. and Canadian reports was provided by Natural Resources Canada and the U.S. Department of Energy Office of Energy Efficiency and Renewable Energy's Wind Energy Technologies Office, Water Power Technologies Office, and Solar Energy Technologies Office. The Government of Mexico also provided funding for the NARIS project. 


\section{Preface}

This report is one of four reports published as part of the North American Renewable Integration Study, or NARIS:

- The North American Renewable Integration Study: A U.S. Perspective (this report)

- The North American Renewable Integration Study: A U.S. PerspectiveExecutive Summary

- The North American Renewable Integration Study: A Canadian Perspective

- The North American Renewable Integration Study: A Canadian PerspectiveExecutive Summary

For more information about NARIS, see www.nrel.gov/analysis/naris.html. 


\section{Acknowledgements}

The North American Renewable Integration Study (NARIS) was a multiyear, international effort on which many institutions collaborated and to which many individuals contributed. We would like to thank everyone who was involved in the study.

Members of the NARIS Technical Review Committee-which included experts representing approximately 50 utilities, grid system operators, and industry organizations throughout North America - helped guide the study assumptions, data, and methodologies to address relevant questions. Although the committee members helped review the report, it might not reflect the specific views or interpretations of any member of the committee or their institution. We would like to thank everyone who attended committee meetings (in person and virtual) or provided guidance during the study process, including those who provided specific comments on this report.

The authors would like to extend a special thanks for serving on the NARIS management team to Charlton Clark, Guohui Yuan, Sam Bockenhauer, Jian Fu, Tracey Kutney, Tom Levy, and Bronwyn Lazowski, and to Aaron Bloom for inspiration and support.

We would like to thank Jimmy Royer, Marcia Blanchette, Leonardo Beltrán Rodríguez, Efraín Villanueva Arcos, Fidel Carrasco, Riccardo Bracho, and Carlo Brancucci for helping develop the vision for NARIS and providing support. Thanks to Devonie McCamey, Mike Meshek, Madeline Schroeder, and Liz Craig for communications support.

Wes Jones, Harry Sorensen, and Tim Kaiser helped provide resources on computational science, which was invaluable for such a computationally intensive study. Thanks to Jo Ann Ranola, Robert Spencer, Ana Dyreson, and Billy Roberts for visualization of the inputs and results.

The authors of the report would also like to acknowledge the reviewers at Natural Resources Canada and the CanmetENERGY Research Centers, and Environment and Climate Change Canada for their review and feedback in the development of the companion report for Canada (these comments also improved this report). In addition to those already mentioned, we would like to thank Doug Arent, Gian Porro, Jennie Jorgenson, Kathryn Jackson, Hill Balliet, and Cynthia Bothwell for their reviews of the NARIS reports. Any omissions or errors are the responsibility of the authors.

Primary funding for the U.S. and Canadian reports was provided by Natural Resources Canada and the U.S. Department of Energy Office of Energy Efficiency and Renewable Energy's Wind Energy Technologies Office, Water Power Technologies Office, and Solar Energy Technologies Office. The Government of Mexico also provided funding for the NARIS project. 


\section{List of Acronyms and Abbreviations}

\begin{tabular}{|c|c|}
\hline $\mathrm{AB}$ & Alberta \\
\hline AEO & Annual Energy Outlook \\
\hline ATB & Annual Technology Baseline \\
\hline BAU & business as usual \\
\hline $\mathrm{BC}$ & British Columbia \\
\hline CAISO & California Independent System Operator \\
\hline CAMX & California and Mexico \\
\hline dGen & Distributed Generation Market Demand \\
\hline DPV & distributed photovoltaics \\
\hline ECMWF & European Centre for Medium-Range Weather Forecasts \\
\hline EIA & Energy Information Administration (United States) \\
\hline ERCOT & Electricity Reliability Council of Texas \\
\hline EUE & expected unserved energy \\
\hline FRCC & Florida Reliability Coordinating Council \\
\hline HQ & Hydro Quebec \\
\hline HVDC & high-voltage direct current \\
\hline IESO & Independent Electricity System Operator \\
\hline ISO & independent system operator \\
\hline LCOE & levelized cost of electricity \\
\hline LOLE & loss-of-load expectation \\
\hline LOLH & loss-of-load hours \\
\hline LTRA & Long-Term Reliability Assessment \\
\hline MAE & mean absolute error \\
\hline $\mathrm{MH}$ & Manitoba Hydro \\
\hline MISO & Midcontinent Independent System Operator \\
\hline MWh & megawatt-hours \\
\hline NARIS & North American Renewable Integration Study \\
\hline NEB & National Energy Board (Canada) \\
\hline NEM & net energy metering \\
\hline NERC & North American Electric Reliability Corporation \\
\hline NREL & National Renewable Energy Laboratory \\
\hline NWPP & Northwest Power Pool \\
\hline NYISO & New York Independent System Operator \\
\hline PCM & production cost model \\
\hline PRAS & Probabilistic Resource Adequacy Suite \\
\hline PRODESEN & Programa de Desarrollo del Sistema Eléctrico Nacional \\
\hline PV & photovoltaics \\
\hline ReEDS & Regional Energy Deployment System Model \\
\hline $\mathrm{reV}$ & Renewable Energy Potential Model \\
\hline RMRG & Rocky Mountain Reserve Group \\
\hline RTO & regional transmission organization \\
\hline SENER & Secretaría de Energía de México \\
\hline SPP & Southwest Power Pool \\
\hline SRSG & Southwest Reserve Sharing Group \\
\hline TEPPC & Transmission Expansion Planning Policy Committee \\
\hline
\end{tabular}


TWh

TW-mi

USD

VG

WECC

WIND

WRF terawatt-hours

terawatt-miles

U.S. dollars

variable generation

Western Electricity Coordinating Council

Wind Integration National Dataset

Weather Research and Forecasting 


\section{Table of Contents}

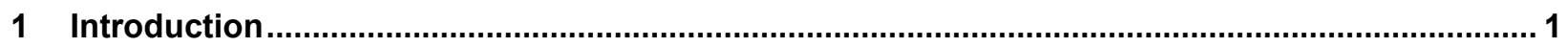

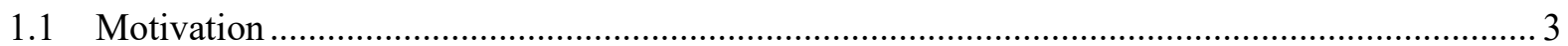

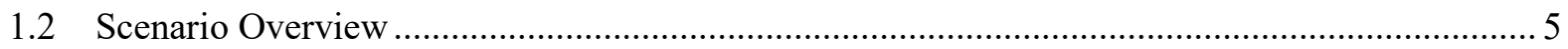

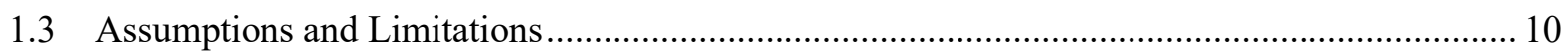

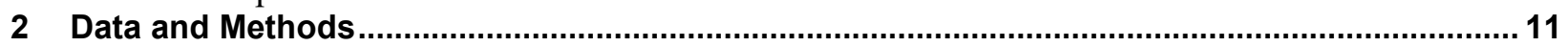

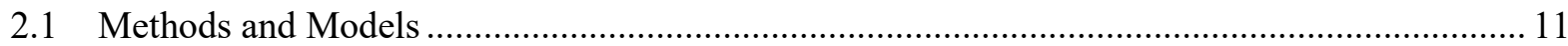

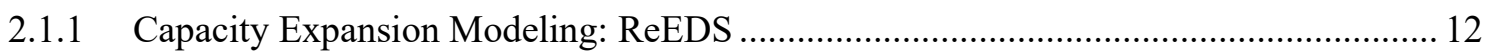

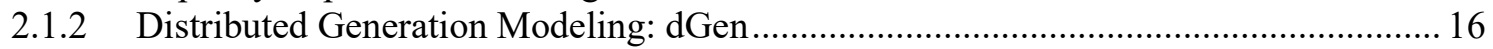

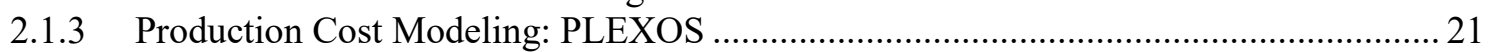

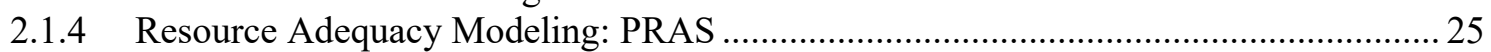

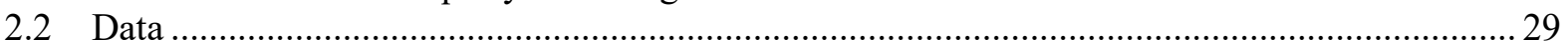

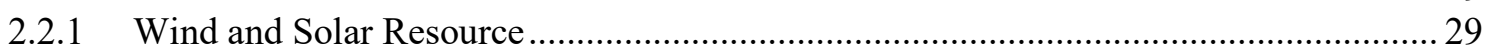

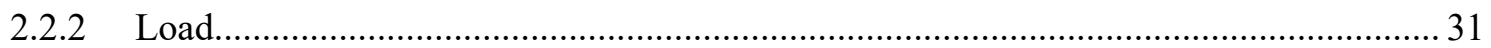

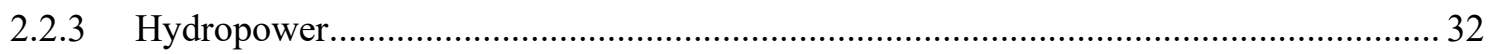

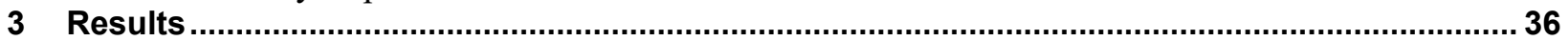

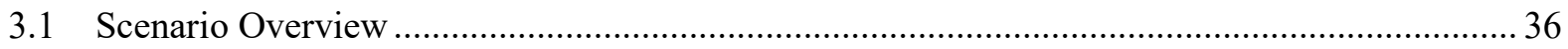

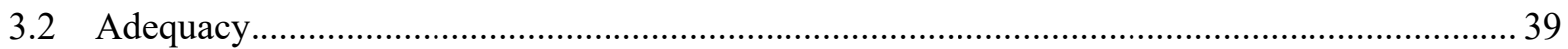

3.2.1 Resource adequacy can be maintained in low-carbon scenarios through 2050 ............ 39

3.2.2 All generation types can contribute to reliability in future scenarios.......................... 42

3.2.3 Thermal generation operates differently in future scenarios and provides more adequacy

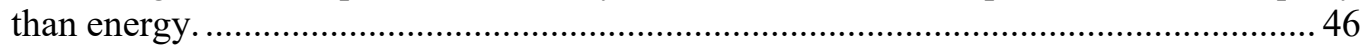

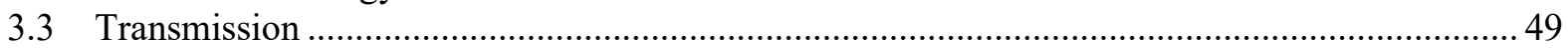

3.3.1 Cooperation and transmission between regions and countries leads to economic and

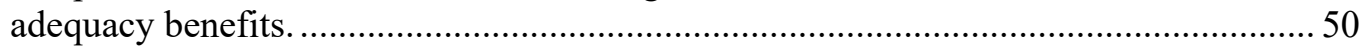

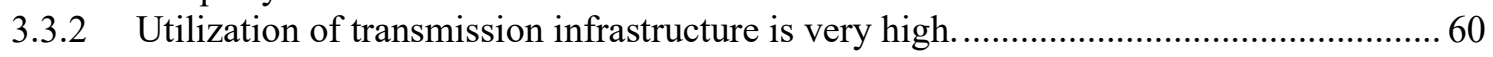

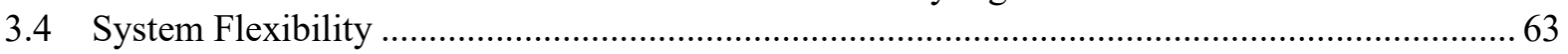

3.4.1 Operational flexibility comes from transmission, flexible operation of hydropower and

thermal resources, storage, and curtailment of wind and solar generation......................63

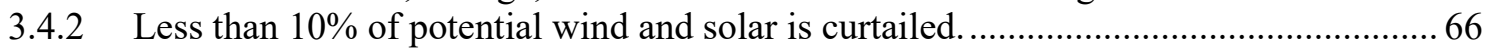

3.4.3 Hydropower contributes significantly to energy, adequacy, and flexibility................... 68

3.4.4 Hydropower flexibility reduces system costs by more than $\$ 2$ billion per year........... 70

3.4.5 Hundreds of gigawatts of storage could be installed if costs came down significantly. 73

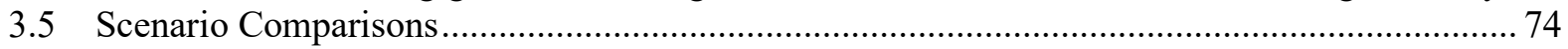

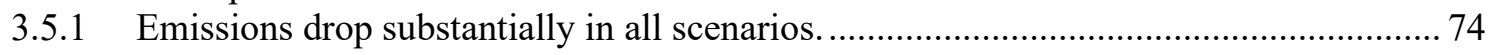

3.5.2 Distributed generation is likely to play a significant role in generation; costs strongly

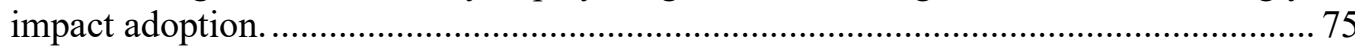

3.5.3 Total costs are more sensitive to electrification and assumptions about wind and solar

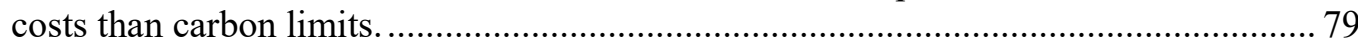

3.5.4 Widespread electrification requires approximately doubling infrastructure investment

from other core scenarios; further research is needed.............................................. 80

3.5.5 Using better information during unit commitment reduces costs and curtailment......... 84

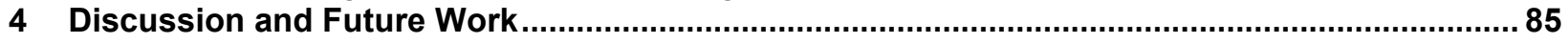

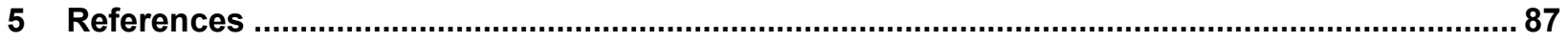




\section{List of Figures}

Figure 1. North American wind (top) and solar (bottom) resource ..................................................... 4

Figure 2. Installed hydropower and transmission lines of North America ............................................... 5

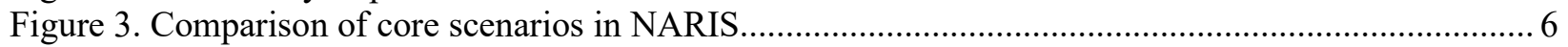

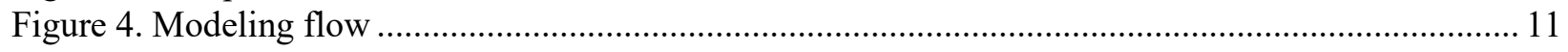

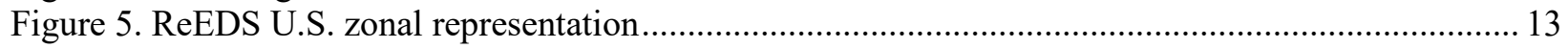

Figure 6. Cost comparison for wind (left) and solar PV (right) in the 2018 ATB and the 2020 ATB ...... 16

Figure 7. Distributed PV resource quality by country ................................................................ 18

Figure 8. Distributed PV resource quality within the United States by sector...................................... 18

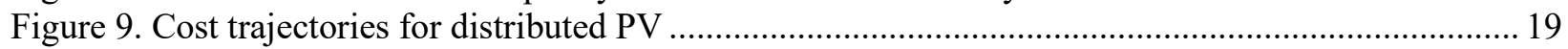

Figure 10. Sample PLEXOS output of U.S. generation dispatch stack for the week of June 24 (2050 Low

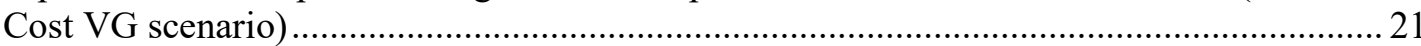

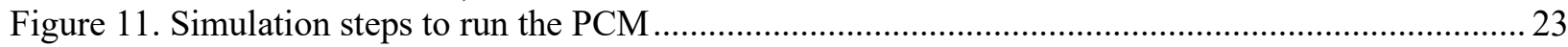

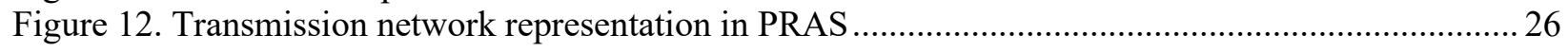

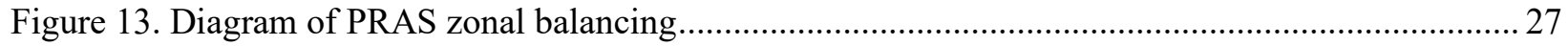

Figure 14. The three domains used in NARIS for wind modeling ..................................................... 30

Figure 15 . Weekly maximum, mean, and minimum hydropower generation from U.S. generators .......... 34

Figure 16. U.S. generation in 2024 and 2050 in the NARIS core scenarios........................................ 37

Figure 17. U.S. generation capacity in 2024 and 2050 in the NARIS core scenarios ............................... 37

Figure 18. Fraction of generation coming from renewable generators in the United States...................... 39

Figure 19. Normalized average aggregate EUE (ppm) by scenario and load multiplier for the

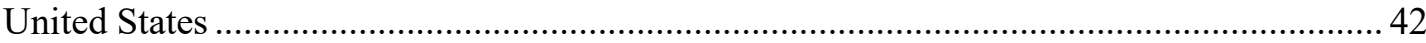

Figure 20. U.S. contribution of different technologies to energy and planning reserve in the Low Cost VG

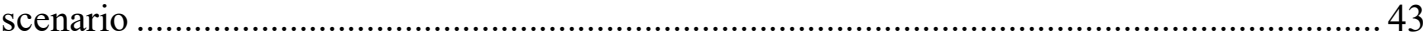

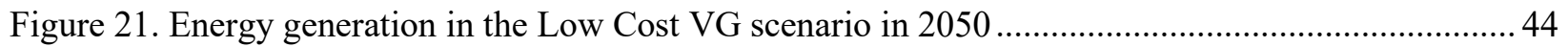

Figure 22. Summer planning reserve in the Low Cost VG scenario......................................................45

Figure 23. Winter planning reserve in the Low Cost VG scenario ...................................................... 45

Figure 24. Contribution of renewable generators to summer planning reserve needs in the United States 46

Figure 25. Thermal generation utilization in Low Cost VG scenario in 2050 by interconnection ............. 48

Figure 26. Thermal generation utilization in the U.S. Western Interconnection (Low Cost VG 2050) ..... 48

Figure 27. Thermal generation utilization in the U.S. Eastern Interconnection (Low Cost VG 2050)....... 49

Figure 28. Thermal generation utilization in the Texas Interconnection (Low Cost VG 2050) ................ 49

Figure 29 Added transmission capacity in the core scenarios (measured in GW of interface expansion) . 50

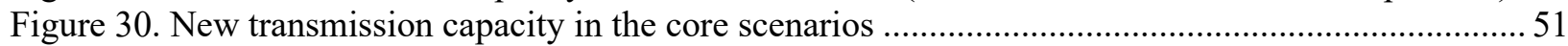

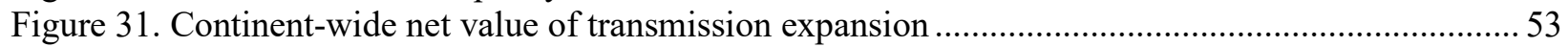

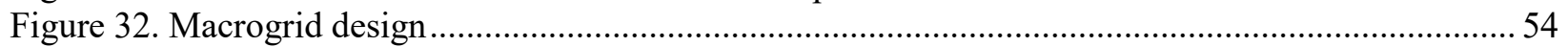

Figure 33. Net United States/Canada trade in all scenarios (core scenarios colored) ................................ 55

Figure 34. Gross United States/Canada trade in all scenarios (with core scenarios colored) .................... 55

Figure 35 Net U.S./Mexico trade in all scenarios (with core scenarios colored)..................................... 57

Figure 36 Gross U.S./Mexico trade in all scenarios (with core scenarios colored) .................................. 57

Figure 37. Maximum utilization of paths in the near-term (2024) PRAS adequacy model....................... 58

Figure 38. Maximum utilization of paths in the Low Cost VG 2050 scenario in PRAS model ................ 59

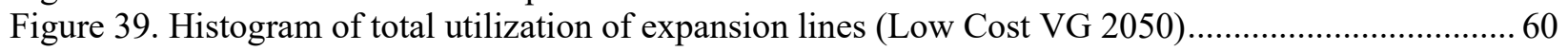

Figure 40. Net interchange between regions and their neighbors over the year (Low Cost VG 2050)...... 61

Figure 41. Gross interchange between regions and their neighbors over the year (Low Cost VG 2050)... 62

Figure 42. Duration curve of flows along major U.S. interfaces in Low Cost VG 2050......................... 63

Figure 43. U.S. Eastern Interconnection generation dispatch stack for early September (Low Cost VG 2050)

Figure 44. U.S. Western Interconnection generation dispatch stack for early September (Low Cost VG 2050) 
Figure 45. Texas Interconnection generation dispatch stack for early September (LowCost VG 2050).... 65

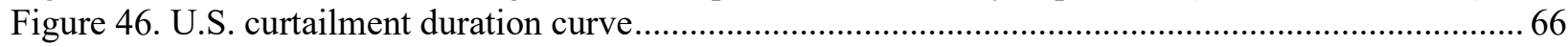

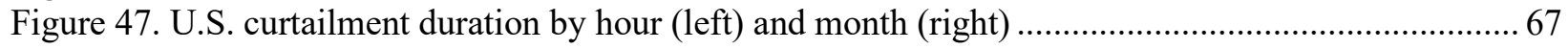

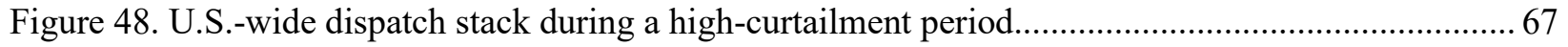

Figure 49. U.S. Western Interconnection hydropower and net load during a week with both high- and low-load days in September in the Low Cost VG 2050 scenario ........................................... 68

Figure 50 U.S. Western Interconnection hydropower generation and net load during a week with high

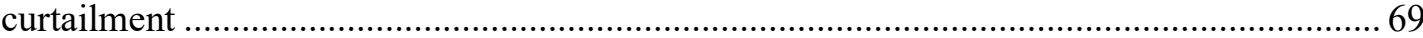

Figure 51 Total U.S. generation versus total U.S. net load for the entire year .................................... 70

Figure 52. Daily cost reduction from hydropower flexibility ......................................................... 72

Figure 53. Change in 2050 capacity for core scenarios with lower-cost storage availability.................... 73

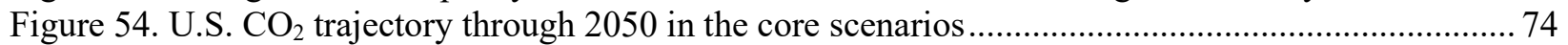

Figure 55. Cumulative U.S. DPV deployment by cost scenario ............................................................... 75

Figure 56. Projected DPV installed capacity (Mid Cost Scenario) by county .......................................... 77

Figure 57. Histograms of average retail cost of electricity $(\$ / \mathrm{kWh})$ across United States by sector.......... 78

Figure 58. DPV payback periods by year across sectors and scenarios................................................. 79

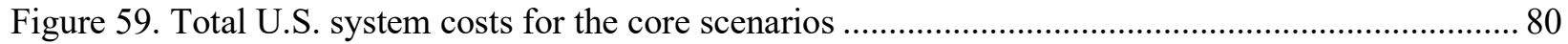

Figure 60. Load growth due to additional electrification in the Electrification scenario......................... 81

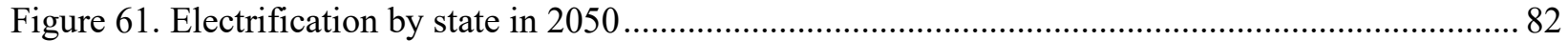

Figure 62. Generation capacity difference in 2050 (left) and total new transmission builds (right) between

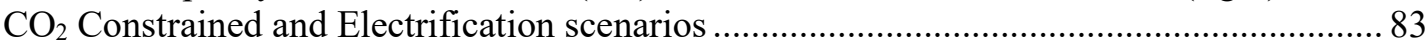

\section{List of Tables}

Table 1. Key Assumptions in the NARIS Core Scenarios through 2050 ............................................. 5

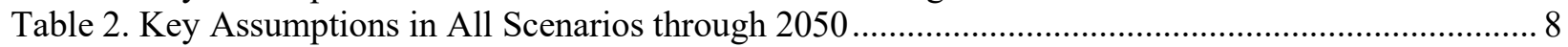

Table 3. Data Sources for All Three Countries in the Core Scenarios in ReEDS .................................... 14

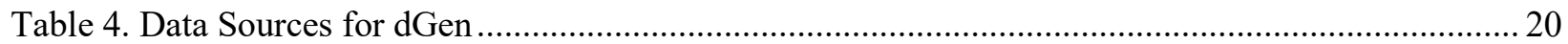

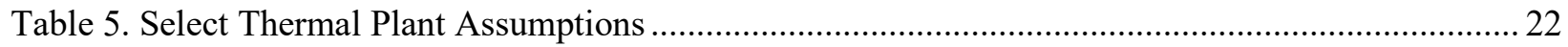

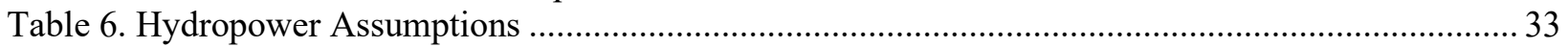

Table 7. U.S. Generation Capacity (GW) in 2024 and 2050 in the NARIS Core Scenarios ...................... 38

Table 8. EUE by Scenario and Meteorological Year for the United States, Compared to NERC LTRA .. 40

Table 9. Loss of Load Hours (LOLH) by Scenario, Compared to NERC LTRA....................................... 41

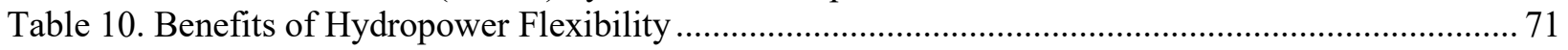

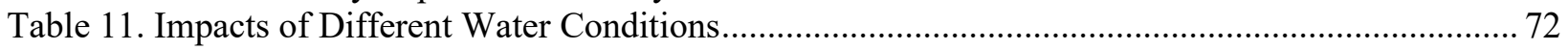

Table 12. Cumulative Adoption (GW) in 2050 by Region for Cost and Policy Sensitivities.................... 76

Table 13. Continent-Wide Cost Impacts of Forecast Quality Used During Unit Commitment ................. 84 


\section{Introduction}

The North American Renewable Integration Study (NARIS) is the first detailed power system integration study for the entire North American continent. NARIS aims to inform grid planners, operators, policymakers, and other stakeholders about the potential opportunities for system integration of large amounts of wind, solar, and hydropower to create a low-carbon grid in the future. The NARIS project began in 2016. This report describes a U.S. perspective in coordination with the U.S. Department of Energy, and a companion report describes a Canadian perspective in coordination with Natural Resources Canada.

The North American electric power grids are evolving toward higher contributions of variable generation (VG) resources (i.e., wind and solar) for several reasons, including lower costs and lower emissions. NARIS analyzes the entire North American continent, which is composed of five asynchronous interconnections that overlap the three countries. The analysis and conclusions of the study can help guide stakeholders to understand how the components of the power system can help work together to create a reliable, cost-effective, low-carbon grid in North America. This includes understanding the benefits of different technologies and operating practices to the future system.

The key analysis goals of NARIS were to evaluate a set of possible pathways for North American grid evolution through 2050 and to leverage production cost and Monte Carlo modeling tools to understand key questions about grid flexibility and resource adequacy.

NARIS extends and complements grid integration studies from the past, including the Pan Canadian Wind Integration Study (GE Energy Consulting 2016), Western Wind and Solar Integration Study (GE Energy 2010), and Eastern Renewable Generation Integration Study (Bloom et al. 2016). However, there are a few key differences between NARIS and most of these large, stakeholder-driven studies:

- NARIS studies all the grid-connected portions of Canada, the United States, and Mexico and applies consistent methods and data throughout. This includes the Eastern Interconnection, the Western Interconnection, the Texas Interconnection, the Quebec Interconnection, and the Sistema Eléctrico Nacional (Mexico).

- Partly because of its longer study horizon, NARIS studies higher deployment of renewable generation, especially VG resources such as wind and solar photovoltaics, throughout North America.

- NARIS optimizes the entire generation fleet and transmission infrastructure evolution through 2050, which makes each scenario specifically designed to key assumptions (Section 1.2). Many previous integration studies started with a planned system and added wind and solar to that system, without additional retirements or changes to the rest of the generating fleet. 
Some of the key accomplishments of NARIS include:

- Analysis

- Performed the most comprehensive long-term analysis of power system evolution to date on the North American grid using models and data sets described in Section 2

- Analyzed the feasibility and adequacy of high-renewable scenarios

- Analyzed the value of technologies, including transmission, hydropower flexibility, and storage in the future power system

- Tools and Methods

- Created continental capacity expansion planning tool (Regional Energy Deployment System Model, or ReEDS) based on expansion of the existing U.S. tool. The ReEDS model and data for the United States is open-sourced, with extensibility for Canada and Mexico pending public data. Aggregated results from the ReEDS modeling in NARIS are available on the NARIS website. ${ }^{1}$

- Created open-sourced the Probabilistic Resource Adequacy Suite (PRAS) ${ }^{2}$ modeling framework to assess multiregional system reliability metrics.

- Improved methods for representing resource adequacy in capacity expansion models to produce reliable scenarios. This method has been open-sourced as part of ReEDS.

- Created open-sourced, consistent, continent-wide wind resource data with 5minute time resolution representing 2007-2014 (expanding the existing U.S. data set for wind). Solar 5-minute data were downscaled from existing the 30-minute National Solar Radiation Database data set. ${ }^{3}$

- Created 5-minute resolution data sets for wind power, solar power, and load for a variety of scenarios

- Created the open-source Renewable Energy Potential Model (reV) ${ }^{4}$ model for geospatial analysis and data preparation for consistent use between modeling platforms.

- Created dGen (Distributed Generation Market Demand) ${ }^{5}$ distributed photovoltaics (DPV) adoption models for Canada and Mexico by extending the existing U.S.

\footnotetext{
1 "North American Renewable Integration Study," NREL, https://www.nrel.gov/analysis/naris.html.

2 "Probabilistic Resource Adequacy Suite," GitHub, https://github.com/NREL/PRAS.

${ }^{3}$ Data are available at "NREL Wind Integration National Dataset," Amazon Web Services, https://registry.opendata.aws/nrel-pds-wtk/. Usage examples are available at "NREL Highly Scalable Data Service (HSDS) Examples," GitHub, https://github.com/nrel/hsds-examples. Solar data are available at "NSRDB: National Solar Radiation Database," NREL, https://nsrdb.nrel.gov/.

4 "reV: The Renewable Energy Potential Model," NREL, https://www.nrel.gov/gis/renewable-energy-potential.html.

5 “Distributed Generation Market Demand," NREL, https://www.nrel.gov/analysis/dgen/.
} 
model, with as much data consistency with the U.S. model as the data sources allow

- Refined hydropower flexibility assumptions in the models, enabling sensitivities to understand the value of flexibility.

The primary technologies considered in NARIS were wind, solar PV, and hydropower, with a focus on the flexibility benefits of existing hydropower. Transmission and storage were examined with a variety of modeling runs. Other renewable generation technologies that might contribute to the system in 2050 but were not a key focus in the study include concentrating solar power, geothermal, and biomass; for these resources (and also nuclear generation), existing assumptions in the models and data sets were used (for costs and performance of new and existing assets), but no additional scenario analysis was done to understand the potential pathways for these resources.

The methods and analysis for this study were guided by the NARIS Technical Review Committee, which helped ensure the methods and data were rigorous, and that we were addressing important questions.

\subsection{Motivation}

North America has abundant and diverse energy resources, including renewable resources. For example, Figure 1 (page 4) shows wind and solar resource, and Figure 2 (page 5) shows hydropower installations and transmission infrastructure. However, with significant growth in wind and solar generation in the past decade, the grid is becoming more meteorologically dependent than ever before. NARIS endeavors to examine the challenges and opportunities associated with this increased dependence.

Existing and new generation technologies like reservoir, run-of-river, and pumped-storage hydropower; battery storage; and thermal generation all play a role in the future grid. NARIS' findings, like those of much previous work, verify that transmission infrastructure with coordinated operation can help North America take advantage of the diversity of resources to produce affordable and reliable energy. NARIS aims to analyze some of the ways these technologies can work together in a variety of future scenarios. 

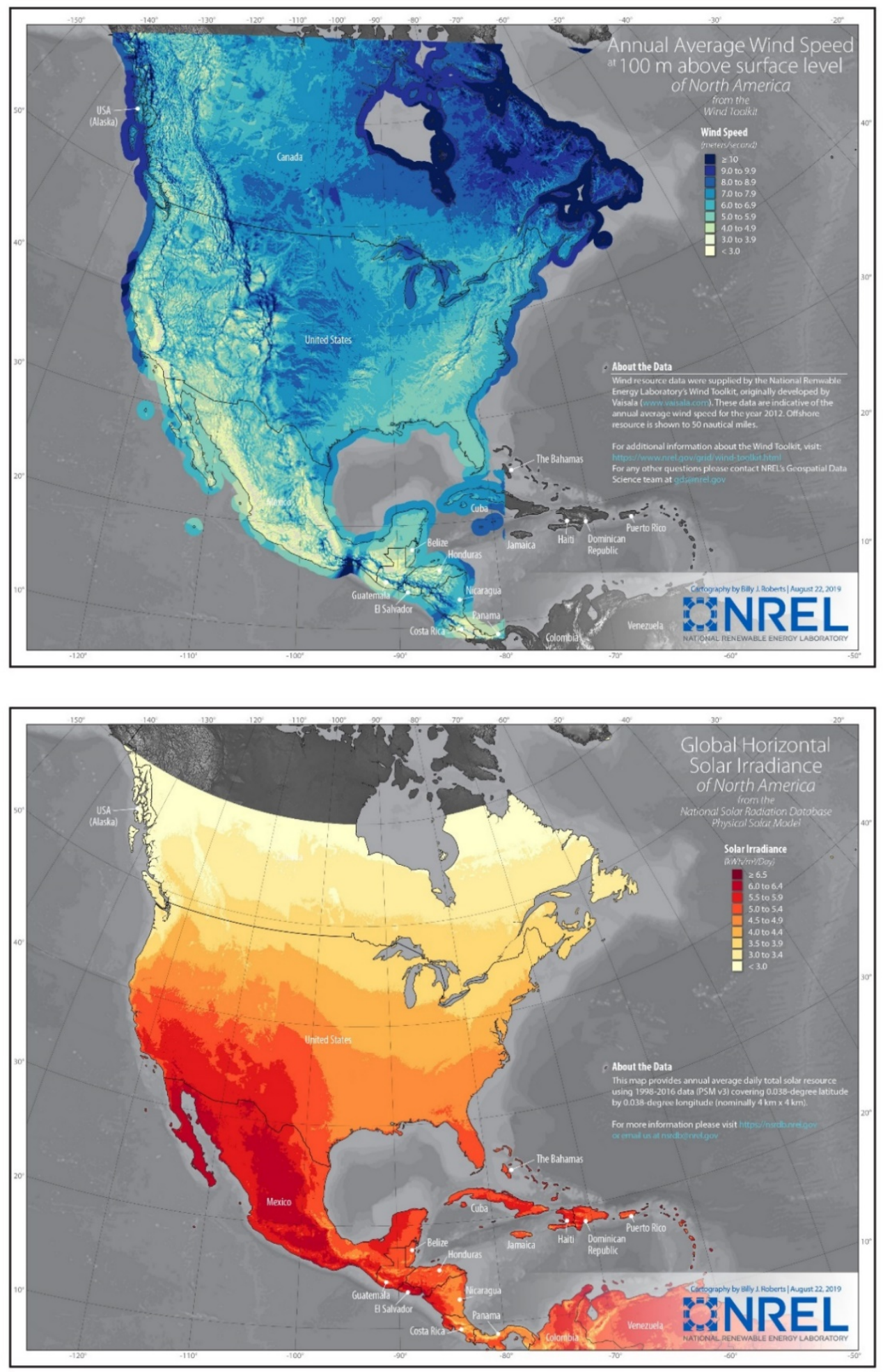

Figure 1. North American wind (top) and solar (bottom) resource

North America has some of the best wind and solar resource in the world, and all regions have excellent wind or solar resources nearby. Many regions have good resource for both wind and solar. These maps show the resource potential; siting and other constraints will limit deployment in some areas, and other inputs like temperature and air density will impact the translation of the resource to power. 


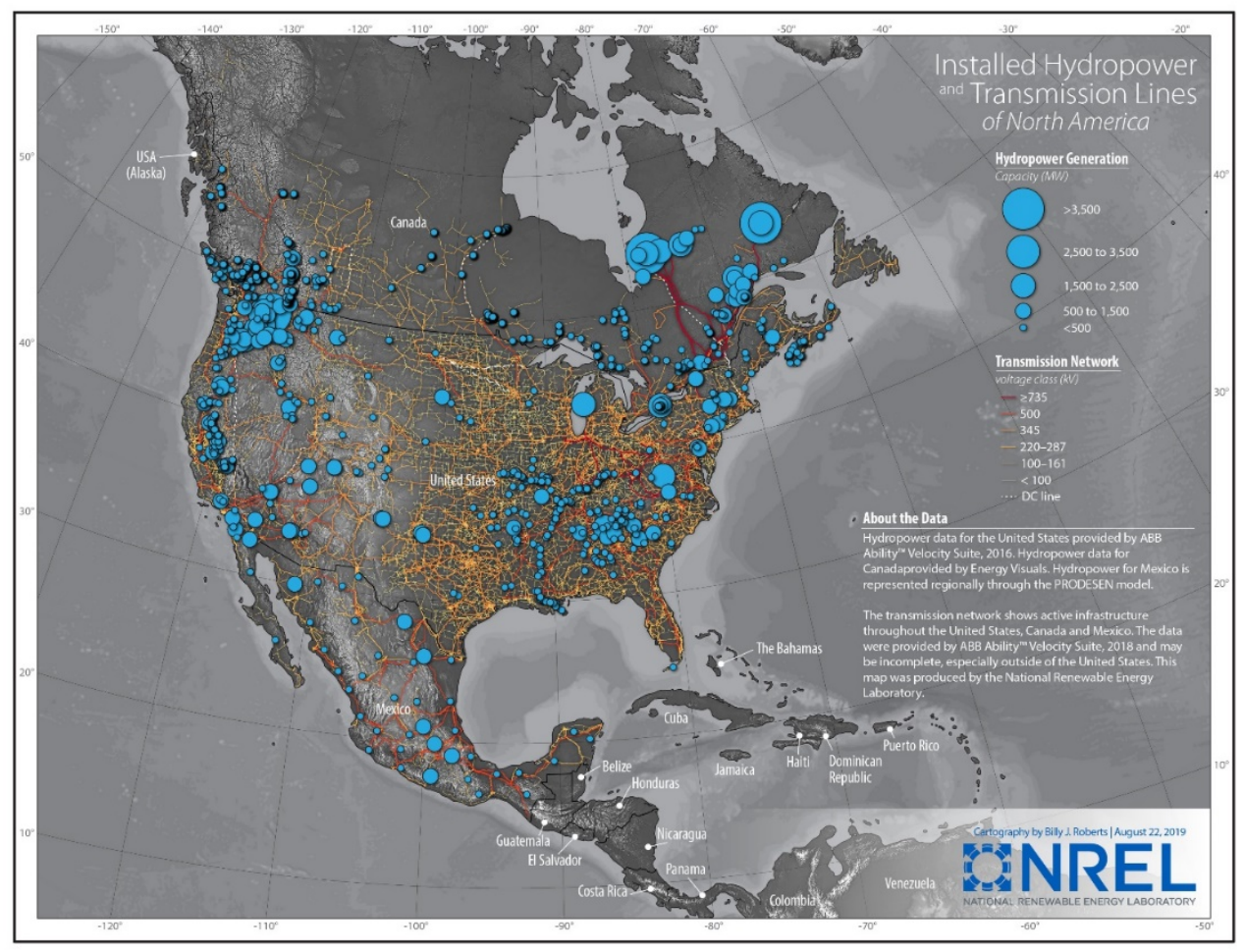

Figure 2. Installed hydropower and transmission lines of North America

North America has hydropower resource concentrated in several regions throughout the continent. It is evident that many high-voltage transmission lines have been built to connect hydropower with load centers (e.g., the West Coast and East Coast). Transmission helps enable geographic diversity among all generating resources and load, and hydropower generation can also contribute to the flexibility. Although the NARIS scenarios do not model extensive hydropower expansion, the value provided by hydropower is examined in Section 3.4

\subsection{Scenario Overview}

The NARIS scenarios were designed to examine a range of future possible grid evolution; many of them share assumptions with the annual National Renewable Energy Laboratory (NREL) Standard Scenarios ${ }^{6}$ work. The four "core scenarios" shown in Table 1 indicate four potential pathways of North American grid evolution through 2050. Figure 3 shows the key assumptions for the core scenarios; detailed assumptions are available in Section 2.

Table 1. Key Assumptions in the NARIS Core Scenarios through 2050

\begin{tabular}{|c|c|}
\hline Scenario & Key Assumptions \\
\hline $\begin{array}{l}\text { Business as Usual } \\
\text { (BAU) }\end{array}$ & $\begin{array}{l}\text { The North American grid continues to evolve with expected trajectories for all } \\
\text { technology costs, and there are no major changes to carbon legislation across } \\
\text { the continent. The scenario includes only state-based requirements as of } \\
\text { October } 2018 \text { in the United States. }\end{array}$ \\
\hline $\begin{array}{l}\text { Low-Cost Variable } \\
\text { Generation (Low- } \\
\text { Cost VG) }\end{array}$ & 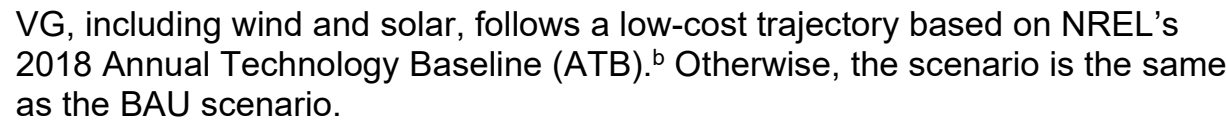 \\
\hline
\end{tabular}

\footnotetext{
6 “'Standard Scenarios ," NREL, https://www.nrel.gov/analysis/standard-scenarios.html.
} 


\begin{tabular}{|c|c|}
\hline Scenario & Key Assumptions \\
\hline $\begin{array}{l}\text { Carbon Constrained } \\
\left(\mathrm{CO}_{2} \text { Constrained }\right)\end{array}$ & $\begin{array}{l}\text { Carbon emissions from the electricity sector are reduced throughout North } \\
\text { America, including an } 80 \% \text { reduction from } 2005 \text { levels in the United States and } \\
\text { Mexico and a } 92 \% \text { reduction in Canada, also from } 2005 \text { levels. }{ }^{\text {a Otherwise, the }} \\
\text { scenario is the same as the BAU scenario. }\end{array}$ \\
\hline Electrification & $\begin{array}{l}\text { New end-use energy demands, including heating and transportation are } \\
\text { electrified. And } 2050 \text { loads are nearly double the } 2020 \text { loads. Otherwise, the } \\
\text { scenario is the same as Carbon Constrained scenario. }\end{array}$ \\
\hline
\end{tabular}

a The starting points for the carbon assumptions, especially in the Carbon Constrained scenarios, were the Paris Agreement Mid-Century Strategy documents in all three countries (Government of Canada 2016; SEMARNATINECC 2016; White House 2016), with the BAU being based on legislation in Canada

b “Annual Technology Baseline: 2018 ATB," NREL, https://atb.nrel.gov/electricity/2018/.

\section{Low-cost VG}

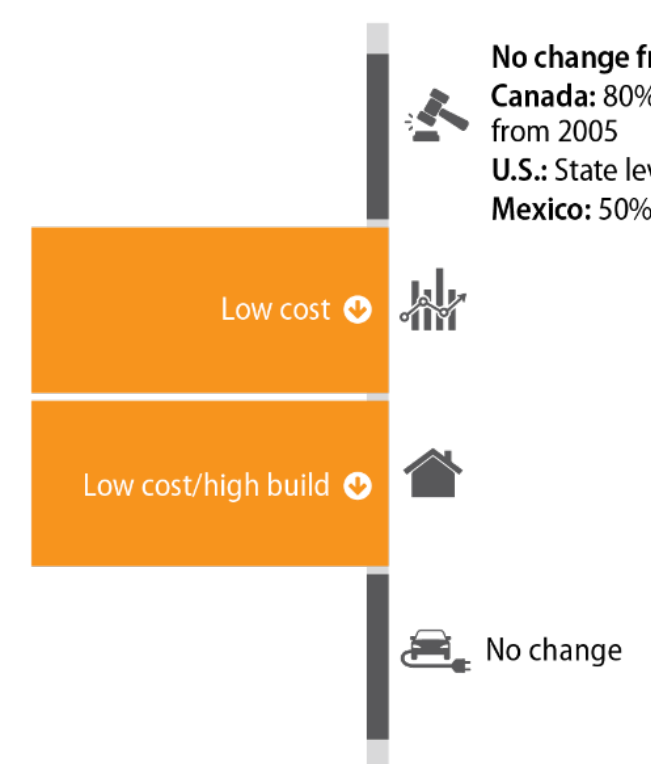

BAU

\section{$\mathrm{CO}_{2}$ constrained}
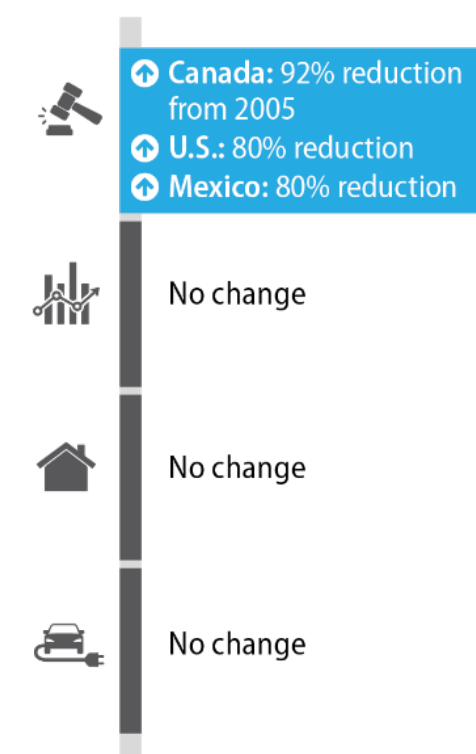

BAU

\section{Electrification}

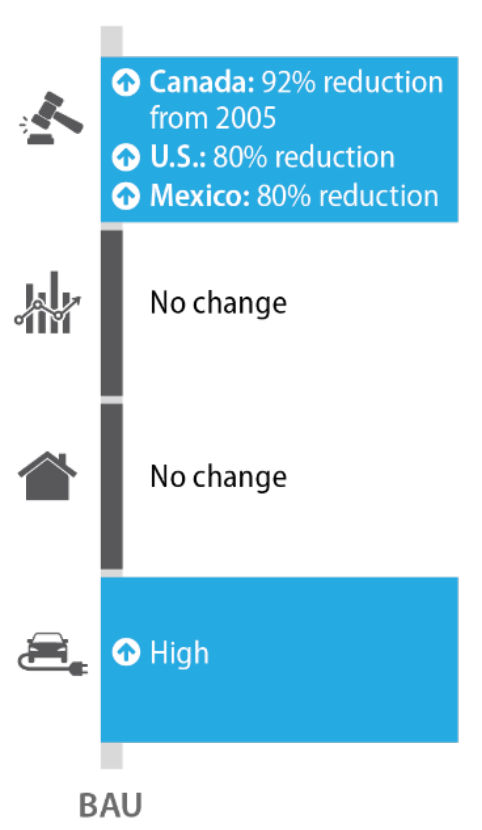

$\underline{\text { Legend }}$

- Carbon policies

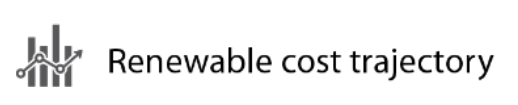

Distributed generation

Electrification

Figure 3. Comparison of core scenarios in NARIS

All changes noted above are in comparison with the BAU. 
We also studied a variety of sensitivities to these core scenarios, typically by varying one assumption at a time. These changes include gas prices, transmission build assumptions, storage costs, and other variables. Each sensitivity describes the entire evolution of the grid through 2050 and is referred to as a "scenario" throughout the report. This report focuses primarily on the core scenarios, especially the BAU and Low-Cost VG. The sensitivities help us understand uncertainty and help us quantify the impacts of key assumptions or technologies. Where the additional scenarios are important for conclusions, they are described and presented in the appropriate section. Detailed results for all scenarios are available are available on the NARIS website. $^{7}$

7 “North American Renewable Integration Study,” NREL, https://www.nrel.gov/analysis/naris.html. 
Table 2. Key Assumptions in All Scenarios through 2050

\begin{tabular}{|c|c|c|c|c|c|c|c|c|}
\hline $\begin{array}{l}\text { Scenario } \\
\text { (+ Sensitivity Tag) }\end{array}$ & $\begin{array}{l}\text { Canada Carbon } \\
\text { Policy }^{b}\end{array}$ & $\begin{array}{l}\text { U.S. Carbon } \\
\text { Policyb }\end{array}$ & $\begin{array}{l}\text { Mexico Carbon } \\
\text { Policyb }\end{array}$ & $\begin{array}{l}\text { Cost } \\
\text { Trajectories }\end{array}$ & Transmission ${ }^{c}$ & Retirements $^{d}$ & Electrification ${ }^{\mathrm{e}}$ & $\begin{array}{l}\text { Gas } \\
\text { Price }\end{array}$ \\
\hline Business as Usual (BAU) & $80 \%$ Reduction & State-Level & $50 \%$ clean & BAU & Coordinated & BAU & BAU & BAU \\
\hline BAU Early Retire & - & - & - & - & - & Early & - & - \\
\hline BAU High Cost Gas & - & - & - & - & - & - & - & High \\
\hline BAU Low Cost Gas & - & - & - & - & - & - & - & Low \\
\hline BAU Low Cost Storage & - & - & - & $\begin{array}{l}\text { Low-cost } \\
\text { storage }\end{array}$ & - & - & - & - \\
\hline BAU Macro Grid & - & - & - & - & + Macrogrid & - & - & - \\
\hline $\begin{array}{l}\text { BAU No Cross-Border } \\
\text { Expansion }\end{array}$ & - & - & - & - & $\begin{array}{l}\text { + No new cross- } \\
\text { border lines } \\
\text { allowed }\end{array}$ & - & - & - \\
\hline $\begin{array}{l}\text { BAU No Cross-Border } \\
\text { Expansion Uncoordinated }\end{array}$ & - & - & - & - & $\begin{array}{l}\text { Uncoordinated, } \\
\text { no new cross- } \\
\text { border lines }\end{array}$ & - & - & - \\
\hline BAU Uncoordinated & - & - & - & - & Uncoordinated & - & - & - \\
\hline $\begin{array}{l}\text { Low-Cost Variable } \\
\text { Generation (VG) }\end{array}$ & $80 \%$ Reduction & State-Level & $\begin{array}{l}\mathbf{5 0} \% \text { Clean } \\
\text { Energy }\end{array}$ & Low-Cost RE & Coordinated & BAU & BAU & BAU \\
\hline Low Cost VG Early Retire & - & - & - & - & - & Early & - & - \\
\hline Low Cost VG High Cost Gas & - & - & - & - & - & - & - & High \\
\hline Low Cost VG Low Cost Gas & - & - & - & - & - & - & - & Low \\
\hline Low Cost VG and Storage & - & - & - & $\begin{array}{l}\text { Low-cost } \\
\text { storage + VG }\end{array}$ & - & - & - & - \\
\hline Low Cost VG Macro Grid & - & - & - & - & + Macrogrid & - & - & - \\
\hline $\begin{array}{l}\text { Low Cost VG No Cross-Border } \\
\text { Expansion }\end{array}$ & - & - & - & - & $\begin{array}{l}\text { + No new cross- } \\
\text { border lines } \\
\text { allowed }\end{array}$ & - & - & - \\
\hline $\begin{array}{l}\text { Low Cost VG No Cross-Border } \\
\text { Expansion Uncoordinated }\end{array}$ & - & - & - & - & $\begin{array}{l}\text { Uncoordinated, } \\
\text { no new cross- } \\
\text { border lines }\end{array}$ & - & - & - \\
\hline Low Cost VG Uncoordinated & - & - & - & - & Uncoordinated & - & - & - \\
\hline Carbon Constrained & $92 \%$ Reduction & $80 \%$ Reduction & $80 \%$ Reduction & $\mathrm{BAU}$ & Coordinated & $\overline{B A U}$ & $\overline{B A U}$ & BAU \\
\hline CO2 Constrained Early Retire & - & - & - & - & - & Early & - & - \\
\hline CO2 Constrained High Cost Gas & - & - & - & - & - & - & - & High \\
\hline CO2 Constrained Low Cost Gas & - & - & - & - & - & - & - & Low \\
\hline $\begin{array}{l}\text { CO2 Constrained Low Cost } \\
\text { Storage }\end{array}$ & - & - & - & $\begin{array}{l}\text { Low-cost } \\
\text { storage }\end{array}$ & - & - & - & - \\
\hline CO2 Constrained Macro Grid & - & - & - & - & + Macrogrid & - & - & - \\
\hline $\begin{array}{l}\text { CO2 Constrained No Cross- } \\
\text { Border Expansion }\end{array}$ & - & - & - & - & $\begin{array}{l}+ \text { No new cross- } \\
\text { border lines } \\
\text { allowed }\end{array}$ & - & - & - \\
\hline $\begin{array}{l}\text { CO2 Constrained No Cross- } \\
\text { Border Expansion } \\
\text { Uncoordinated }\end{array}$ & - & - & - & - & $\begin{array}{l}\text { Uncoordinated, } \\
\text { no new cross- } \\
\text { border lines }\end{array}$ & - & - & - \\
\hline $\begin{array}{l}\text { CO2 Constrained } \\
\text { Uncoordinated }\end{array}$ & - & - & - & - & Uncoordinated & - & - & - \\
\hline CO2 Constrained Low Cost VG & - & - & - & Low-cost VG & - & - & - & - \\
\hline $\begin{array}{l}\text { CO2 Constrained Low Cost VG } \\
\text { High Gas }\end{array}$ & - & - & - & Low-cost VG & - & - & - & High \\
\hline $\begin{array}{l}\text { CO2 Constrained Low Cost VG } \\
\text { and Low Cost Storage }\end{array}$ & - & - & - & $\begin{array}{l}\text { Low-cost VG and } \\
\text { storage }\end{array}$ & - & - & - & - \\
\hline Electrification & $92 \%$ Reduction & $80 \%$ Reduction & $80 \%$ Reduction & $\mathrm{BAU}$ & Coordinated & $\mathrm{BAU}$ & High & $\mathrm{BAU}$ \\
\hline Electrification Early Retire & - & - & - & - & - & Early & - & - \\
\hline Electrification High Cost Gas & - & - & - & - & - & - & - & High \\
\hline Electrification Low Cost Gas & - & - & - & - & - & - & - & Low \\
\hline Electrification and Storage & - & - & - & $\begin{array}{l}\text { Low-cost } \\
\text { storage }\end{array}$ & - & - & - & - \\
\hline Electrification Macro Grid & - & - & - & - & + Macrogrid & - & - & - \\
\hline $\begin{array}{l}\text { Electrification No Cross-Border } \\
\text { Expansion }\end{array}$ & - & - & - & - & $\begin{array}{l}+ \text { No new cross- } \\
\text { border lines } \\
\text { allowed }\end{array}$ & - & - & - \\
\hline $\begin{array}{l}\text { Electrification No Cross-Border } \\
\text { Expansion Uncoordinated }\end{array}$ & - & - & - & - & $\begin{array}{l}\text { Uncoordinated, } \\
\text { no new cross- } \\
\text { border lines }\end{array}$ & - & - & - \\
\hline Electrification Uncoordinated & - & - & - & - & Uncoordinated & - & - & - \\
\hline Electrification Low Cost VG & - & - & - & Low-cost VG & - & - & - & - \\
\hline $\begin{array}{l}\text { Electrification Low Cost VG } \\
\text { High Gas }\end{array}$ & - & - & - & Low-cost VG & - & - & - & High \\
\hline $\begin{array}{l}\text { Electrification Low Cost VG and } \\
\text { Low Cost Storage }\end{array}$ & - & - & - & $\begin{array}{l}\text { Low-cost VG and } \\
\text { storage }\end{array}$ & - & - & - & - \\
\hline
\end{tabular}


The table does not include hydropower sensitivities (flexibility, wet/dry, or Canadian supply sensitivities), described later in the report

a — Indicates no change from core case for the scenario

\section{b Carbon}

- Canada: Assumes $\mathrm{BAU}$ is an $80 \% \mathrm{CO}_{2}$ reduction and Carbon Constrained is a $92 \%$ reduction, which is more in line with Mid-Century Strategy, and is $80 \%$ economy-wide

- United States: Assumes BAU is state-level policies only and Carbon Constrained is a $80 \%$ reduction (in line with Mid-Century Strategy)

- Mexico: Assumes BAU is $50 \%$ clean energy standard and Carbon Constrained is a $80 \%$ reduction

\section{c Transmission}

- $\quad$ Coordinated: The model builds and operates transmission in an optimal way.

- Uncoordinated: The model sees hurdle rates (cost to flow power) between regions and only builds lines that have a benefit-cost ratio above 3 .

- No cross-border: The model runs the same as coordinated but without any new cross-border transmission allowed (to help understand the benefit of new cross-border lines).

- $\quad$ Macrogrid: The model runs as coordinated, with an HVDC (high-voltage direct current) macrogrid. Some potential benefits of this grid might not be well captured in standard modeling frameworks. The macrogrid is based on the grid for the U.S. Interconnections Seam study, with an extension into Canada.

\section{d Retirements}

- This scenario represents potential concerns for early thermal unit retirement.

- Coal: In the Early Retirements scenario, coal is assumed to retire early based on whether the ReEDS model continues to operate with more than $75 \%$ capacity factor. This could be driven by lack of cost recovery or carbon or other pollutant policies. In BAU, only announced retirements are included.

- $\quad$ Nuclear: In the Early Retirements scenario, all nuclear is assumed to not be relicensed (but operates until relicensing), based on ongoing retirement concerns. In the BAU assumption, $50 \%$ of nuclear is relicensed and still operating in 2050 (based on commission date)

\section{e Electrification and Load Growth}

- Canada: BAU (nonelectrification) cases assume 2050 load of 780 terawatt-hours (TWh) (based on Canada's National Energy Board extrapolated). Electrification cases assume 1,070 TWh (based on EnergyPATHWAYS modeling for NARIS). 2016 load is 600 TWh.

- United States: BAU (nonelectrification) cases assume 2050 load of 5,100 TWh (based on U.S. Energy Information Administration [EIA] extrapolated). Electrification cases assume 7,100 TWh (based on NREL's Electrification Futures Study). 2016 load is 3,950 TWh.

- Mexico: Because the Programa de Desarrollo del Sistema Eléctrico Nacional (PRODESEN) and the MidCentury Strategy have similar assumptions for load growth, both scenarios are identical in load. 2016 load is 310 TWh. 2050 load is 790 TWh.

- In current runs, no hourly profile changes are considered for electrification, except optimal vehicle charging. Reference the Electrification Futures Study ${ }^{8}$ for more work on this topic.

\footnotetext{
8 “Electrification Futures Study,” NREL, https://www.nrel.gov/analysis/electrification-futures.html.
} 


\subsection{Assumptions and Limitations}

This section describes the key assumptions and limitations of NARIS so stakeholders can understand the context for interpreting the study results.

- NARIS is not a forecast or official plan for any given region or state. The scenarios were produced through specific optimization methods, so infrastructure decisions may differ from actual decisions organizations choose to make. The study analyzes a suite of scenarios to understand ways the grid could evolve and operate to help inform planners. In many cases, the optimization is shallow and there are alternative infrastructure builds with similar costs.

- This study considers enacted legislation with binding targets for renewable or clean energy portfolios that cover electricity generation at the federal or state/province levels by October 2018; it does not attempt to extrapolate local or corporate targets, or to understand how they could impact infrastructure builds. For the United States, federal policies include tax credits but no renewable portfolio rules or carbon limits for the BAU scenarios.

- More study is needed to understand dynamic concerns, including frequency stability. This study does not perform any AC or dynamic power flow modeling.

- Operational practices will continue to change between today and 2050, including the way balancing authorities interact with each other. Aside from several scenarios, this study assumes regions can efficiently trade electricity or build infrastructure if it is optimal.

- NARIS is not a detailed analysis of electricity markets. Specific market rules and participant behavior will impact the evolution and operation of the grid; the study is based mostly on optimization models and assumes overall cost-optimal resources will be developed and operated (as described in Section 2.1). The study does not attempt to determine whether generation resources will receive sufficient revenue in existing or future market structures.

- The study does not consider the impact of climate change on demand patterns, wind, solar, hydropower, or thermal generation.

- NARIS assumes decision-making at the retail (consumer adoption of rooftop PV) and wholesale (utility-scale generation and transmission) is made differently, and subject to different sets of policy assumptions. See Sections 2.1.1 and 2.1.2 for details.

- No policy recommendations are made in this report.

- All costs are in 2018 USD. 


\section{Data and Methods}

This section provides an overview of the data, models, and methods used in NARIS; many of the models and data are documented elsewhere and are open-sourced.

\subsection{Methods and Models}

Figure 4 provides an overview of the modeling process used in the NARIS. Four primary modeling types underpin the analysis:

- Distributed generation market adoption: The NREL dGen model is an agent-based consumer adoption model that projects different pathways of distributed PV deployment for the residential, commercial, and industrial sectors.

- Generation and transmission capacity expansion: The NREL ReEDS model co-optimizes the build-out of generation and transmission infrastructure, subject to the assumptions in each scenario.

- Production cost (unit commitment and dispatch): The Energy Exemplar PLEXOS model simulates the operation of the power system at hourly and 5-minute time-scales.

- Reliability (resource adequacy) model: The NREL PRAS model simulates simplified system operation for every hour for 7 years of meteorological conditions (affecting wind, solar, and load profiles), and thousands of random draws of outages of thermal generators.

The same data were used throughout NARIS for different temporal and geographic scales. The distributed generation and capacity expansion models were used to explore the uncertainty in power system evolution, and then the production cost and resource adequacy models were used to study a few key scenarios in detail.

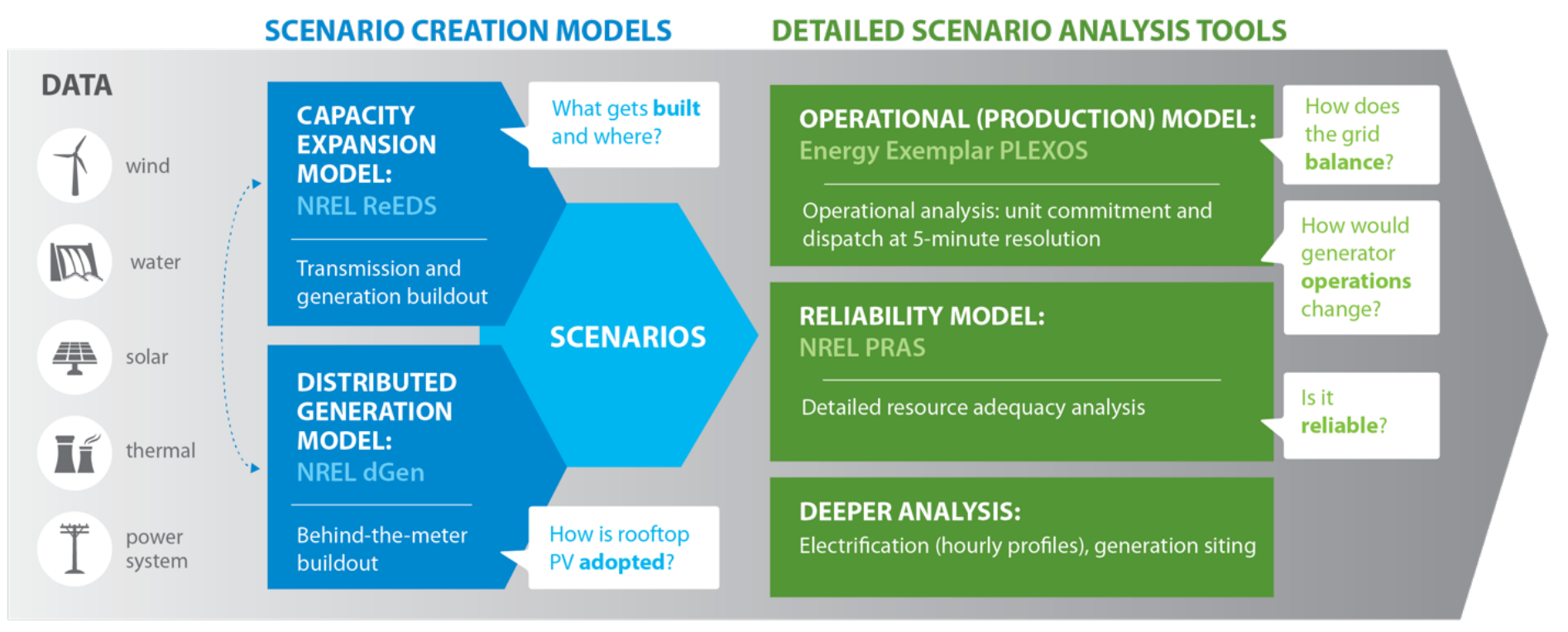

Figure 4. Modeling flow

This diagram shows the modeling flow of the key models used in NARIS, including the transmission-level capacity expansion (NREL ReEDS), distributed PV adoption (NREL dGen), production cost grid simulation (Energy Exemplar PLEXOS), and resource adequacy (NREL PRAS). The reV geospatial tool helped keep the data consistent at all modeling scales. 


\subsubsection{Capacity Expansion Modeling: ReEDS}

The NREL Regional Energy Deployment System (ReEDS) model is an electricity sector capacity expansion model representing the North American power system. The model, through least cost optimization, evaluates the location and timing generation and transmission investments throughout the system. For a detailed explanation of the model, see Cohen et al. (2019).

ReEDS represents the diverse spectrum of generation, storage, and transmission technologies relevant to power system decision makers. As part of the modeling process ReEDS contains an endogenous representation of power system needs. These include operational requirements in electric power including, balancing demand, renewable resource availability, generation technology limits. System reliability is ensured by including planning reserve and spinning reserve requirements. Planning reserves can be served by all types of resources; capacity credits for wind and solar resources are estimated in each model region and year by estimating the contribution of these resources in periods of high load and low wind and solar generation. These estimates are done using hourly load, wind, and solar data (see Section 2.2) using 2012 meteorology. Other years are tested in the PRAS modeling (see Section 2.1.4). U.S. federal and state policies are explicitly represented, including renewable production and investment tax credits and state based clean energy policies like California's SB-100.

ReEDS selects a least-cost mix of operation and investment decisions while satisfying all modeled requirements described in this section. Model simulations occur in 2-year periods starting in 2010 (build decisions through 2020 are fixed to historical builds) and ending in 2050 . In historical years, investment decisions are restricted to match the location and timing transmission and generation developments that occurred. Within each simulation, a year of operations decisions are modeled with a reduced order dispatch, using 17 representative timeslices to represent year. For each of the four seasons, time blocks of morning, afternoon, evening, and overnight hours are aggregated based on time of day in local time to form time-slices. An additional $17^{\text {th }}$ super-peak time-slice is created from the top 40 summer afternoon $(1 \mathrm{pm}-5 \mathrm{pm})$ hours. Reducing the operational dispatch from 8,760 hours to 17 representative time-slices preserves seasonal and diurnal variability within the model while reducing the computational burden. Outside the simulation, more granular hourly data sets are also used by the model to estimate curtailments and the capacity value provided by variable renewable technologies.

The representation of the United States is divided into 134 balancing areas, and 356 wind and solar resource regions (Figure 5). Alaska, Hawaii, and U.S. territories are not included as part ReEDS representation of the United States; nor are nongrid connected generation and load. The U.S. aggregated transmission network is connected by 418 transmission lines (that represent interfaces between regions) among three asynchronous regions. 


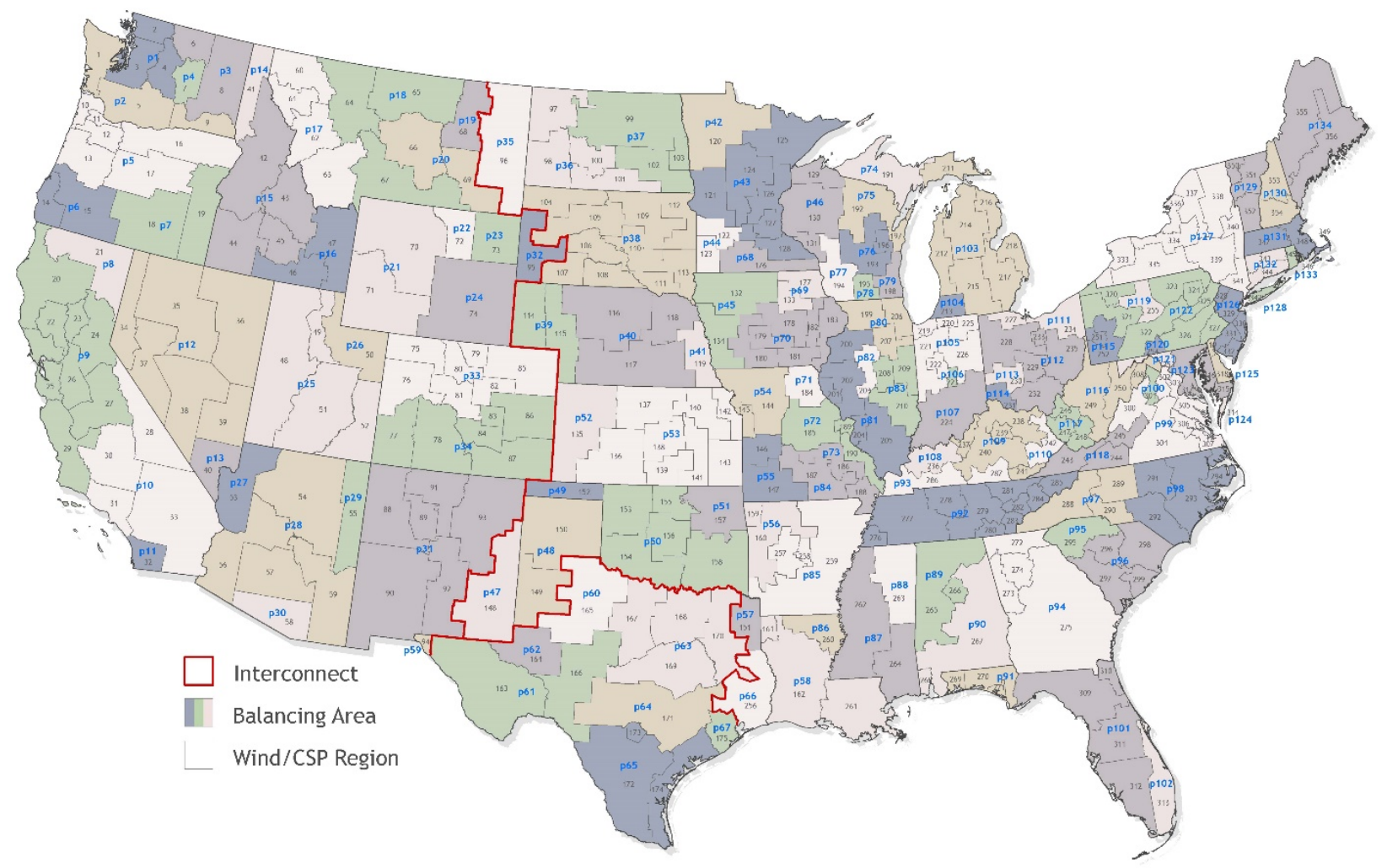

Figure 5. ReEDS U.S. zonal representation

The resulting outputs of a ReEDS solution contain detailed information about the evolution of the power system relevant to decision makers. The model outputs extends beyond the energy generated and capacity of plants and transmission interfaces within the United States. Examples of more-detailed operations outputs include the capacity value of wind and solar and the distribution of reserves by region and technology. ReEDS also outputs detailed system cost information, which helps to understand the implications of different regulatory and technological futures. The results also include a diverse range of environmental outputs, including $\mathrm{CO}_{2}$ emissions. Shadow prices are used to understand economic questions, including why certain generation technologies are developed and prices ranging from competitive electricity prices to environmental constraints. Interregional and cross-border international transmission and power flows are also output. The ReEDS model was run on all scenarios described in Section 1.2; additional analysis beyond the ReEDS model was done for several key scenarios, as described later in the report.

Table 3 lists the data sources for all three countries in the core scenarios in ReEDS. 
Table 3. Data Sources for All Three Countries in the Core Scenarios in ReEDS

\begin{tabular}{|c|c|c|c|}
\hline Category & Canada Assumption & Mexico Assumption & U.S. Assumption \\
\hline $\begin{array}{l}\text { Natural gas supply } \\
\text { curve and regional } \\
\text { consumption }\end{array}$ & $\begin{array}{l}\text { Regional gas supply curves } \\
\text { were derived from U.S. Energy } \\
\text { Information (EIA) Annual } \\
\text { Energy Outlook (AEO2018) } \\
\text { (EIA 2018) price and } \\
\text { consumption data. } \\
\\
\text { Supply curves were extended } \\
\text { to include adjacent Canadian } \\
\text { provinces by adjusting natural } \\
\text { gas consumption based on } \\
\text { consumption in Canada's } \\
\text { National Energy Board (NEB) } \\
\text { Canada's Energy Futures } \\
2017 \text { (NEB 2017) }\end{array}$ & $\begin{array}{l}\text { Supply curve was } \\
\text { derived from } \\
\text { AEO2018 (EIA 2018) } \\
\text { West South Central } \\
\text { region, adjusted for } \\
\text { projected gas } \\
\text { consumption and } \\
\text { prices in the } \\
\text { Programa de } \\
\text { Desarrollo del } \\
\text { Sistema Eléctrico } \\
\text { Nacional } \\
\text { (PRODESEN 2018) } \\
\text { (SENER 2018). }\end{array}$ & $\begin{array}{l}\text { Supply curve was } \\
\text { derived from } \\
\text { AEO2018 (See } \\
\text { Cohen et al. 2019.) }\end{array}$ \\
\hline Coal prices & $\begin{array}{l}\text { Canada's Energy Futures } \\
2017 \text { (NEB 2017) (province- } \\
\text { level) }\end{array}$ & PRODESEN 2018a & AEO2018 \\
\hline $\begin{array}{l}\text { Electricity demand } \\
\text { projections (see } \\
\text { Section } 3.5 .4 \text { for } \\
\text { details on } \\
\text { Electrification) }\end{array}$ & $\begin{array}{l}\text { Canada's Energy Futures } \\
2017 \text { (NEB 2017) } \\
\text { Evolved Energy Research } \\
\text { (Electrification scenario) }\end{array}$ & $\begin{array}{l}\text { PRODESEN } 2018 \\
\text { Evolved Energy } \\
\text { Research } \\
\text { (Electrification } \\
\text { scenario) }\end{array}$ & $\begin{array}{l}\text { AEO2018 } \\
\text { Evolved Energy } \\
\text { Research } \\
\text { (Electrification } \\
\text { scenario) }\end{array}$ \\
\hline $\begin{array}{l}\text { Hourly electricity } \\
\text { demand (See } \\
\text { Section } 2.2 .2 \text { for } \\
\text { details.) }\end{array}$ & $\begin{array}{l}\text { Various provincial-level } \\
\text { sources }\end{array}$ & PRODESEN 2018 & $\begin{array}{l}\text { Independent system } \\
\text { operators (ISOs) and } \\
\text { Federal Energy } \\
\text { Regulatory } \\
\text { Commission Form } \\
714\end{array}$ \\
\hline $\begin{array}{l}\text { Existing } \\
\text { generation fleet }\end{array}$ & \multicolumn{3}{|c|}{$\begin{array}{l}\text { ABB Velocity Suite (ABB 2018) was mapped to ReEDS power control areas } \\
\text { using spatial analysis. }\end{array}$} \\
\hline $\begin{array}{l}\text { Announced } \\
\text { retirements }\end{array}$ & $\begin{array}{l}\text { Various provincial-level } \\
\text { sources }\end{array}$ & $\begin{array}{l}\text { ABB Velocity Suite } \\
\text { (ABB 2018), } \\
\text { AEO2018 }\end{array}$ & PRODESEN 2018 \\
\hline $\begin{array}{l}\text { Plant cost and } \\
\text { performance }\end{array}$ & \multicolumn{3}{|c|}{ ABB Velocity Suite (ABB 2018); AEO2018 } \\
\hline $\begin{array}{l}\text { Transmission } \\
\text { costs }\end{array}$ & \multicolumn{3}{|c|}{$\begin{array}{l}\text { Distance per mile costs were estimated from the Eastern Interconnection } \\
\text { Planning Collaborative Phase } 2 \text { Report (EIPC 2015). Transmission costs were } \\
\$ 1,347-\$ 2,333 \text { per MW-mile depending on the line voltage. Spur lines } \\
\text { connecting utility-scale solar and wind to the power system cost } \$ 3,667 / \mathrm{MW} \text { - } \\
\text { mile. }\end{array}$} \\
\hline $\begin{array}{l}\text { Planned } \\
\text { hydropower builds }\end{array}$ & $\begin{array}{l}\text { Canada's Energy Futures } \\
2017 \text { (NEB 2017) (province- } \\
\text { level) }\end{array}$ & PRODESEN 2018 & $\begin{array}{l}\text { Hydropower Vision } \\
\text { Report (DOE 2016), } \\
\text { ABB Velocity Suite } \\
\text { (ABB 2018) }\end{array}$ \\
\hline
\end{tabular}




\begin{tabular}{|c|c|c|c|}
\hline Category & Canada Assumption & Mexico Assumption & U.S. Assumption \\
\hline $\begin{array}{l}\text { Seasonal } \\
\text { hydropower } \\
\text { capacity factors }\end{array}$ & $\begin{array}{l}\text { Canada's Energy Futures } \\
2017 \text { (NEB 2017) (province- } \\
\text { level) }\end{array}$ & $\begin{array}{l}\text { PRODESEN } 2018 \\
\text { fleetwide average }\end{array}$ & $\begin{array}{l}\text { Western Electricity } \\
\text { Coordinating Council } \\
\text { (WECC) } \\
\text { Transmission } \\
\text { Expansion Planning } \\
\text { Policy Committee } \\
\text { (TEPPC) } 2024 \text { (West } \\
\text { Only); National } \\
\text { Hydropower Asset } \\
\text { Assessment Program }\end{array}$ \\
\hline $\begin{array}{l}\text { Onshore wind } \\
\text { resource supply } \\
\text { curve }\end{array}$ & \multicolumn{3}{|c|}{$\begin{array}{l}\text { 2-km } \times 2-k m \text { Wind Toolkit meteorological were processed using the Renewable } \\
\text { Energy Potential model (reV) to generate cost and performance supply curves } \\
\text { for wind. Generated data are available at the level of subpower control areas } \\
\text { and are consistent with assumptions from the NREL Annual Technology } \\
\text { Baseline (ATB). }\end{array}$} \\
\hline $\begin{array}{l}\text { PV resource } \\
\text { supply curve }\end{array}$ & \multicolumn{3}{|c|}{$\begin{array}{l}\text { 4-km x 4-km National Solar Radiation Database solar irradiance data were } \\
\text { processed using reV to generate cost and performance supply curves for utility- } \\
\text { scale PV. Both utility scale (rural development) and distributed utility scale } \\
\text { (urban development) were included with distinct resource costs consistent with } \\
\text { the ATB. }\end{array}$} \\
\hline $\begin{array}{l}\text { State renewable } \\
\text { portfolio standards } \\
\text { and clean energy } \\
\text { standards }\end{array}$ & $\begin{array}{l}\text { Province-level policies } \\
\text { including the British Columbia } \\
\text { carbon tax and New } \\
\text { Brunswick, Nova Scotia, and } \\
\text { Prince Edward Island } \\
\text { renewable portfolio standards }\end{array}$ & N/A & $\begin{array}{l}\text { State renewable } \\
\text { portfolio standards } \\
\text { and clean energy } \\
\text { standards policies } \\
\text { derived from regular } \\
\text { ReEDS updates from } \\
\text { the Database of State } \\
\text { Incentives for } \\
\text { Renewables }\end{array}$ \\
\hline $\begin{array}{l}\text { International } \\
\text { trading rules for } \\
\text { renewable energy } \\
\text { certificates }\end{array}$ & $\mathrm{N} / \mathrm{A}$ & N/A & $\begin{array}{l}\text { State-specific trading } \\
\text { rules from the } \\
\text { Database of State } \\
\text { Incentives for } \\
\text { Renewables }\end{array}$ \\
\hline
\end{tabular}

Canada's Energy Future 2018 was not yet published by the National Energy Board when we finalized our assumptions and synchronized the model across the three countries. We did confirm that the key variables did not change significantly from 2017. Starting in 2019, the Canada Energy Regulator now publishes this report.

a PRODESEN, Programa de Desarrollo del Sistema Eléctrico Nacional, https://www.gob.mx/sener/acciones-yprogramas/programa-de-desarrollo-del-sistema-electrico-nacional-33462, accessed 2018.

The cost trajectories used for these model runs are from NREL 2018 Annual Technology Baseline (ATB), as noted above. Figure 6 plots these cost trajectories in comparison to the 2020 ATB equivalent. Note that the NARIS BAU (2018 ATB Mid case) is closer to the 2020 ATB Conservative case costs for PV and wind, and it is slightly higher in 2050. The NARIS Low Cost trajectories are generally between the Advanced and Moderate trajectories for the 2020 ATB. 
These are levelized cost of electricity ${ }^{9}$ (LCOE) comparisons based on moderate-quality resource for both wind and solar. Note that LCOE was not used for any purpose in the NARIS modeling; however, it is a useful metric for comparisons that depend on both the cost and the performance of technologies.

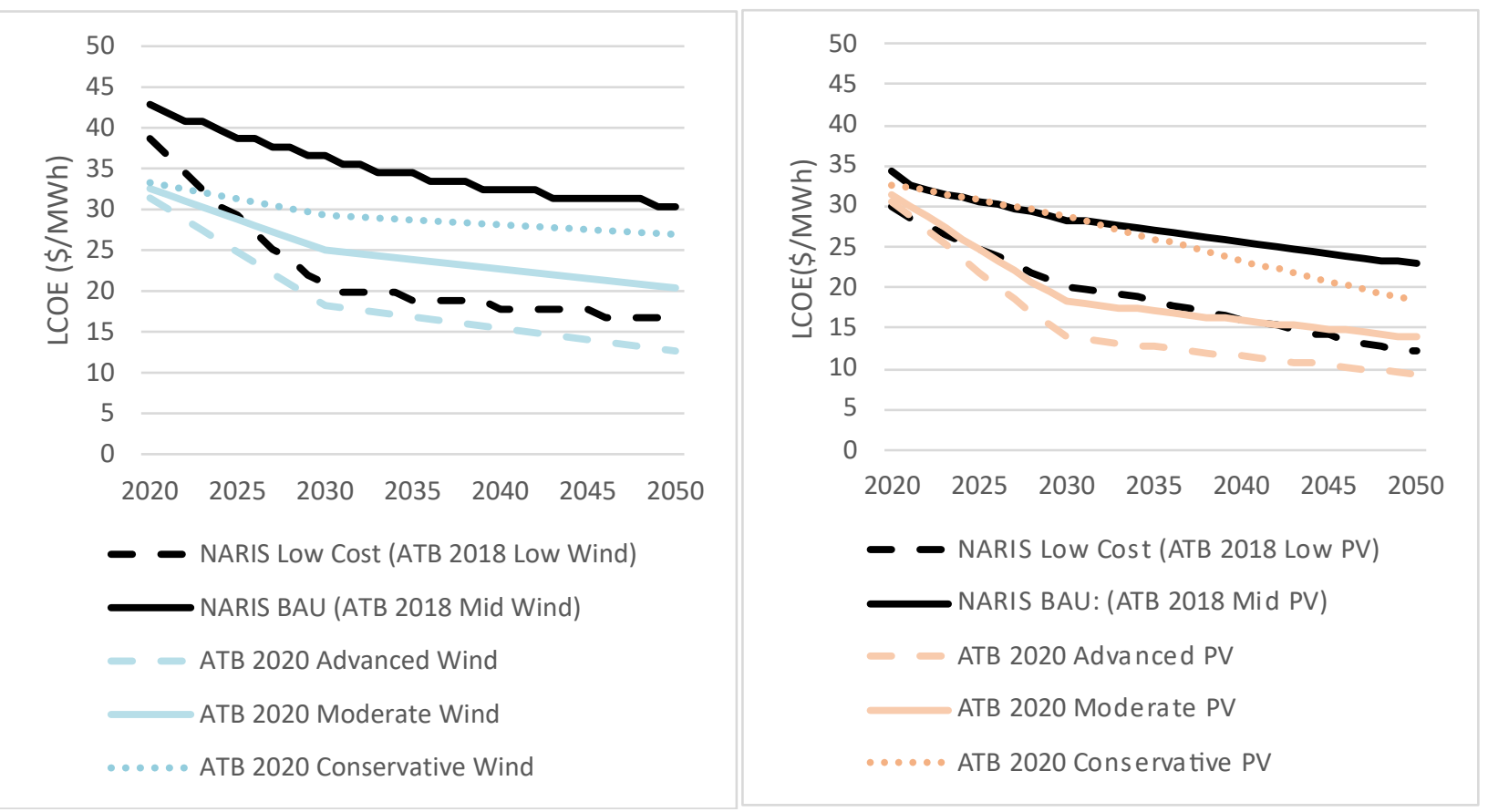

Figure 6. Cost comparison for wind (left) and solar PV (right) in the 2018 ATB and the 2020 ATB

All costs in report are 2018 USD.

\subsubsection{Distributed Generation Modeling: dGen}

Consumer adoption of distributed energy resources is made under a different framework than that of transmission-connected generation resources, and thus requires a separate approach. And three aspects of distributed energy resources are particularly germane to the distributionconnected versus transmission-connected discussion. First, distributed-connected resources are physically sited closer to load, leading to a different power flow than would otherwise be seen. Second, motivations for adoption are wholly different: transmission-connected resources are valued at the wholesale rate of electricity, and behind-the-meter resources are valued at the retail level. Moreover, consumers themselves have several drivers of adoption, including economic factors such as savings on electricity bills and a hedge against future rate changes, but also noneconomic ones such as environmental concerns and social influence from family and peers. Finally, a different set of policies is used to incentivize adoption of distributed energy resources than is used with utility-scale resources.

${ }^{9} \mathrm{LCOE}$ is a "summary metric that combines the primary technology cost and performance parameters" to estimate the average cost per megawatt-hour of electricity based on cost and performance assumptions. See "Equations and Variables in ATB," NREL, http://atb.nrel.gov/electricity/2020/equations-variables.php. 
To reflect these differences in drivers of distributed energy resources capacity expansion, we used the Distributed Generation Market Demand (dGen) model to develop rooftop PV projections for the residential, commercial, and industrial sectors. ${ }^{10}$ For NARIS, we developed new modules for Canada and Mexico. dGen is an agent-based model, representing bottom-up customer adoption. Agents are statistically representative based on sampling from distributions of customer attributes for each geography modeled. Agent sampling rates vary by country and sector, primarily because of data availability.

For the U.S. implementation of dGen, agents are sampled based on geography for the residential, commercial, and industrial sectors by county $(\mathrm{n}=3108)$ in the United States. Thus, an "agent" represents a statistical cluster of multiple customers. For the U.S. version of dGen we used in NARIS, up to 30 agents were statistically sampled for each county (a total of 93,240 agents) based on representative distributions of features such as power consumption, rooftop size and angle.

Adoption projections in dGen are modeled through a four-step approach:

1. Generating agents (i.e., customers) and assigning them attributes based on a statistical sampling of their attributes (e.g., annual electricity consumption and roof size)

2. Applying technical and siting restrictions, such as resource quality, rooftop availability and quality for each agent

3. Analyzing cash flow to consider project costs, retail electricity rates, incentives, and netbilling/net metering policies; agents "select" PV systems that maximize their net present value

4. Projecting the future market share based on a generalized Bass diffusion model ${ }^{11}$ to account for consumer behavior (Dong and Sigrin 2019). Market share is primarily determined by the system payback period, and the rate of diffusion is based on regressions of historical growth.

Technical potential is calculated in the first two steps by determining the number of developable roofs and the unshaded area. A building is "developable" if it meets shading, tilt, azimuth, and minimum area requirements (Gagnon et al. 2016); additionally, adoption is not considered for multifamily residential or renter-occupied residential buildings. In dGen for the United States, average roof sizes have been collected for each sector in each geography from Census data. Figure 7 displays the total technical potential of rooftop PV across Canada, Mexico, and the United States, ranked by capacity factor and sector. Technical potential includes all rooftop availability, subject to sting restrictions mentioned above.

\footnotetext{
${ }^{10} \mathrm{dGen}$ can also model distributed wind, storage, and geothermal technologies, but we focused on distributed rooftop solar for NARIS.

11 The Bass diffusion model determines how quickly consumers adopt consumer goods (in this case, PV).
} 


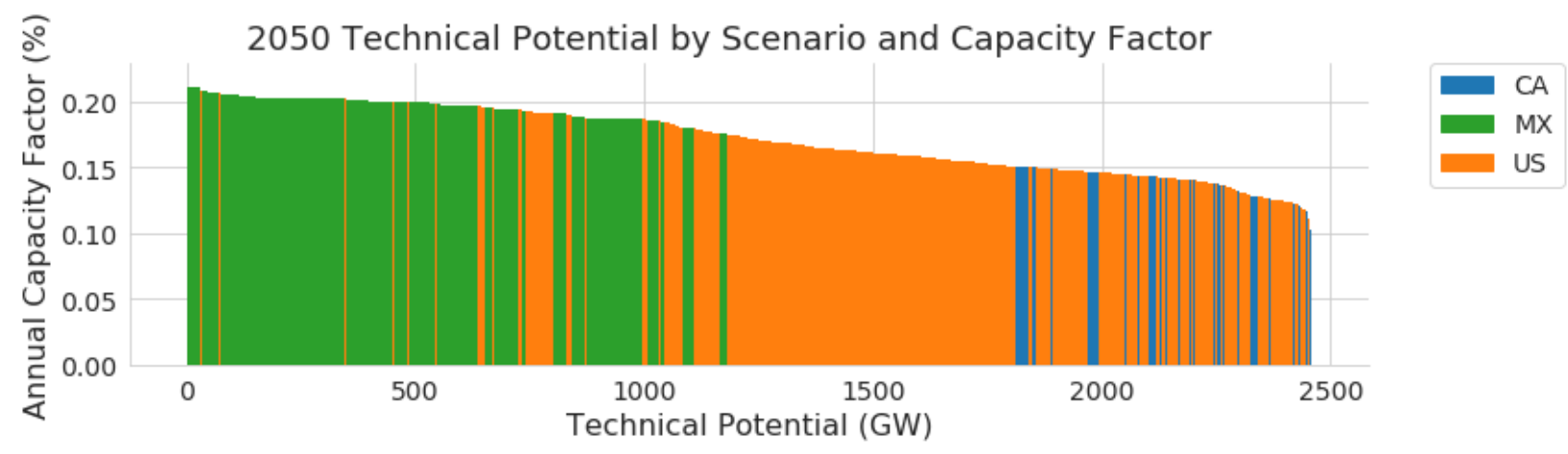

Figure 7. Distributed PV resource quality by country

This figure shows the technical potential of the rooftop resource in each country, ordered by capacity factor. Most of the best $600 \mathrm{GW}$ of resource in North America are in Mexico. The United States has substantial capacity available above $15 \%$ capacity factors annually.

Within the United States, technical potential varies and is well distributed among sectors. Figure 8 displays cumulative technical potential by sector and capacity factor, with high capacity factors available in residential, commercial, and industrial sectors.

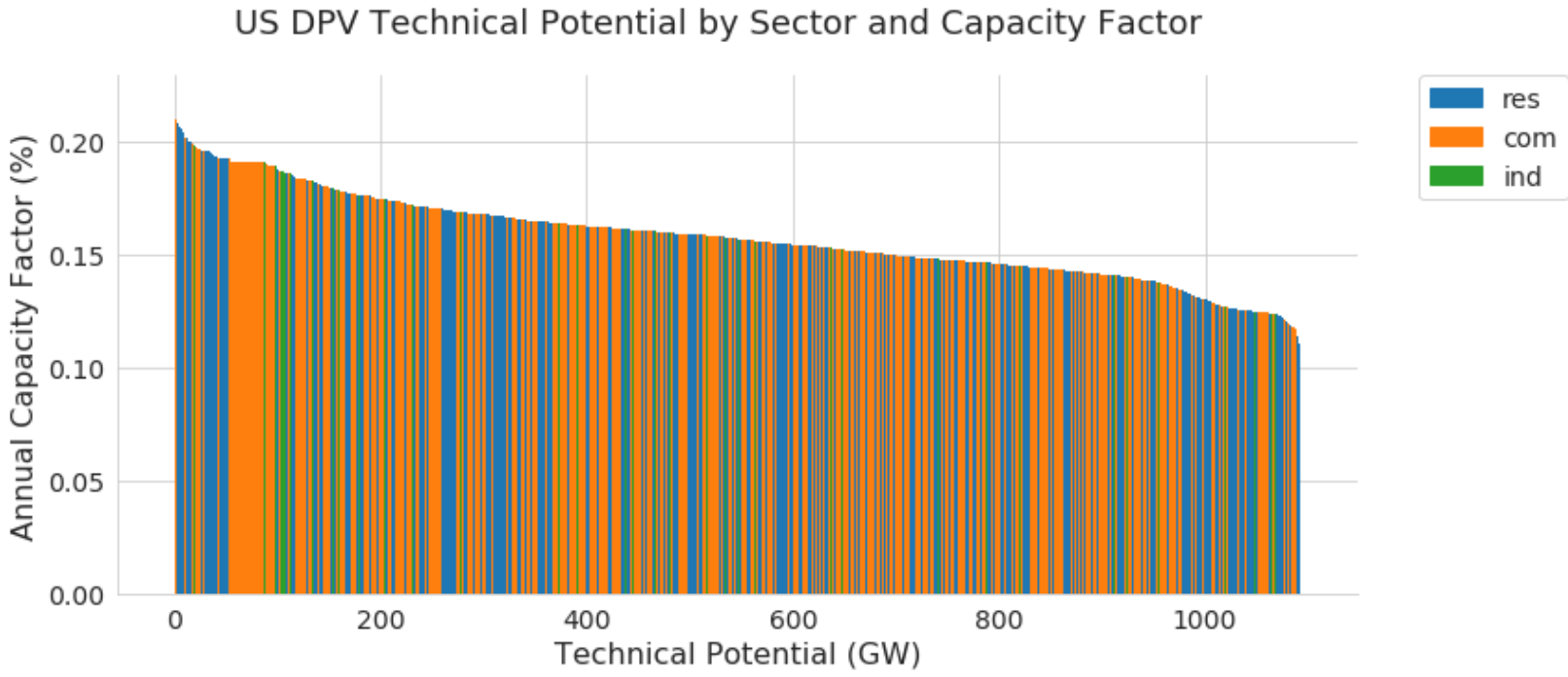

Figure 8. Distributed PV resource quality within the United States by sector

This figure shows the technical potential of the rooftop resource in each sector (residential, commercial, and industrial) within the United States, ordered by capacity factor. There is good resource in all sectors.

More than 1,000 GW of rooftop PV capacity is currently assessed to be technically feasible in the United States, but most of this is not yet economically feasible based on the NARIS modeling and assumptions. To determine the total achievable potential, dGen performs a detailed cashflow analysis for each agent to calculate the net present value of adopting solar. Various system sizes are tested to determine the economically optimal system size for a given agent based on their unique load consumption profile, solar resource availability profile, roof-size, retail rate, and financing terms. The optimal system size and net present value, once calculated, are translated into a payback period, which represents the number of years before electricity bill savings from the system's generation will offset system cost. 
Previous customer surveys have solicited consumer willingness-to-adopt solar at various payback periods. The results from these surveys are aggregated to determine the rooftop PV maximum market share (Sigrin and Drury 2014). Using historical adoption data and the calculated maximum-market share, a Bass diffusion model is used to project PV market share in each year. Payback period is used to determine the maximum (i.e., terminal) market share, and a regression on historical adoption trends is used to inform the rate of diffusion for each region-sector.

For NARIS, three scenarios were examined to assess agent sensitivity to changes in PV capital costs. The scenarios were harmonized by country in real terms based on the 2018 ATB for the Mid (Reference), Low, and Constant Costs scenarios. For reference, the 2050 Mid Costs value is $\$ 1,140 / \mathrm{kW}$ for residential-scale systems and $\$ 954 / \mathrm{kW}$ for nonresidential-scale systems. In the Low Costs, they are $\$ 560 / \mathrm{kW}$ and $\$ 517 / \mathrm{kW}$ respectively; in the Constant Costs scenario, they are $\$ 2,857 / \mathrm{kW}$ and $\$ 1,936 / \mathrm{kW}$ respectively. Operation and maintenance costs, which include inverter replacement are $\$ 3.6-\$ 17 / \mathrm{kW}$-year depending on scenario and sector.

We ran scenarios incorporating existing net energy metering (NEM) policies assuming all excess generation is credited at the retail electricity rate. In a state where the NEM has expired or has a mandated expiration date, exported generation was valued at the wholesale cost of electricity whereas the self-consumed energy was still valued at the retail rate of electricity (i.e., net billing). We also ran scenarios assuming NEM policies expire and net billing persists in all jurisdictions. Figure 9 shows the annual capital cost of PV per kilowatt used by dGen by sector and scenario. Note that this cost does not include taxes, incentives, or subsidies, which are determined by country.

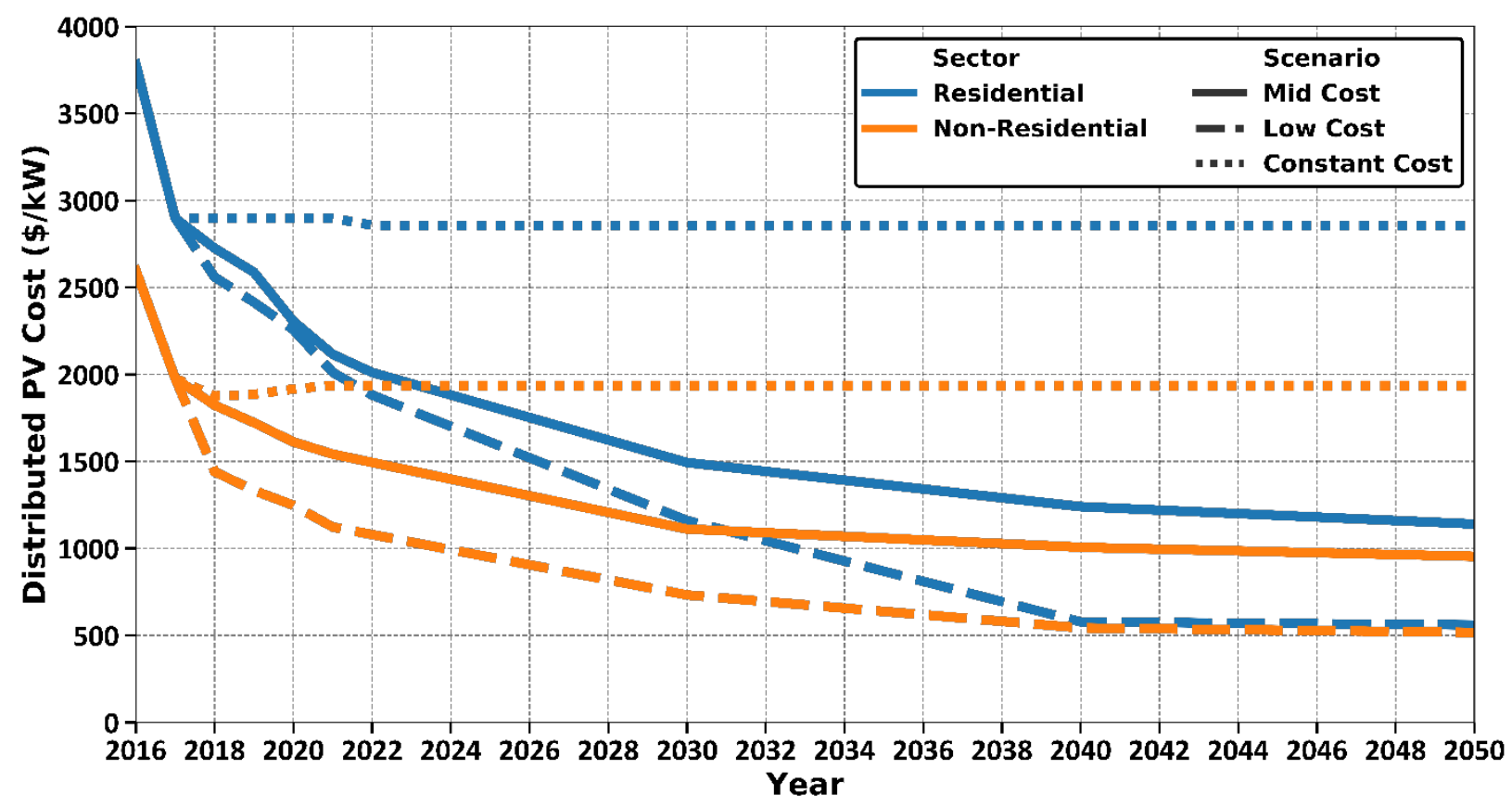

Figure 9. Cost trajectories for distributed PV 
Table 4 contains a list of the data sources used by dGen, summarized for each country. For the sake of comparability, and where possible, agents across the three countries were derived from common sources. For instance, each country models the residential and commercial sector (1) using common capital cost and financing assumptions and (2) excluding consideration of multitenant buildings.

Table 4. Data Sources for dGen

\begin{tabular}{|c|c|c|c|}
\hline Category & $\begin{array}{l}\text { Canadian } \\
\text { Assumption }\end{array}$ & $\begin{array}{l}\text { Mexico } \\
\text { Assumption }\end{array}$ & U.S. Assumption \\
\hline $\begin{array}{l}\text { Model } \\
\text { resolution } \\
\text { (number of } \\
\text { agents } \\
\text { sampled) }\end{array}$ & $\begin{array}{l}\text { Residential sector by } \\
\text { census division }(n= \\
293) \\
\text { Commercial-sector by } \\
\text { province }(n=10)\end{array}$ & $\begin{array}{l}\text { State-level by tariff-class } \\
(n=1024)\end{array}$ & $\begin{array}{l}10 \text { agents per county, by } \\
\text { sector }(n=93,240)\end{array}$ \\
\hline Building stock & $\begin{array}{l}\text { Building counts by } \\
\text { province and sector } \\
\text { (2016 Census } \\
\text { Program) }\end{array}$ & $\begin{array}{l}\text { Counts determined by } \\
\text { tariff classes for each } \\
\text { state using SENER- } \\
\text { provided data }\end{array}$ & $\begin{array}{l}\text { Building characteristics } \\
\text { sampled from Gagnon et al. } \\
\text { (2016), Sigrin and Mooney } \\
2018\end{array}$ \\
\hline Electrical load & See Section 2.2.2. & $\begin{array}{l}\text { Annual consumption by } \\
\text { state and tariff class } \\
\text { Hourly load profiles based } \\
\text { on control regions, using } \\
\text { SENER-provided data }\end{array}$ & $\begin{array}{l}\text { County-level load by sector } \\
\text { (ABB 2013; EIA Residential } \\
\text { Energy Consumption Survey } \\
\text { and Commercial Buildings } \\
\text { Energy Consumption Survey) } \\
\text { Load profiles based on } \\
\text { nearest weather station }\end{array}$ \\
\hline Retail tariffs & \multicolumn{3}{|c|}{$\begin{array}{l}\text { Detailed calculation for current tariffs by utility using the OpenEI U.S. and } \\
\text { International Utility Rate Database }\end{array}$} \\
\hline Policies & \multicolumn{3}{|c|}{$\begin{array}{l}\text { Representation of current NEM policies and financial incentives; both assumed to } \\
\text { expire based on statute }\end{array}$} \\
\hline Solar resource & \multicolumn{2}{|c|}{$\begin{array}{l}\text { Generation profile for } 2012 \text { meteorological year, } \\
\text { using for population-weighted regional midpoint, } \\
\text { south-facing and tilted at latitude; building roof area } \\
\text { based on U.S. sector-specific averages }\end{array}$} & $\begin{array}{l}\text { Generation profile for } 134 \\
\text { weather stations using TMY3 } \\
\text { irradiance profiles. }\end{array}$ \\
\hline $\begin{array}{l}\text { Existing } \\
\text { deployment }\end{array}$ & $\begin{array}{l}\text { Annual installations } \\
\text { and installed capacity } \\
\text { by Province }(2016)\end{array}$ & $\begin{array}{l}\text { System-level } \\
\text { interconnection records } \\
(2016)\end{array}$ & $\begin{array}{l}\text { Annual installation by county } \\
\text { and sector (2016) }\end{array}$ \\
\hline $\begin{array}{l}\text { Technology } \\
\text { costs } \\
\text { Financing }\end{array}$ & \multicolumn{3}{|c|}{ Based on 2018 ATB for residential-scale and commercial-scale PV systems } \\
\hline
\end{tabular}

a "Utility Rate Database," OpenEI, https://openei.org/wiki/Utility Rate Database, accessed 2018. b NSRDB (National Solar Radiation Database), NREL, https://nsrdb.nrel.gov, accessed 2018. 
The results from the dGen model (based on consumer adoption) were considered in the ReEDS model capacity expansion to be generation available to the system to serve load within each zone. An iteration was done between the two models to create the generation inputs for ReEDS (from dGen), and then to reestimate electricity costs for dGen (based on ReEDS outputs). ReEDS was then rerun with the new distributed generation build-out. This was done for the Low-Cost VG scenario and the BAU.

\subsubsection{Production Cost Modeling: PLEXOS}

To understand the operation of future power systems, we used PLEXOS, a production cost model (PCM) developed by Energy Exemplar. The PCM simulates unit commitment and economic dispatch of the future grid infrastructure built by ReEDS. In this report, all production cost modeling results are from the Low Cost VG scenario in 2050. The results of the PCM run allow us to understand how transmission and generation operations change at hourly and subhourly levels while ensuring a reliable and efficient grid. The goal of modeling with 5-minute resolution 30 years in the future is to understand the overall feasibility and implications of operations - not to make a precise forecast of the future. Overall, the goal of the modeling is to demonstrate supply-demand balance using a unit commitment model, considering forecast error, with 5-minute dispatch resolution and a nodal transmission network.

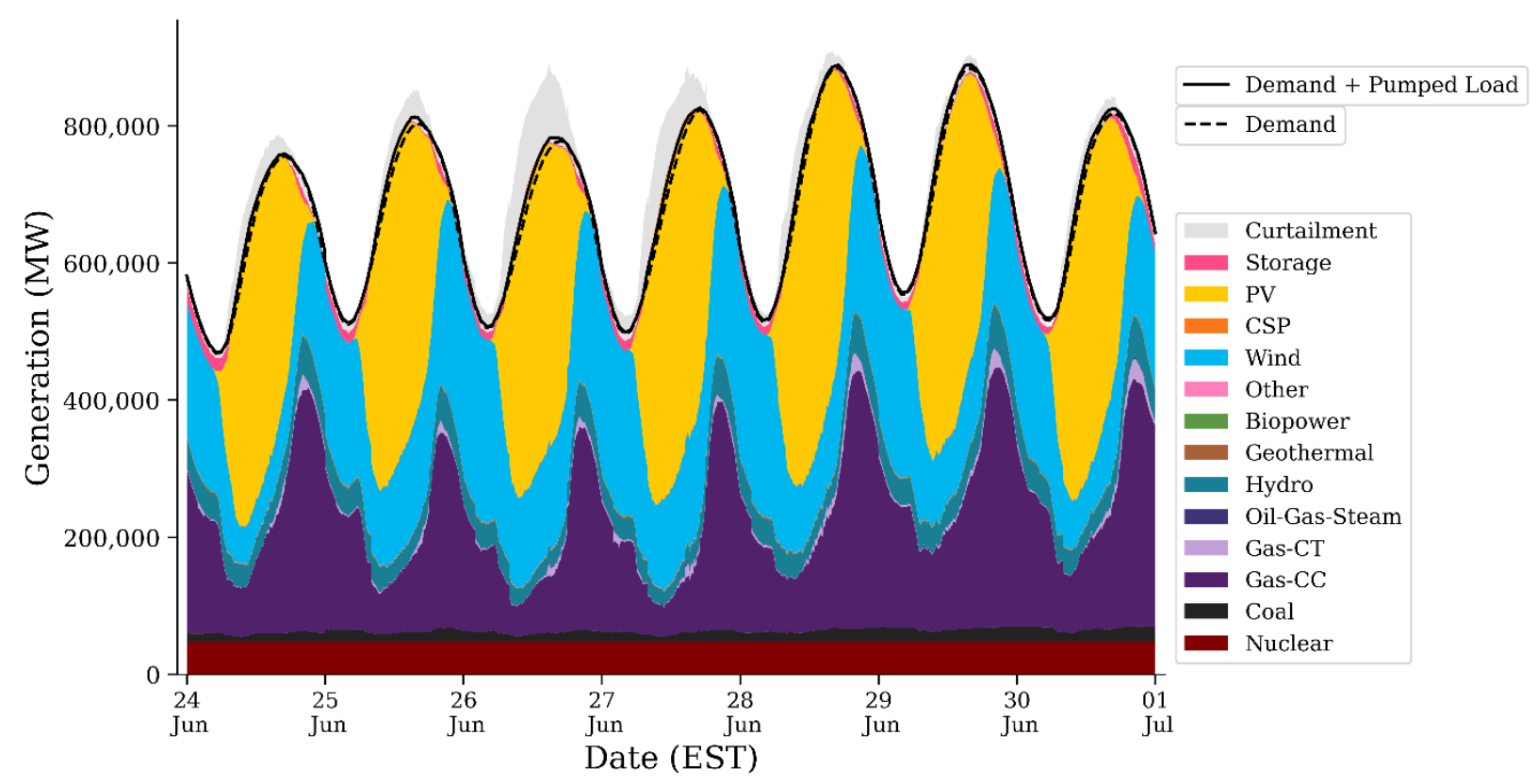

Figure 10. Sample PLEXOS output of U.S. generation dispatch stack for the week of June 24 (2050 Low Cost VG scenario)

Gas-CT: gas-combustion turbine; Gas-CC: gas-combined cycle

The production cost modeling for NARIS leverages a variety of assumptions and methods for modeling hydropower and thermal plants for the Western Interconnection (Brinkman et al. 2016) and the Eastern Interconnection (Bloom et al. 2016); assumptions about thermal unit start-up 
costs, outage rates, and hydropower conditions in NARIS are from these previous studies. Key differences are described below and in the description of the data (Section 2.2).

Installed capacity assumptions in the base model represent a 2024 power system. The expected installed thermal and hydropower generation capacity in 2024 came from several sources. For the Eastern Interconnection, generation capacity, location and type came from the 2026 Summer Peak Eastern Reliability Assessment Group Multiregional Modeling Working Group power flow case. For the Western Interconnection, capacity, location, and type came from the Western Electricity Coordinating Council's (WECC's) Transmission Expansion Planning Policy Committee (TEPPC) 2024 model with updates from the TEPPC 2026 case. Parameters for the Texas Interconnection came from the Electricity Reliability Council of Texas (ERCOT). Announced retirements and retirements modeled in $\operatorname{ReEDS}^{12}$ were removed from the model.

Some thermal operating limits for existing generators deviated from Brinkman et al. (2016) and Bloom et al. (2016). The new operating limits were developed by analyzing historical data from the U.S. Environmental Protection Agency's Continuous Emissions Monitoring Systems. The data and approach for parameterizing for production cost modeling is described by Rossol et al. (2019). That analysis provided unit-specific full load heat rates, part load heat rate curves, and minimum generation levels for every generator with enough data in the Continuous Emissions Monitoring Systems data set. Previous work (Bloom et al. 2016) used generic heat rate curves and minimum stable levels for thermal plants.

Forced outage rates, maintenance outage rates, and mean repair times for nuclear, coal, gas, oil, and hydroelectric generators were taken from North American Electric Reliability Corporation (NERC) Generator Availability Data System data (GADS 2016). The Generator Availability Data System provides detailed information by unit maximum capacity for most major generator types, and these data were applied to the PCM. Other assumptions adopted from Bloom et al. (2016) are documented in Table 5.

\section{Table 5. Select Thermal Plant Assumptions}

Hydropower assumptions are in Section 2.2.3.

\begin{tabular}{|l|c|c|c|c|}
\hline Category & Gas CT & Gas CC & Coal & Nuclear \\
\hline Minimum uptime (hours) & 0 & 6 & 24 & N/A \\
\hline Minimum downtime (hours) & 0 & 8 & 12 & N/A \\
\hline Ramp rate $\%$ of maximum capacity per minute) & 8 & 5 & 2 & N/A \\
\hline Start-up cost (\$/MW of maximum capacity) & 69 & 79 & 129 & 0 \\
\hline Variable operation and maintenance cost $(\$ / M W h)$ & 0.6 & 1 & 2.8 & 2.8 \\
\hline $\begin{array}{l}\text { Annual outage rates (sum of forced and maintenance } \\
\text { outages) (\% of year) }\end{array}$ & $5.69 \%$ & $4.69 \%$ & $7.00 \%$ & $3.41 \%$ \\
\hline
\end{tabular}

\footnotetext{
12 ReEDS retirements are based on both announced retirements and modeled retirements. Modeled retirements are age-based (with thermal unit lifetimes of 55-75 years) or utilization-based (for coal plants under $40 \%$ annual capacity factor). See Eurek et al. (2016) for details.
} 
For the base PCM transmission topology, NARIS relied on nodal transmission models developed for the Eastern Interconnection and the Western Interconnection under the guidance of NERC. Power flow and dynamic base case models in the Eastern Interconnection (plus Quebec) are released by the Eastern Reliability Assessment Group Multiregional Modeling Working Group; we adopted the 2026 summer case as our base set of assumptions for the Eastern Interconnection. Line limits for the Eastern Interconnection were enforced for those lines included in the NERC Book of Flowgates. The Western Interconnection topology was originally created by the WECC TEPPC, which also provides the lines that make up the WECC Paths and define the limit to the flow along those paths. The topology for the Texas Interconnection comes from ERCOT. The lines connecting the ERCOT zones were enforced as interface constraints. The zonal representation from the Programa de Desarrollo del Sistema Eléctrico Nacional (PRODESEN) was used for the Mexican portion of the model.

Figure 11 shows the steps involved in a detailed PCM study. These steps are followed to simulate how a system operator might commit and dispatch a given system as forecasts of wind and solar availability and load are updated throughout the day. For NARIS, we did not perform the intraday simulation, but we did perform day-ahead simulations using several different estimations of uncertainty in forecasts (see Section 3.5.5).

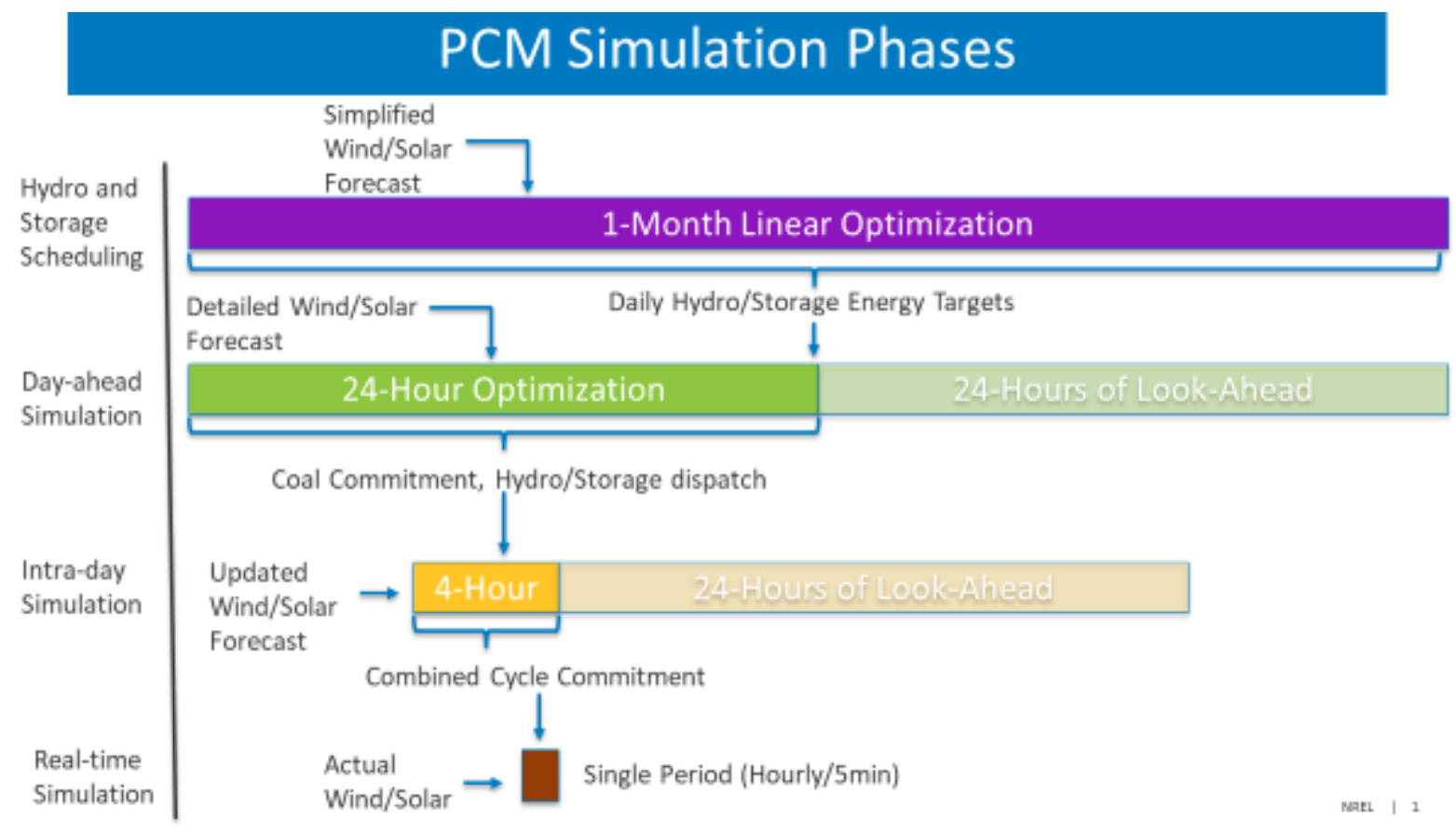

Figure 11. Simulation steps to run the PCM

PCMs are typically run as single-operator models and assume perfect information availability across regions, which is both unrealistic (leading to a solution that is lower in cost than reality) and computationally burdensome. To address these challenges and better reflect market friction and latency between operating regions, NREL designed a geographic decomposition method (Barrows et al. 2019), and we used that method in NARIS. The unit commitment and economic dispatch problem is decomposed into the independent system operator (ISO) and utility regions. This decomposition method is based on three steps: interchange forecast, decomposed unit commitment, and power flow reconciliation. This method presents two major benefits by 
reflecting actual system conditions and reducing computational time by allowing parallelization of the simulation. No hurdle rate or wheeling charge is added to flow power between regions; this assumes more coordination in dispatch than occurs in today's system in some regions.

ReEDS is a zonal model, aggregating actual transmission buses, lines, generators, and loads to a single node for each zone. For the production cost modeling, full nodal detail is maintained. Therefore, new generation capacity, retirement decisions, and transmission expansion must be decomposed from the zonal ReEDS results into the nodal PCM.

The first step to translate a ReEDS result is to determine which units in the PCM are retired. For noncoal units, ReEDS provides a capacity of generation by type for each zone that should be retired. Coal units are tracked individually in ReEDS (as they tend to be larger, and fewer new ones are built), rather than as an aggregated capacity for each zone. Each PCM node is mapped back to a ReEDS zone, and PCM generation capacity within each zone is retired until the ReEDS retirement amount is reached. For noncoal units, units are prioritized for retirement based on their heat rate, retiring the least efficient units first.

The next step is to add new units. Again, ReEDS provides the expanded capacity by type for each zone. That new capacity is broken down into reasonable generator sizes and placed at PCM nodes. Nodes are prioritized for connecting new generation by first adding units to nodes with generation that had been retired, which is followed by placing units at high-voltage and wellconnected (i.e., number of lines and summed capacity of those lines) nodes. New wind and solar locations are determined by reV geospatial tool (Maclaurin et al. 2019) and are connected to PCM nodes by placing them at the closest high-voltage bus.

Expanded transmission built by ReEDS is also translated to the PCM. We simplified expanded transmission by assuming all new lines are direct current (DC). This reduces the complexity of adding new alternating current (AC) lines, as new DC lines do not impact loop flow on the existing network. However, this does increase the operational flexibility of these lines. The goal of this process is to represent the ReEDS modeled increases to interregional interfaces, and DC lines do that. Bloom et al. (submitted) ${ }^{13}$ explore a method to expand AC infrastructure in a zonalto-nodal translation, but those $\mathrm{AC}$ lines do not represent the same new interregional transfer capability. Designing AC infrastructure to expand interfaces while avoiding loop flow constraints for the entire continent is beyond the scope of NARIS. To avoid unrealistic unserved energy because of these AC loop flow constraints (with transformation of the generating fleet compared to today), the flow limits on AC lines and interfaces were allowed to exceed nonemergency ratings for a penalty cost of $\$ 12,000$ per megawatt.

In reality, the new transmission expansion may be a combination of DC and $\mathrm{AC}$ infrastructure, and a variety of transmission or generation infrastructure could alleviate the $\mathrm{AC}$ transmission constraints. Detailed regional power flow studies are needed to determine the local and regional benefits of each option. To test the potential overall cost impact of these two assumptions (DC modeling in production cost tool and penalty on $\mathrm{AC}$ violations), we made cost estimates of

\footnotetext{
${ }^{13}$ For more information, see “Interconnections Seam Study,” NREL, https://www.nrel.gov/analysis/seams.html.
} 
infrastructure to solve the issue in the model. These are both overestimates of potential cost impacts, because the optimal solution would be better than this simplification. For example:

- If we calculated costs to consider the costs of making all AC ReEDS expansion lines into DC (including converter stations), the cost increase could represent $0.4 \%$ of total system costs in the Low Cost VG scenario. This is an overestimate of the impact, because not all new lines would be DC, but this gives us an idea about how significant the assumption could be. This estimate is calculated by multiplying the AC build (in GW) by the cost of the converter stations $(80,000 \mathrm{MW} * \$ 253,000$ per megawatt assumed cost of DC converter stations).

- If new transmission infrastructure were built to augment every violated line to accommodate its maximum 5-minute violation, it would add up to $0.1 \%$ to the total continental cost in the Low Cost VG scenario (5 TW-mi of violation * \$1,347/MW-mi). Some of these costs are already considered in the ReEDS model, which includes costs for intrazonal transmission lines for new generation. Other scenarios would likely have similar adders, making comparisons of scenarios consistent without this adder.

End points for the new lines were determined by connecting strongly connected buses within the two regions between which ReEDS chose to add new transmission capacity. When possible, because new lines should relieve congestion, buses on opposing sides of an enforced transmission constraint were chosen to connect the new lines. Given the varying sizes of ReEDS regions, some new transmission capacity between two regions was modeled with multiple new lines, while other regions were modeled with just one new line. The aggregate capacity of the new DC lines between any two regions is set by the amount ReEDS expanded the transmission between them.

\subsubsection{Resource Adequacy Modeling: PRAS}

Resource adequacy refers to the ability of a power system to serve electricity demand with an acceptably low risk of failure because of shortfalls in power supply or deliverability. The Probabilistic Resource Adequacy Suite (PRAS [Stephen 2021]) is an NREL-developed collection of tools for quantifying this shortfall risk in terms of standard probabilistic risk metrics, such as loss-of-load hours (LOLH), loss-of-load expectation (LOLE), and expected unserved energy (EUE). PRAS estimates these metrics using a sequential Monte Carlo analysis that performs a simplified power flow (see Figure 12, page 26) to confirm supply exceeds demand for sequences of random generator outage patterns. The reported metrics for NARIS are:

- Loss-of-load hours (LOLH): LOLH is "generally defined as the expected number of hours per period (often one year) when a system's hourly demand is projected to exceed the generating capacity" (NERC 2018). It is evaluated using not only the peak hours or days but every hour of the year.

- Expected unserved energy (EUE): EUE is "the summation of the expected number of megawatt hours of demand that will not be served in a given period as a result of demand exceeding the available capacity across all hours" (NERC 2018). For NARIS, annual EUE is reported, representing the sum of EUE in all hours of the year. It quantifies both the probability and magnitude of a shortfall occurrence, but as a result cannot distinguish between a small, likely shortfall and a large, unlikely one. EUE can also be reported as normalized EUE by expressing the expected energy shortfall as a fraction (usually in 
parts per million, or ppm) of total energy demand in the period; this is convenient for comparing reliability levels across different systems.

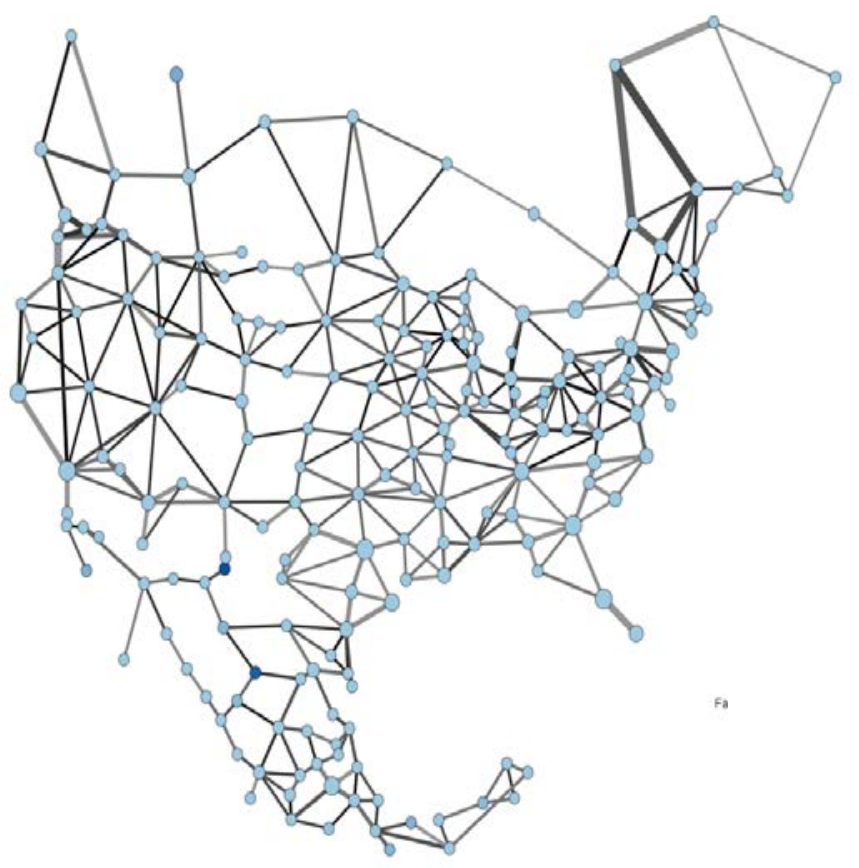

Figure 12. Transmission network representation in PRAS

Figure depicts the connectivity in the PRAS model. Circles represent regions, while lines represent interfaces.

For NARIS, PRAS was used to simulate many alternative realizations of simplified annual hourly power system operations over a year. Each realization corresponds to operations under a different collection of representatively sampled thermal generator unplanned outage profiles. The simulation performs a simplified operational dispatch on every random sample, at every period. The simplified dispatch constrains the flow between regions to the available transmission capacity while recording the time and location of events where supply cannot meet demand. 


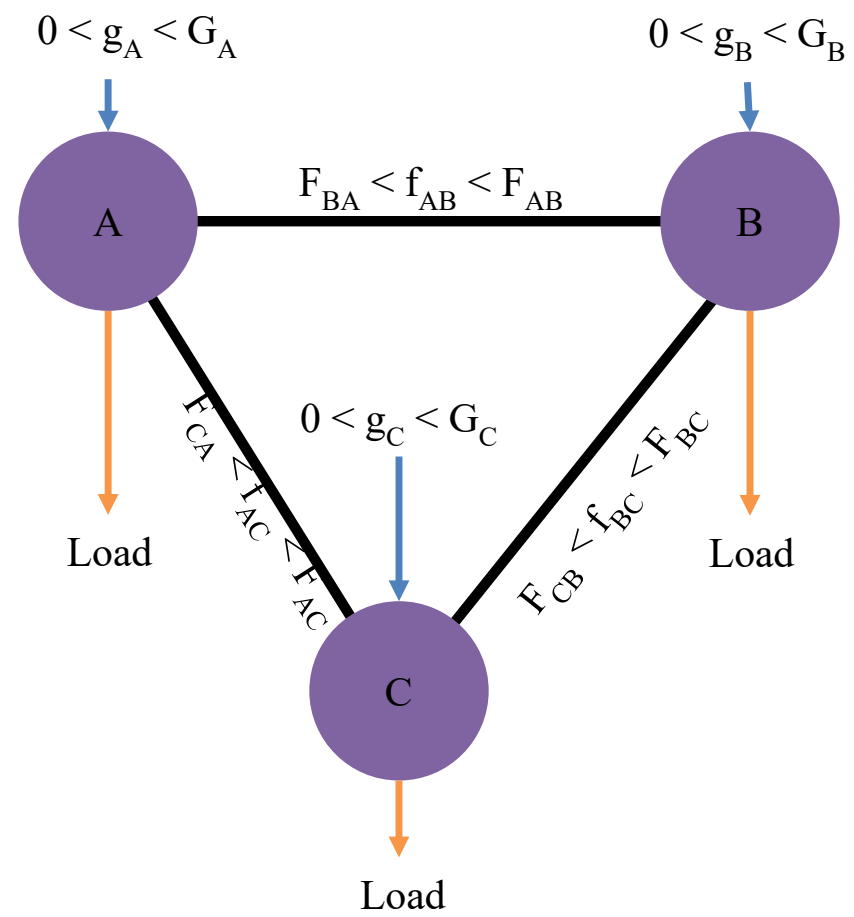

Figure 13. Diagram of PRAS zonal balancing

PRAS performs an optimized power flow (transport model) for every sample for each zone, determining whether generation and import supply is sufficient to meet demand (Load) in each zone. Constraints include enforcing that generation $(g)$ is less than generating capacity $(G)$ and that interface flow $(f)$ is within flow limits $\left(F_{A C}\right)$.

By simulating continent-wide system operations under a wide range of generator outages conditions, the risk of encountering a system state in which load is unserved because of a supply or deliverability shortfall can be quantified probabilistically and compared to risk levels of today's grid or industry standards.

To perform these simulations fast enough to make simulating hundreds of thousands of years of operations practical, PRAS makes more simplifying assumptions than a nodal static or dynamic power flow model. PRAS does not model power flow between buses but rather groups buses into regions (zones). Power transfer between buses within a single region is assumed to take place on a "copper sheet" with no intraregional transfer limits or line reliability limitations being considered. Power transfers between regions are modeled with a simple power balance ("pipeand-bubble" or transport model) ${ }^{14}$ representation constrained by the thermal capacities of interregional lines (in NARIS, all lines were assumed to be $100 \%$ reliable). The operational objective was to minimize the system's unserved energy, and unit-level generating costs were not considered.

These simplifications are consistent with commercial resource adequacy models used in industry (e.g., the NERC Long-Term Reliability Assessment). Resource adequacy is a necessary, but not sufficient, condition for power system reliability, and resource adequacy modeling is intended to

\footnotetext{
${ }^{14}$ The transport model assumes all lines and interfaces are controllable, and it is different from a DC-optimal power flow model, which ensures Kirchoff's voltage law is respected.
} 
complement, not replace, other kinds of modeling that can evaluate additional operating considerations, such as generator flexibility (ramp rates and unit commitment constraints), AC power flow feasibility, and transient stability issues, albeit for many fewer potential operating conditions.

Capacity expansion models such as ReEDS perform a simplified internal resource adequacy assessment to maintain computational tractability. ${ }^{15}$ For systems with large contributions of variable and energy-limited resources (e.g., storage), such as those being studied in NARIS, it is desirable to supplement this basic evaluation with a more rigorous probabilistic risk assessment using a dedicated resource adequacy tool such as PRAS. In this case, the generation and transmission build-out determined by ReEDS is provided to PRAS, which reports probabilistic risk metrics (LOLE and normalized EUE) corresponding to the system build-out.

PRAS is run hourly with wind, solar, run-of-river hydropower, and load time series data as described in Section 2.2 (the 7-year period represents over 60,000 hours). PRAS was configured in NARIS to ignore monthly energy constraints associated with reservoir hydropower, thus treating this class of resource as capacity that is available to be dispatched. PLEXOS modeling for NARIS demonstrated that hydropower does have the flexibility to contribute significantly during the most important hours (Section 3.4). Pumped-storage hydropower and ReEDS-built storage (mostly 4-hour batteries) were dispatched as energy-limited storage resources. These storage resources are optimized for providing capacity; they charge when capacity is available in a region, and discharge only when it is needed. Market operations of a storage device could potentially reduce the ability of storage to provide capacity to a region, specifically if forecasting error led to suboptimal storage dispatch.

PRAS was developed in part to improve on existing techniques for representing transmissionconstrained systems that include significant generation from variable renewable sources that are correlated with load. The key limitations to PRAS are the data inputs (which are limited to the 7 years for which we have consistent, time-synchronous load, wind, and solar data), and zonal transmission representation. N-1 analysis and dynamic transmission modeling are important for overall reliability assessment, but these are not considered in adequacy analysis. In this report, the PRAS results for the 2024 model and 2050 in the Low Cost VG and BAU scenarios are described. See Section 3.2.1 for a comparison with modeling from NERC and others.

\footnotetext{
${ }^{15}$ ReEDS uses a planning reserve margin, with wind and solar resources contributing based on an hourly estimate of the most important hours in each region.
} 


\subsection{Data}

\subsubsection{Wind and Solar Resource}

High-quality, highly resolved wind and solar resource information is important for understanding how the North American grid could evolve and operate in the future. Figure 1 (page 4) shows the wind and solar resource throughout the continent. The solar data for NARIS (see Figure 1) were developed using NREL's National Solar Radiation Data Base, which is based on satellite-based observations of the atmosphere. The database has a 4-km by 4-km spatial resolution and halfhourly temporal resolution covering the 18 years from 1998 to 2017.

We used the Weather Research and Forecasting model (WRF) ${ }^{16}$ (Skamarock et al. 2008) to simulate wind speeds for Mexico and Canada by extending existing WRF runs for the United States. The WRF model is a community numerical weather prediction model maintained by the National Center for Atmospheric Research in the United States. It has been successfully applied to wind studies and resource assessments (e.g., Draxl et al. 2013; Carvalho et al. 2014;; GarciaDiez et al. 2012; Ji-Hang et al. 2014; Lundquist et al. 2014). The WRF model allows for accurate simulations of winds near the surface and at heights that are important for wind energy purposes. WRF's ability to downscale to required resolutions allows for modeling mesoscale features, such as fronts, sea breezes, or winds influenced by orography, which are all important factors in describing the wind characteristics over the North American continent.

For NARIS, data were simulated over Mexico and Canada and output every 5 minutes on a 2-km grid following the WIND (Wind Integration National Dataset) Toolkit setup for the United States for consistency. The details of the setup, and meteorological validation, are available in Draxl et al. (2015). The simulations for Mexico and Canada were different than the WIND Toolkit setup in only a few aspects. ${ }^{17}$ Figure 14 shows the three different domains that were used in the study; all three are publicly available. Most wind sites in Canada were in Domain A. To ensure consistency with Domain A, Domain B sites were bias-corrected using time-synchronous information from nearby sites in the area overlapping Domain A and Domain B. We biascorrected the wind speeds and confirmed that annual power output shows no bias between Domain A and Domain B in and near the overlapping region.

\footnotetext{
16 "Weather Research and Forecasting Model," National Center for Atmospheric Research, https://www.mmm.ucar.edu/weather-research-and-forecasting-model.

${ }^{17}$ A few changes were needed because of numerical stability and the switch to a newer WRF version. The MellorYamada-Nakanishi-Niino boundary layer parameterization was used. And for numerical stability, we changed the mixing term (dif_opt $=2$ ) and added time off-centering for vertical sound waves $($ epssm $=0.5)$, no nudging was applied. Moreover, we upgraded to WRF v3.7.1 with recent versions of netcdf (4.6) with pnetcdf for faster implementations.
} 


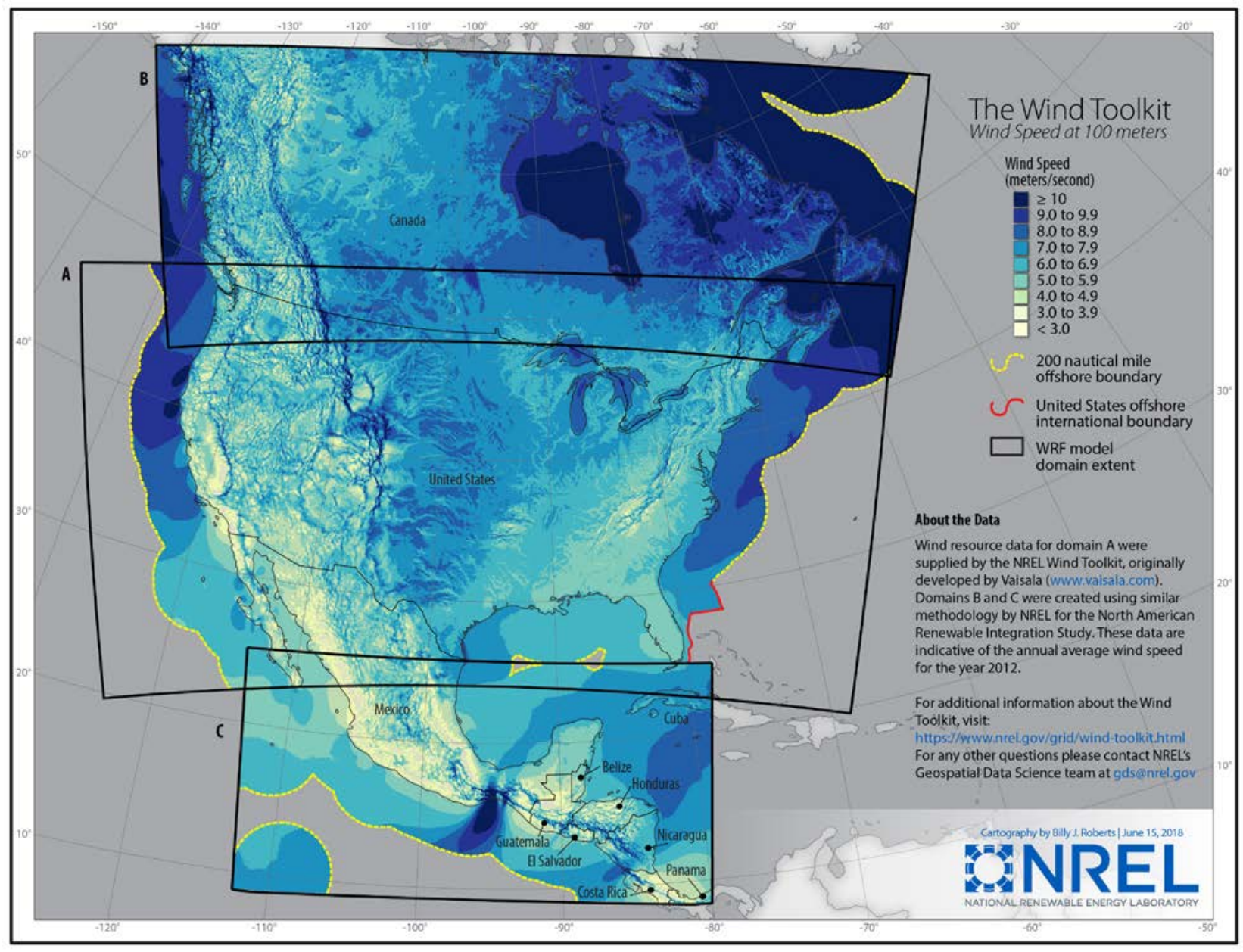

Figure 14. The three domains used in NARIS for wind modeling

Wind and solar data were processed using the NREL System Advisor Model to determine 5minute resolution generation profiles. All the wind ${ }^{18}$ and solar ${ }^{19}$ data sets are publicly available in their native resource formats. The cost and performance projections for capacity expansion modeling were consistent across the continent with the 2018 ATB. The amount, location, and transmission spur line costs for new onshore wind and PV resources in NARIS were assessed using reV (Maclaurin et al. 2019; Rossol, Buster, and Bannister 2021) for input to ReEDS and other models. The modeled wind turbine power curve is consistent with improvements made for the 2019 ATB. The wind turbine technology used for the 2050 PCM was based on future technology performance projections from the 2019 ATB (Cole et al. 2019) to better represent the specific power curve of a future (circa 2030) wind turbine. ${ }^{20}$ For utility-scale solar PV, panels with inverter loading ratios of 1.3 and 1-axis tracking were assumed (and parameters from the 2019 ATB were also used). For distributed PV, a mixture of orientations, including flat and a

18 “NREL Wind Integration National Dataset,” NREL, https://registry.opendata.aws/nrel-pds-wtk/.

19 “NSRDB: National Solar Radiation Database,” NREL, https://nsrdb.nrel.gov/.

${ }^{20}$ Icing impacts were modeled as reducing the plant output to zero when the temperature was below $0{ }^{\circ} \mathrm{C}$ and $95 \%$ humidity; low-temperature cutout was assumed to happen at $-35^{\circ} \mathrm{C}$ 
variety of tilted orientations based on Sigrin et al. (2018) were assumed (Gagnon et al. 2016). Day-ahead forecasts were used for wind and solar based on the European Centre for MediumRange Weather Forecasts (ECMWF). The ECMWF historical data were downloaded and processed using identical System Advisor Model parameters. Continent-wide real data time series were insufficient to tune any of the state-of-the-art solar forecasting methods (e.g., Dobbs et al. 2017). The WRF model has also been extended to improve solar forecasting with WRFSolar, ${ }^{21}$ but it was not used for NARIS.

The wind forecast data were bias-corrected with simple annual correction factors based on the ratio of annual generation in the forecasts to actual generation. The forecasted profiles were blended with the actual profiles at various ratios to produce the forecasts described in Section 3.5.5. The $10 \%$ mean absolute error (MAE, see formula below) wind forecast was created with a $1 / 3$ actual, 2/3 forecast blend (MAE calculated at plant-level and then averaged). This approach represents improvements state-of-the-art wind power forecasts have over the raw ECMWF implementation, which is intended for a wide variety of uses and has less-granular spatial resolution than the WRF model. The 5\% MAE wind forecast was created with a 2/3 actual, 1/3 forecast blend, and represents an intraday forecast time horizon.

$$
M A E=\frac{\sum_{i=\text { Site }} \sum_{t=\text { time }} \mid \text { Actual }_{i, t}-\text { Predicted }_{i, t} \mid}{\text { Number of Sites } \times \text { Number of time intervals }}
$$

\subsubsection{Load}

Load data were obtained from a variety of sources for 2007-2015. The multiyear time series is important for consistent time-synchronous patterns with the 2007-2013 wind and solar data. The sources of the data were:

- Independent System Operator (ISO) and Regional Transmission Organization (RTO) Regions: For ISO/RTO regions, the load data were either downloaded or requested at the most granular spatial resolution available to the public.

- Utilities: For utilities outside ISOs in the United States, data were obtained from Federal Energy Regulatory Commission Form 714. For Canada, data were obtained from provincial sources directly for regions outside ISOs. ${ }^{22}$

- Mexico: For Mexico, load data from PRODESEN 2018 were used in NARIS.

All load data were cleaned of problems, which were often either erroneous time zone stamps or erroneous data during the hours of switching to or from Daylight Savings Time. The data were extrapolated to 2050 for most scenarios by a simple scalar factor based on extrapolated annual demand projections from the U.S. Energy Information Administration (EIA), Canada's National Energy Board (NEB), and Mexico's Secretaría de Energía (SENER). This means the annual energy demand for all meteorological years is identical for 2050, but the peak demand and hourly shapes are different. The load factor for each year will be the same because the scalar multiplier is the same for every hour; this will also preserve all correlations between load, wind,

21 “WRF-SOLAR,” National Center for Atmospheric Research, https://ral.ucar.edu/pressroom/features/wrf-solar.

${ }^{22}$ Hourly profiles for Prince Edward Island were taken from the hourly shapes from New Brunswick, scaled to peak load in Prince Edward Island. 
and solar for the future year analysis. The exception to these descriptions is the electrification scenarios, which are discussed in Section 3.5.4.

\subsubsection{Hydropower}

Hydropower generation is a potential source of flexible, carbon-free generation and storage to the grid. Hydropower technologies in North America include run-of-river hydropower (which has power outputs that depend primarily on water inflow at any given time), reservoir hydropower (which can store significant amounts of water and shift energy), and pumpedstorage hydropower. The operation of hydropower turbines is very flexible. The overall constraints to hydropower flexibility can be complicated to model, as they come from various physical and institutional sources. Some of these key sources include:

- Cascading Constraints (Physical): When hydropower generators exist in a series of cascaded reservoirs in a basin, the inflows at lower reservoirs depend on the outflows from upper reservoirs.

- Hydrology Constraints (Physical): When and where water becomes available to dams is a key constraint on hydropower flexibility and generator outputs. In some seasons, even large reservoirs can fill and need to flow water at high levels at all times.

- Flow Requirements (Institutional): Requirements for water usage from downstream users for agricultural, recreational, environmental, and other needs impact mandatory flow requirements from dams. These detailed constraints are generally not modeled in power systems models, but are represented with proxy variables for minimum generation, ramp rates, and other characteristics.

For NARIS, the starting point for hydropower dispatch assumptions were the assumptions used in the Eastern Renewable Generation Integration Study (Bloom et al. 2016) for the Eastern Interconnection, the California Low Carbon Grid Study (Brinkman et al. 2016) in the Western Interconnection, and PRODESEN in Mexico. These assumptions were refined based on feedback from the NARIS Technical Review Committee for the PLEXOS modeling. Refinements included:

- Energy limit adjustments for generators in the Hydro Quebec, Manitoba Hydro, and Bonneville Power Administration service areas.

- More-constraining ramp rates for Eastern Interconnection and Hydro Quebec generators. For Hydro Quebec, this helped act as a proxy for cascading constraints ${ }^{23}$ that are not included in the continental model.

- Refinements to the timescale of flexibility (e.g., optimization over a day or a week, and pure run-of-river with no adjustability) at various dams in the Hydro Quebec and Bonneville Power Administration service areas.

\footnotetext{
${ }^{23}$ Cascaded reservoirs have complicated intertemporal interactions that require significant data inputs and add computational complexities to the modeling. These constraints are typically not included in interconnection-sized production cost studies. In the Western Interconnection, the flexibility limits caused by these types of constraints are often modeled by constraining the outputs of individual dams to historical flows (e.g., treating dams as run of river). For Hydro Quebec, we constrained flexibility with a ramp rate to represent the system-wide ramping limitations of a cascaded system. We also added ramping limitations to the generators in the Eastern Interconnection-including limitations not used in previous studies - to address cascading and other flexibility limitations.
} 
On average, these changes better represent the flexibility of the hydropower generation. See Section 3.4.3 for detailed analysis of hydropower flexibility results from the modeling. Table 6 shows some of the key sources and values for hydropower assumptions in the NARIS PLEXOS model.

Table 6. Hydropower Assumptions ${ }^{a}$

\begin{tabular}{|c|c|c|c|}
\hline Metric & $\begin{array}{l}\text { Eastern } \\
\text { Interconnection }\end{array}$ & $\begin{array}{l}\text { Western } \\
\text { Interconnection }\end{array}$ & $\begin{array}{l}\text { Quebec } \\
\text { Interconnection }\end{array}$ \\
\hline $\begin{array}{l}\text { Water-year used to estimate } \\
\text { energy limits (hourly, monthly, } \\
\text { or daily) }\end{array}$ & 2006 & 2005 & Multiyear average \\
\hline Energy limit sources & $\begin{array}{l}\text { Eastern Renewable } \\
\text { Generation } \\
\text { Integration Study } \\
\text { (original sources } \\
\text { include U.S. EIA, } \\
\text { Southwestern Power } \\
\text { Administration, } \\
\text { Southeastern Power } \\
\text { Administration, U.S. } \\
\text { Army Corps of } \\
\text { Engineers, and } \\
\text { provincial sources) }\end{array}$ & $\begin{array}{l}\text { Western Electricity } \\
\text { Coordinating Council } \\
\text { and Bonneville } \\
\text { Power Administration }\end{array}$ & Hydro Quebec \\
\hline $\begin{array}{l}\text { Monthly, daily, and hourly (run- } \\
\text { of-river) optimization windows } \\
\text { (capacity-weighted } \\
\text { percentage) }\end{array}$ & $\begin{array}{l}79 \% \text { Monthly } \\
12 \% \text { Daily } \\
9 \% \text { Hourly }\end{array}$ & $\begin{array}{l}50 \% \text { Monthly } \\
11 \% \text { Daily } \\
39 \% \text { Hourly }\end{array}$ & $100 \%$ Monthly \\
\hline $\begin{array}{l}\text { Ramp rate (Percentage of } \\
\text { maximum capacity per minute) }\end{array}$ & $1.1 \%$ & $0.5 \%-1.6 \%$ & $0.2 \%-0.5 \%$ \\
\hline $\begin{array}{l}\text { Minimum generation level } \\
\text { range (Percentage of } \\
\text { maximum capacity) }\end{array}$ & $0 \%-20 \%$ & $0 \%-45 \%$ & $20 \%$ \\
\hline
\end{tabular}

a The table does not include pumped-storage hydropower.

b The water-years are intended to be reasonable representations of a "typical" year. Using time-synchronous data is less important with hydropower than it is with wind, solar, or load because the hourly shapes of the water flows into a reservoir are not necessarily correlated with the actual power outputs from the dam.

c The optimization windows represent the time-frames in which the hydropower generation can shift energy. A daily limit would limit the total generation from that unit within a day, subject to the other constraints. For the Eastern Interconnection, the optimization window does not reflect a plant-specific representation; generic parameters were used until dispatch looked similar to historical dispatch (see below for a description). Hydropower in Quebec has more than monthly flexibility; interseasonal and interannual flexibility were not studied in NARIS.

d This value constrains the ramp rates of the generators. It is directly comparable to assumed ramp rates for thermal plants in Table 5.

e For the Eastern Interconnection and the Quebec Interconnection, a minimum generation value of $20 \%$ of maximum capacity was assumed, or the largest value feasible if monthly energy limits require capacity factors of less than $20 \%$. See below for an analysis of minimum generation levels by season. 
The mixture of flexibility timescales, minimum/maximum generation levels, energy limits, and modeling methodologies lead to different flexibility characteristics at different times of the year. To dispatch the hydropower generators with monthly optimization windows, the PLEXOS model runs a simplified monthly dispatch called the MT (Medium-Term) model that categorizes every hour of each month into five categories (or time-slices). It then optimizes dispatch for these timeslices and then determines a daily energy limit for each generator. This energy limit is then optimized in the unit commitment model, along with the hydropower with daily energy limits. The hydropower generation is locked in during the unit commitment, and it does not re-optimize during real-time dispatch.

The goal of NARIS was to represent the overall regional character of the dispatch of hydropower generation —not to accurately represent unit-specific detail for every generator. The character of the hydropower dispatch profiles is qualitatively similar to what was seen in ISOs in 2017, based on figures in the 2017 Hydropower Market Report (Uria-Martinez et al. 2018).

For context, the fall week studied in Section 3.4.3 demonstrates the bounds of operation that these hydropower flexibility assumptions provide. In the United States, there is about $50 \mathrm{GW}$ of operating envelope between minimum generation levels (which coincide with low-load periods) and maximum generation levels (which coincide with high-load periods), providing a reasonable look at the available flexibility given these assumptions. About $27 \mathrm{GW}$ of this $50 \mathrm{GW}$ is in the Western Interconnection, and the rest is in the Eastern Interconnection.

Figure 15 shows the weekly maximum and minimum values of U.S. hydropower generation in the PLEXOS model. The figure is one way of visualizing the flexibility the model allows the hydropower, although there are limitations within the envelope of operation (e.g., ramping and daily/hourly limits). The minimum is on average $50 \%$ less than the average weekly operation, and the maximum is less than double the average for a typical week. Different regions may have differing levels of flexibility, depending on season, water conditions, and other factors.

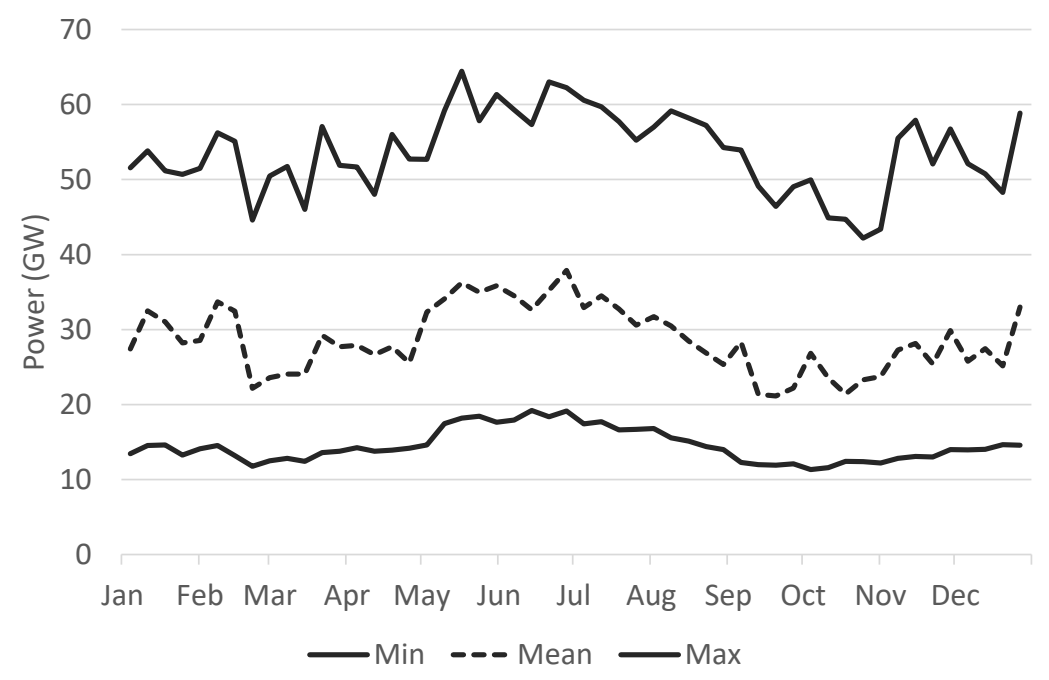

Figure 15. Weekly maximum, mean, and minimum hydropower generation from U.S. generators

These weekly maximum and minimum values show the envelope within which hydropower operates in the United States. A variety of factors (including ramping limits, daily limits, and hourly limits) further limit the flexibility within this envelope. 
To test the impacts of these flexibility assumptions we ran model sensitivities with flexibility eliminated from conventional hydropower resources (treating everything as run of river).

Section 3.4.4 presents the results of this analysis, which demonstrate the benefits of hydropower flexibility to a future scenario with very high wind and solar generation. 


\section{Results}

In this section, we discuss the key conclusions of NARIS for the United States. Although many conclusions are not easily categorized, they are presented in separate sections for improved readability: overview (Section 3.1), adequacy (Section 3.2), transmission (Section 3.3), flexibility (Section 3.4), and general scenario conclusions (Section 3.5).

\subsection{Scenario Overview}

Figure 16 and Figure 17 show the U.S. annual generation and capacity respectively by technology type in the core scenarios compared to a near-term (2024) year in the model. 2024 was selected as a near-term year because the composition of the power system in that year is reasonably well known and that is the basis year for the planning cases used to develop some of the models (see Section 2.1.3). The scenarios were designed using traditional planning methods (using regional planning reserve margin constraints in the ReEDS model) and we demonstrated capacity adequacy using stochastic Monte Carlo methods in PRAS.

Consistent among the scenarios are the major growth in wind generation and the reduction in thermal generation (including coal, nuclear, and natural gas). The largest variation in the core scenarios is the overall increase in generation (mostly from wind) in the Electrification scenario. Another significant difference is the reduction in gas generation in the scenarios that include a carbon limitation $(80 \%$ reduction in the Carbon Constrained and Electrification relative to 2005 Emissions). All scenarios have a reduction in coal and nuclear generation, and an increase in wind and solar. Gas and hydropower generation and capacity was consistent in most of the scenarios (but gas is higher in the BAU versus 2024 and the other core scenarios). Renewable contributions in the scenarios studied vary from $50 \%$ (BAU) to $79 \%$ (Electrification), and the Low Cost VG and Carbon Constrained scenarios were at approximately $70 \%$. 


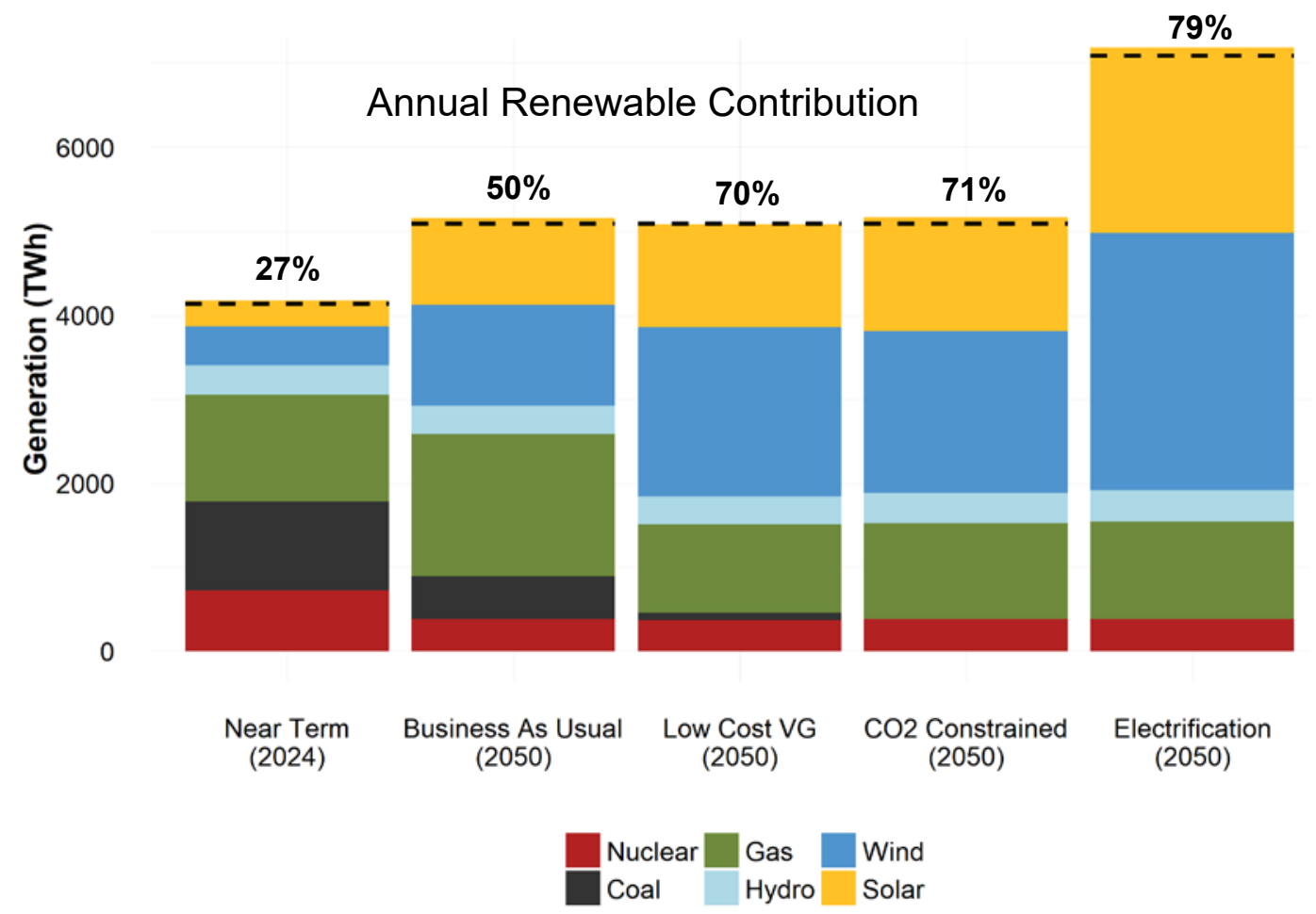

Figure 16. U.S. generation in 2024 and 2050 in the NARIS core scenarios

The dashed lines represent U.S. load (including losses). When the bars are above the load lines, net exports to Canada are happening. See Section 3.3 for a discussion of international trade, which varies widely between scenarios.

3000

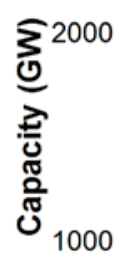

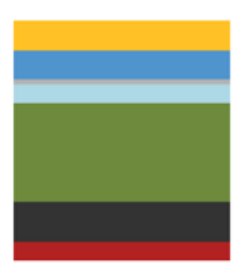

Near Term (2024)
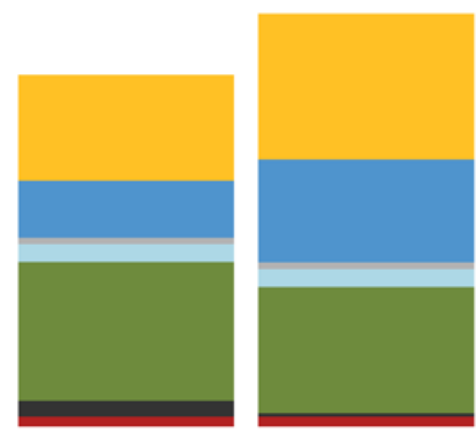

Business As Usual (2050)
Low Cost VG (2050)

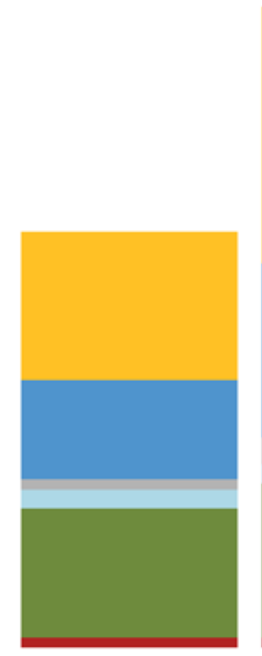

CO2 Constrained (2050)

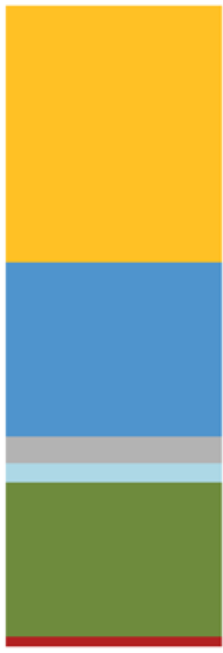

Electrification (2050)

$\begin{array}{lll}\text { Nuclear } & \text { Gas } & \text { Storage } \\ & \text { Coal } & \text { Solar }\end{array}$

Figure 17. U.S. generation capacity in 2024 and 2050 in the NARIS core scenarios

Pumped-storage hydropower is reported in the Storage category throughout the report. 
Table 7. U.S. Generation Capacity (GW) in 2024 and 2050 in the NARIS Core Scenarios

\begin{tabular}{|c|c|c|c|c|c|}
\hline Туре & $\begin{array}{l}\text { Near-Term } \\
(2024)\end{array}$ & BAU (2050) & $\begin{array}{l}\text { Low-Cost VG } \\
(2050)\end{array}$ & $\begin{array}{l}\text { Carbon } \\
\text { Constrained } \\
(2050)\end{array}$ & $\begin{array}{l}\text { Electrification } \\
(\mathbf{2 0 5 0 )}\end{array}$ \\
\hline Coal & 190 & 80 & 20 & 0 & 0 \\
\hline Gas & 470 & 670 & 610 & 620 & 740 \\
\hline Hydro & 90 & 90 & 90 & 90 & 90 \\
\hline Nuclear & 50 & 50 & 50 & 50 & 50 \\
\hline Solar & $\begin{array}{r}140 \\
\text { (20 rooftop) }\end{array}$ & $\begin{array}{r}510 \\
\text { (60 rooftop) }\end{array}$ & $\begin{array}{r}700 \\
\text { (160 rooftop) }\end{array}$ & $\begin{array}{r}710 \\
\text { (60 rooftop) }\end{array}$ & $\begin{array}{r}1230 \\
\text { (60 rooftop) }\end{array}$ \\
\hline Storage & 20 & 30 & 30 & 60 & 130 \\
\hline Wind & 140 & 280 & 490 & 480 & 840 \\
\hline
\end{tabular}

Values are rounded to the nearest $10 \mathrm{GW}$. Rooftop PV capacities are given in parentheses. Note that the dGen model was not run with new building-level demand assumptions for the Electrification scenario, so trajectories for electrification scenarios follow either the BAU or Low-Cost scenarios for rooftop PV.

The modeled deployment of technologies in the $\mathrm{CO}_{2}$ Constrained scenario is very similar to the that of the Low-Cost VG scenario. The detailed hourly and 5-minute integration analyses focus on the Low-Cost VG scenario. More methodology development is needed to understand the hourly impacts of electrification and how flexible additional electrified end-use demands could be. This scenario is useful for comparison with the others for many key metrics, but we did not do any unit commitment or resource adequacy modeling with it. Future work (along with the recent Electrification Futures Study for the United States) could help address more-detailed issues about operations in this scenario. Some technologies (e.g., nuclear and fossil fuels with carbon capture) have assumed costs that are too high for large-scale adoption in these scenarios. However, cost breakthroughs and newer technologies (e.g., small modular reactors) could change that conclusion. For NARIS, we assumed no breakthrough changes to those technologies to understand how the grid could evolve without large-scale technological breakthrough. Any additional cost breakthroughs would help reduce overall costs. Over 99\% of the wind deployed in these scenarios is onshore; ongoing changes to the North American offshore wind market and state legislation will likely change that conclusion.

Figure 18 shows the fraction of generation coming from renewable generators. Although the Low Cost VG and the $\mathrm{CO}_{2}$ Constrained scenarios are quite similar in 2050, there is divergence in the middle years. Less-expensive wind and solar in the Low Cost VG scenario accelerates high adoption of renewables more than the other scenarios, with slowed development after 2030. The more aggressive carbon limit in the $\mathrm{CO}_{2}$ Constrained and Electrification scenarios diverges from the BAU scenario by the early 2030s. Final renewable contributions in carbon-limited scenarios surpasses or equals the Low-Cost VG case by 2050. See Section 3.5 for discussion of emissions impacts. 


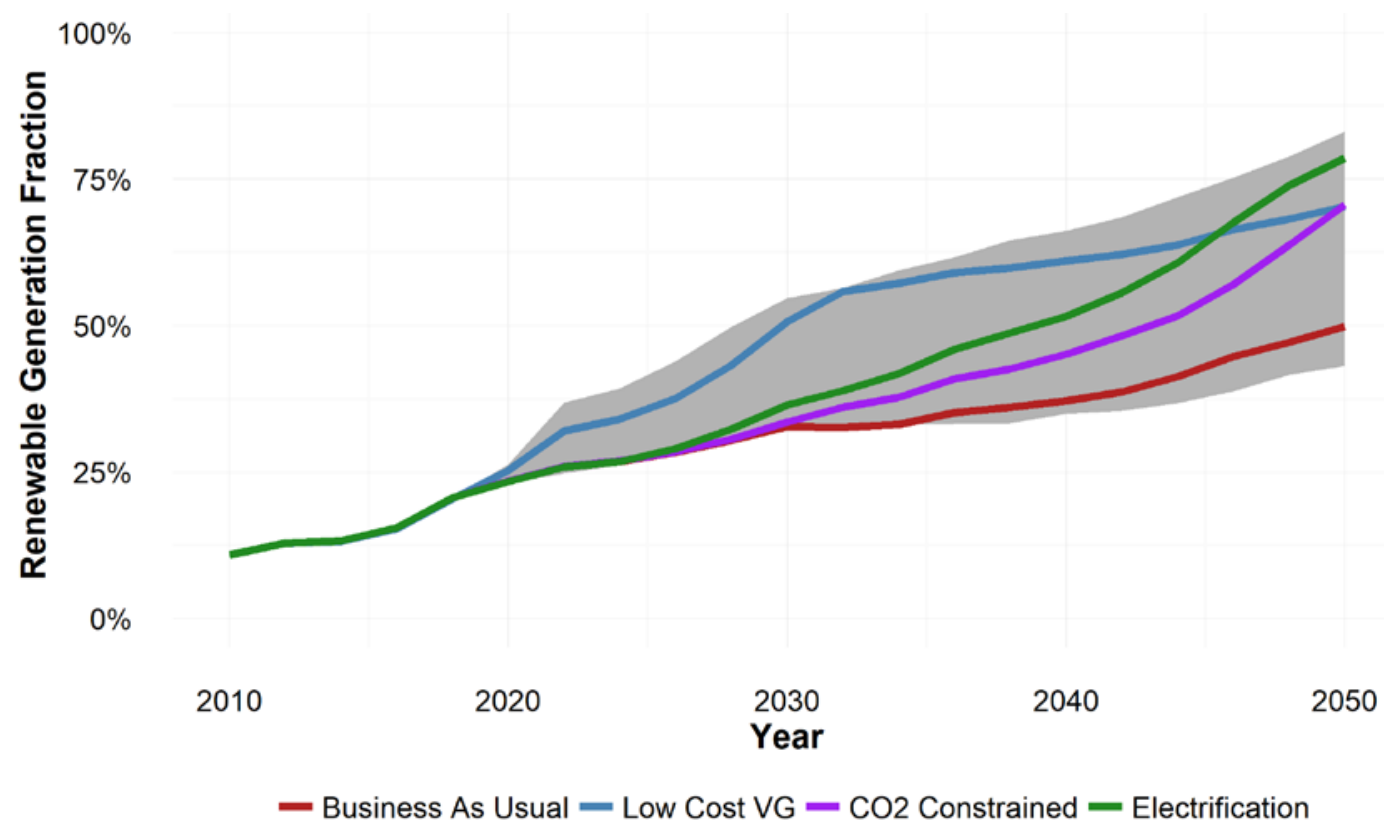

Figure 18. Fraction of generation coming from renewable generators in the United States Core scenarios are colored. The shaded region represents the envelope of all scenarios.

\subsection{Adequacy}

\subsubsection{Resource adequacy can be maintained in low-carbon scenarios through 2050.}

To examine resource adequacy in the U.S. power system, we used PRAS to calculate EUE and loss of load hours (LOLH) from selected scenarios as built by ReEDS. As described in Section 2.1.4, PRAS can compute several common resource adequacy metrics. For NARIS, we focused on EUE and LOLH for consistency with the NERC 2020 LTRA (NERC 2020). EUE can be aggregated by country or continent, while the LOLH does not scale with system size, so the reported values are summary statistics of the NERC Assessment Areas. EUE, which is reported in megawatt-hours (MWh) and parts per million (ppm), is the unserved energy as a fraction of the total demand.

We began by assessing the adequacy of the BAU 2024, BAU 2050, and Low Cost VG 2050 scenarios as built by ReEDS. Each scenario is assessed over 7 historical meteorological years, which affects the scenario's load, wind, and solar generation output at an hourly time-scale. For each scenario and meteorological year ${ }^{24}$ combination, we generated 10,000 sequential Monte Carlo samples of the year and used those samples to calculate EUE for each region in each hour. We report total EUE for each meteorological year, along with the average across meteorological years, for each scenario in Table 8. The NERC 2020 LTRA assessment for 2022 is also included

\footnotetext{
${ }^{24}$ Unusual weather events are taken into account in the 7 years of continental meteorology. Using historical years allows greater precision in wind, solar, and load modeling than using modeled future data. However, we did not consider the impacts of climate change on wind, solar, or load patterns in NARIS.
} 
for reference. The methods are similar, but not identical, so the numbers are not directly comparable.

Table 8. EUE by Scenario and Meteorological Year for the United States, Compared to NERC LTRA

The top part of this table presents results from the PRAS modeling for NARIS. EUE values rounded to the nearest MWh or the nearest $0.1 \mathrm{ppm}$. U.S. regions only.

\begin{tabular}{|c|c|c|c|c|c|c|}
\hline \multirow{2}{*}{$\begin{array}{l}\text { Meteorological } \\
\text { Year }\end{array}$} & \multicolumn{2}{|c|}{ BAU 2024} & \multicolumn{2}{|c|}{ BAU 2050} & \multicolumn{2}{|c|}{ Low Cost VG 2050} \\
\hline & MWh & $\mathrm{ppm}$ & MWh & ppm & MWh & $\mathrm{ppm}$ \\
\hline 2007 & 0 & 0.0 & 0 & 0.0 & 0 & 0.0 \\
\hline 2008 & 0 & 0.0 & 0 & 0.0 & 0 & 0.0 \\
\hline 2009 & 0 & 0.0 & 0 & 0.0 & 0 & 0.0 \\
\hline 2010 & 0 & 0.0 & 5,834 & 1.2 & 16,864 & 3.4 \\
\hline 2011 & 0 & 0.0 & 10 & 0.0 & 4 & 0.0 \\
\hline 2012 & 0 & 0.0 & 0 & 0.0 & 158 & 0.0 \\
\hline 2013 & 0 & 0.0 & 0 & 0.0 & 0 & 0.0 \\
\hline Annual Average & 0 & 0.0 & 835 & 0.2 & 2,432 & 0.5 \\
\hline \multicolumn{7}{|c|}{ NERC 2020 LTRA Values for Comparison } \\
\hline $\begin{array}{l}2022 \\
\text { Assessment Year }\end{array}$ & 12,845 & 2.7 & & & & \\
\hline
\end{tabular}

a WECC-CAMX (California and Mexico) region is excluded from this average because it was an outlier in the 2022 and 2024 assessment years, with over 1,000,000 MWh of EUE.

The results demonstrated adequacy generally comparable to or better than the 2020 NERC LTRA for the contemporary grid for the scenarios examined. All scenarios had at least five times lower EUE compared to today's grid. The NERC assessments are done using industry tools and variety of statistical methods (depending on region); some using Monte Carlo methods similar to PRAS. PRAS, however, uses consistent simultaneous assessment for all regions for each hour of the simulation. This helps ensure consistency in treatment of both variable renewable and other resources within and between regions. Though there is no national EUE standard in the United States, for reference, the Australian resource adequacy standard was recently changed from 20 ppm to 6 ppm. $^{25}$

Only 2010 meteorological conditions led to more than one part per million EUE. In particular, an early fall, record-setting heatwave in California in 2010 caused high loads to occur after evening drop-offs in solar output. This led to EUE in the 2050 scenarios for the 2010 meteorological year. The ReEDS model did not see the 2010 meteorological year in its decision-making (only 2012), but PRAS simulates it.

\footnotetext{
25 "Energy Security Board Interim Reliability Measures - RRO Trigger", https://energyministers.gov.au/publications/energy-security-board-rro-trigger-rule-change.
} 
Table 9 shows LOLH statistics in several scenarios, compared to the 2020 NERC LTRA. This method also demonstrates that the NARIS scenarios studied with this model are generally comparable in adequacy to today's grid. Note that for all comparisons with average values in LTRA, the WECC-CAMX region was excluded because it was an extreme outlier (over one TWh of EUE).

Table 9. Loss of Load Hours (LOLH) by Scenario, Compared to NERC LTRA

\begin{tabular}{|c|c|c|c|c|}
\hline Metric & $\begin{array}{l}\text { BAU } \\
2024\end{array}$ & $\begin{array}{l}\text { BAU } \\
2050\end{array}$ & $\begin{array}{l}\text { Low Cost } \\
\text { VG } 2050\end{array}$ & $\begin{array}{l}2020 \text { NERC LTRA } \\
\text { (2022 Assessment Year) }\end{array}$ \\
\hline $\begin{array}{l}\text { Average LOLH of all } \\
\text { assessment areas }\end{array}$ & 0.00 & 0.03 & 0.05 & 0.04 \\
\hline $\begin{array}{l}\text { Median LOLH of all } \\
\text { assessment areas }\end{array}$ & 0.00 & 0.00 & 0.00 & 0.00 \\
\hline $\begin{array}{l}\text { Number of areas in "Green" } \\
\text { category (below } 0.1 \text { LOLH) }\end{array}$ & 13 & 12 & 12 & 10 \\
\hline $\begin{array}{l}\text { Number of areas in "Yellow" } \\
\text { category }(0.1-2.4 \text { LOLH) }\end{array}$ & 0 & 1 & 1 & 2 \\
\hline $\begin{array}{l}\text { Number of areas in "Orange" } \\
\text { category }(>2.4 \text { LOLH }\end{array}$ & 0 & 0 & 0 & 1 \\
\hline
\end{tabular}

This table has variety of metrics of LOLH from the PRAS modeling compared to 2020 NERC LTRA. All numbers are for U.S. regions only. The modeled BAU 2024 outputs are different (less LOLH) from the NERC assets because the ReEDS model builds additional capacity for regions that are short on capacity. WECCCAMX was excluded from the average, but not the median or count statistics (which are not sensitive to outliers).

To analyze how large the adequacy buffer is on average in each scenario, we repeated the analysis and uniformly scaled the time series of loads in each region to see how much additional EUE results. If a load increase yields only a small increase in EUE, we conclude that most hours had a nontrivial adequacy buffer; however, if a load increase yielded a large increase in EUE, we conclude the buffer has been exhausted in some hours. This is not standard adequacy modeling practice, but it does help identify how "overbuilt" the system is. There are trade-offs between cost and reliability for customers today and in the future, and these scenarios attempt to build a system that is generally equivalent to today's grid in adequacy.

For each load multiplier (applied by multiplying a uniform scalar value to every hour, preserving the load shapes), we calculated EUE using 1,000 Monte Carlo samples for each meteorological year (2007-2013) for three scenarios (BAU 2024, BAU 2050, and Low-cost VG 2050). To reduce computational burden and compare all scenarios with four different multipliers, we used fewer Monte Carlo draws than the runs for Table 8 and Table 9. We then averaged the results over the seven meteorological years to trace out the relationship between load multiplier and EUE, particularly looking for the inflection point that identifies the load multiplier for which most hours shift from having a buffer to having no buffer (Figure 19). This analysis showed that all scenarios stayed below 10 ppm EUE with a load multiplier of 1.10 (a 10\% increase in load). 

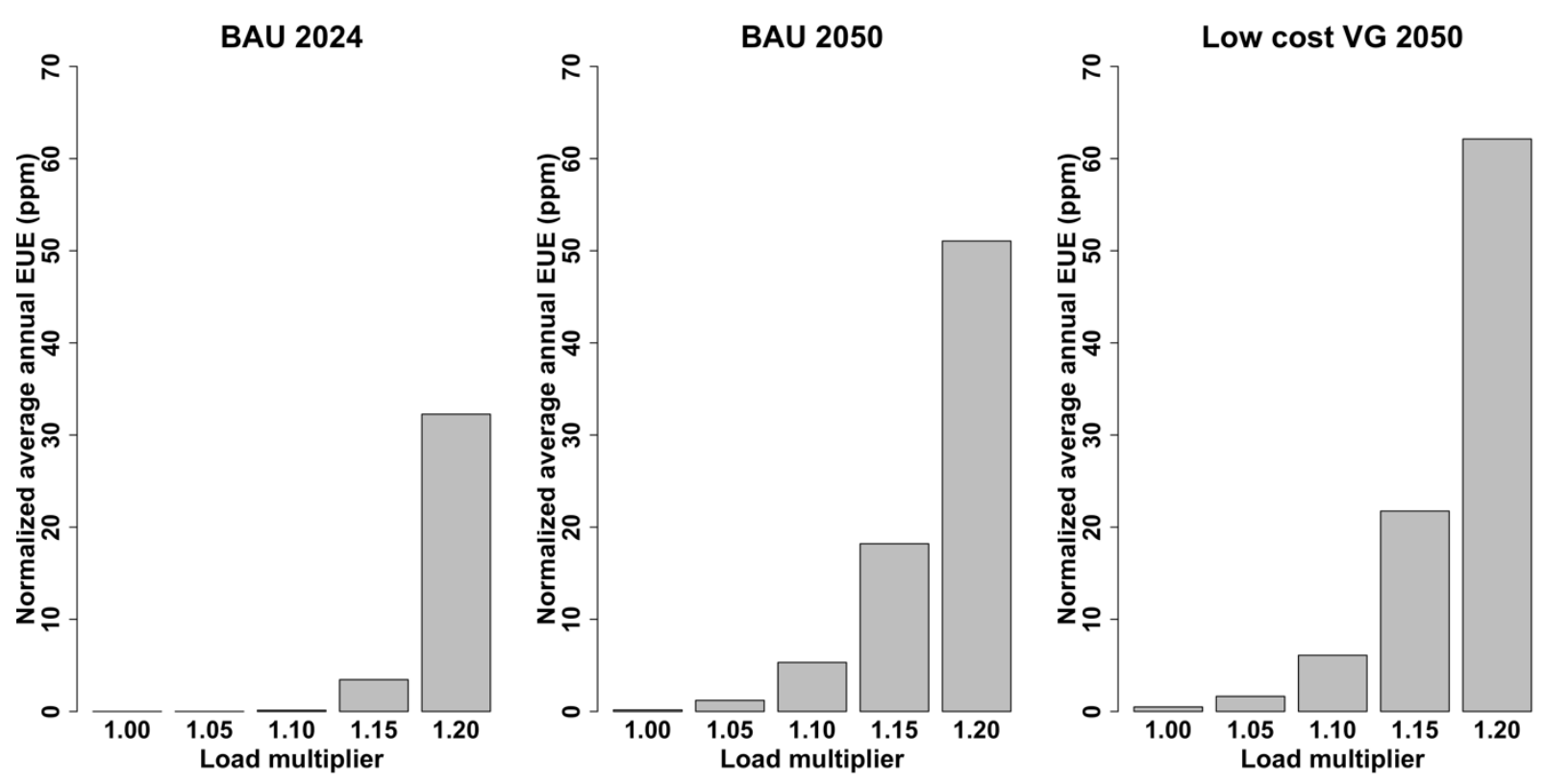

Figure 19. Normalized average aggregate EUE (ppm) by scenario and load multiplier for the United States

Each bar is the average EUE over the 2007-2013 meteorological years. The indicated load multiplier is applied uniformly to each hour of the study year. Note that loads could increase by $10 \%$ in these scenarios and still maintain EUE below 10 ppm.

The key caveats regarding the findings of resource adequacy include:

- PRAS assumes zonal transmission simplifications (in line with industry standard for adequacy models).

- As an adequacy model, PRAS does not consider unit commitment or forecast errorsonly whether capacity is sufficient to serve the load in each region at each simulated hour (which is also in line with industry standard for models like PRAS).

\subsubsection{All generation types can contribute to reliability in future scenarios.}

Figure 20 (page 43) shows the contribution of technologies to energy and capacity adequacy (both summer and winter) based on the ReEDS modeling outcomes. For wind and solar, ReEDS considers the coincidence between hourly generation patterns and load in each region. PRAS provides additional evidence that these results produce an adequate system, subject to the caveats above.

For the United States, hydropower provides a similar contribution to energy and adequacy, and it varies greatly by region. Although hydropower energy limits are lower in late summer (when load is still high), the capacity is still available. Wind provides more energy than adequacy because on average, the wind generates less in peak load hours. Wind generation is more coincident with winter peaks than summer peaks. Solar provides similar contribution to both summer planning reserve and energy. Although solar is very well correlated with summer peak loads, additional contributions from solar eventually shift the net load peak to approximately sunset in many regions. Solar is poorly correlated with winter peak loads, as these often occur in dark hours. Thermal generators provide less energy, but significant adequacy to the grid in both 
seasons (see Section 3.2.3 for a discussion of thermal generator operation). This is because these generators have nonzero marginal cost, and many are primarily providing adequacy and dispatched after the zero-marginal-cost renewable sources. Section 3.2.3 has a discussion of thermal generators operational patterns. The storage category is a combination of pumpedstorage hydropower and batteries with 4-hour duration. Recent work by Frazier et al. (2020) characterized impacts on storage duration on planning reserves for a variety of scenarios and modeled most of the additional storage resources as 2-hour and 4-hour batteries. At higher levels of renewable generation (and storage deployment), longer-duration storage becomes more important.

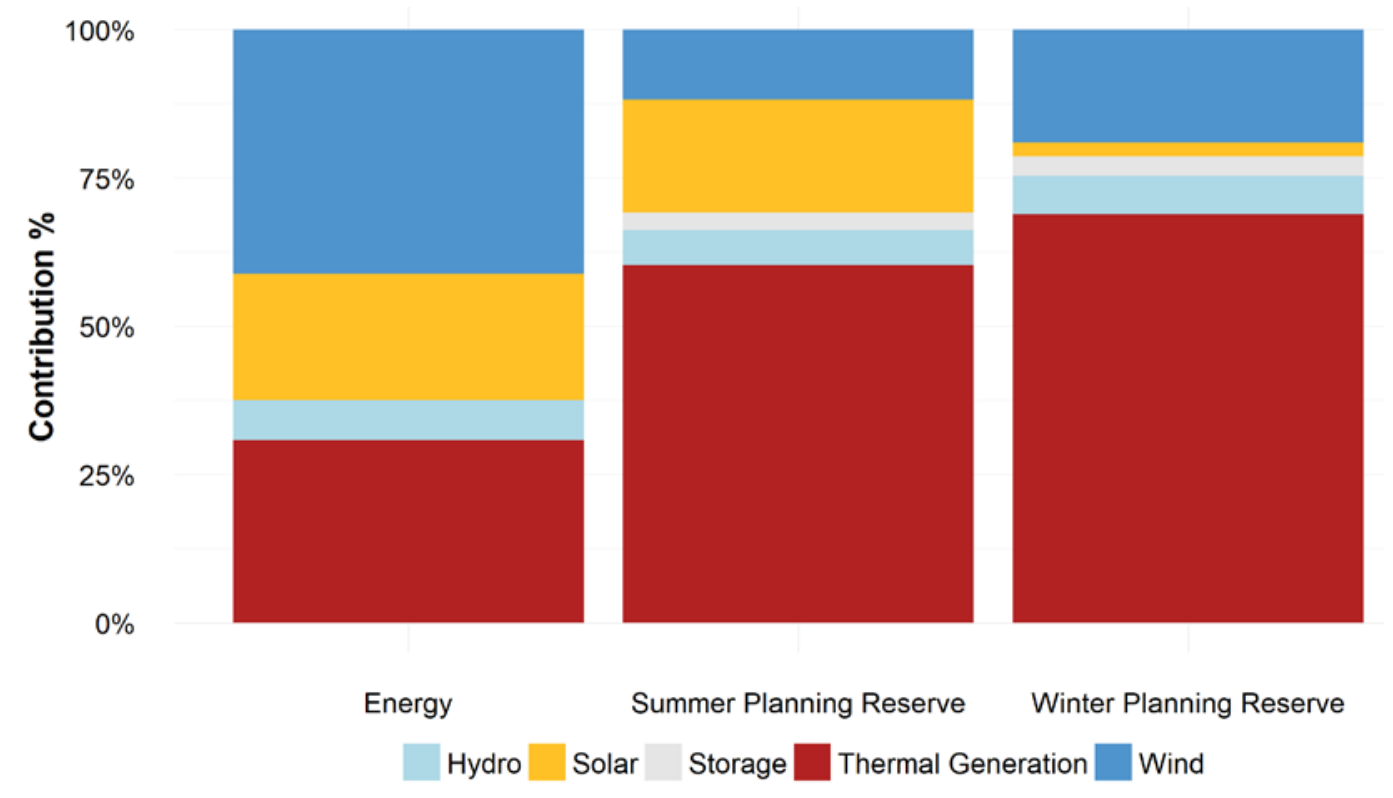

Figure 20. U.S. contribution of different technologies to energy and planning reserve in the Low Cost VG scenario

The energy and planning reserve requirements are all different, so this plot shows the ratio for comparison between technologies. Though hydropower provides similar energy and planning reserves, wind provides more energy than planning reserves, and thermal generation provides more planning reserves than energy.

Figure 21 through Figure 23 show the energy generation and planning reserve procurement (including exchange of energy and capacity) by region. In general, the regions showed similar patterns between energy and planning reserves. Regions where the energy or planning reserves are higher than the dashed line represent regions where power or capacity is being exported, and regions lower than the dashed line are importing. Importing capacity represents transfers similar to those counted by NERC in the LTRA as "net firm capacity transfers" toward resource adequacy. They also represent physical transfers of resources that are owned or operated by a balancing authority in one region but physically exist in another. The ReEDS model does not distinguish between these two categories and does ensure the physical deliverability (with zonal transmission representation) of both energy and capacity. The energy plot in Figure 21 represents the annual total, snapshots in time can look significantly different. See Section 3.3.2 for a discussion of powerflow in the PLEXOS modeling for this scenario. 
The U.S. portions of WECC outside the California Independent System Operator (CAISO) area (abbreviated in the plot below as WECC) on average send both energy and planning reserve into CAISO. CAISO imports energy and capacity in the model in 2050, which is similar to today's conditions. See Section 3.3.2 for a discussion of CAISO energy imports from the PLEXOS model results. Summer peak capacity imports in the ReEDS model in $2050(21 \mathrm{GW})$ are in line with the contribution of imports toward resource adequacy in $2020(16 \mathrm{GW}){ }^{26}$ The summer planning reserve need in the United States (Figure 23) is significantly greater than the winter planning reserve need (Figure 23) for most regions. This allows the United States to send capacity to Canada in the winter and procure capacity from Canada in the summer. On average, Canada also sends energy to the United States in this scenario (70 TWh in the ReEDS model).

Although these plots show the Low Cost VG scenario, the other scenarios (except electrification, which has more wind and solar generation) have generally similar breakdowns by technology (with lower renewable contributions in the BAU).

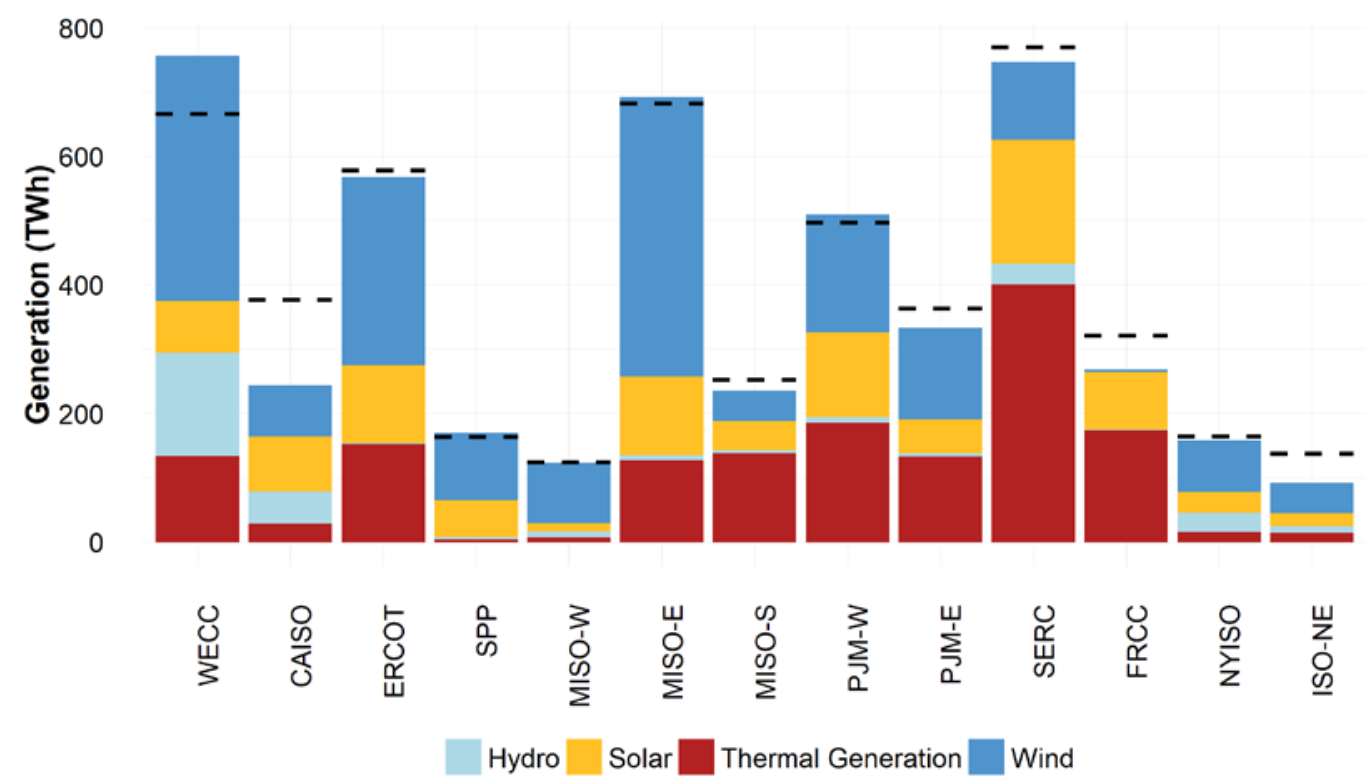

Figure 21. Energy generation in the Low Cost VG scenario in $\mathbf{2 0 5 0}$

The dashed lines represent the electricity demand for each region (including losses). The region labeled WECC includes all U.S. portions of WECC, excluding CAISO. This is a ReEDS model result.

\footnotetext{
${ }^{26}$ The maximum import capability toward resource adequacy in CAISO for 2020 is available at https://www.caiso.com/Documents/ISOMaximumResourceAdequacyImportCapabilityforYear2020.pdf (“California ISO Maximum RA Import Capability for year 2020,” CAISO).
} 


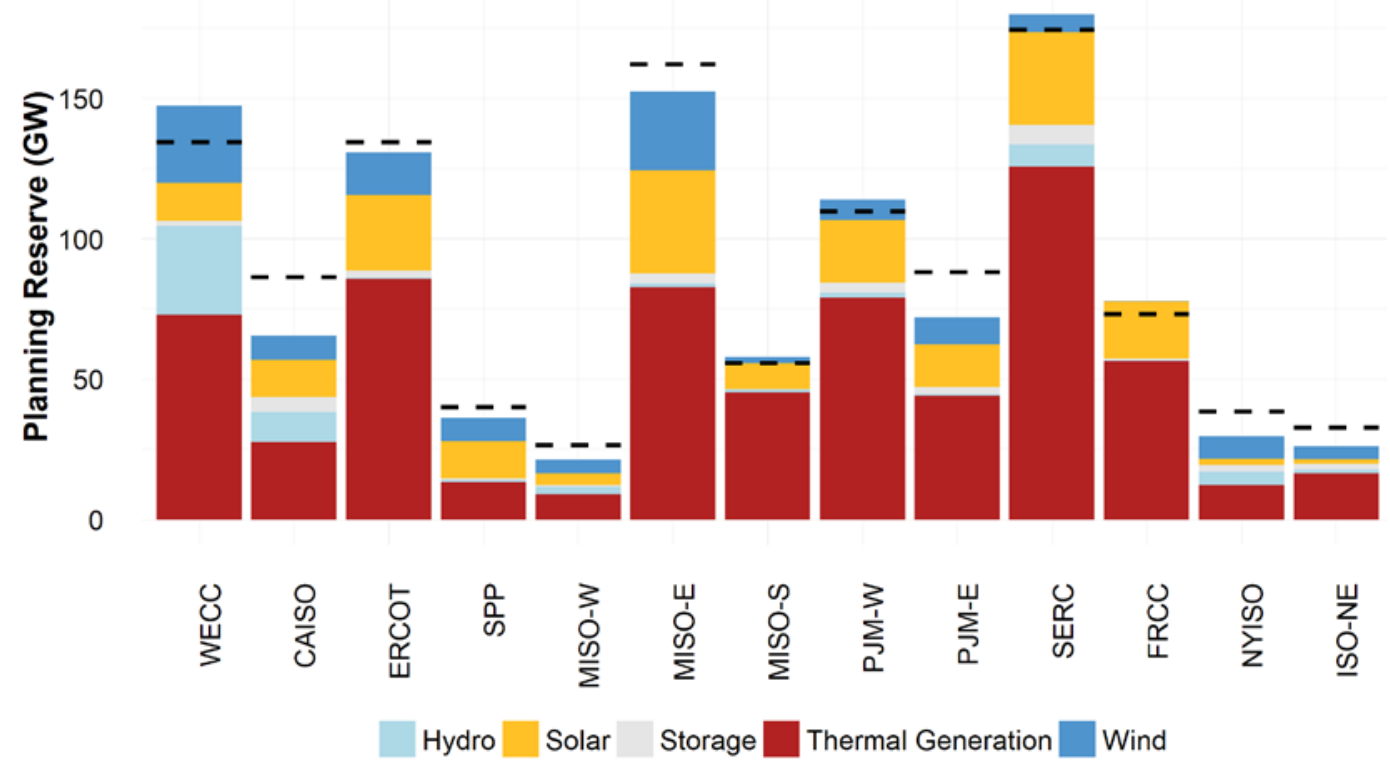

Figure 22. Summer planning reserve in the Low Cost VG scenario

The dashed lines represent the planning reserve requirement for each region. The bars represent the contribution of each resource type to the planning reserve requirement. If the bars are above the dashed line, the excess can be exported to regions that need additional planning reserves. This is comparable to the net firm capacity transfers NERC includes in the LTRA. This is a ReEDS model result.

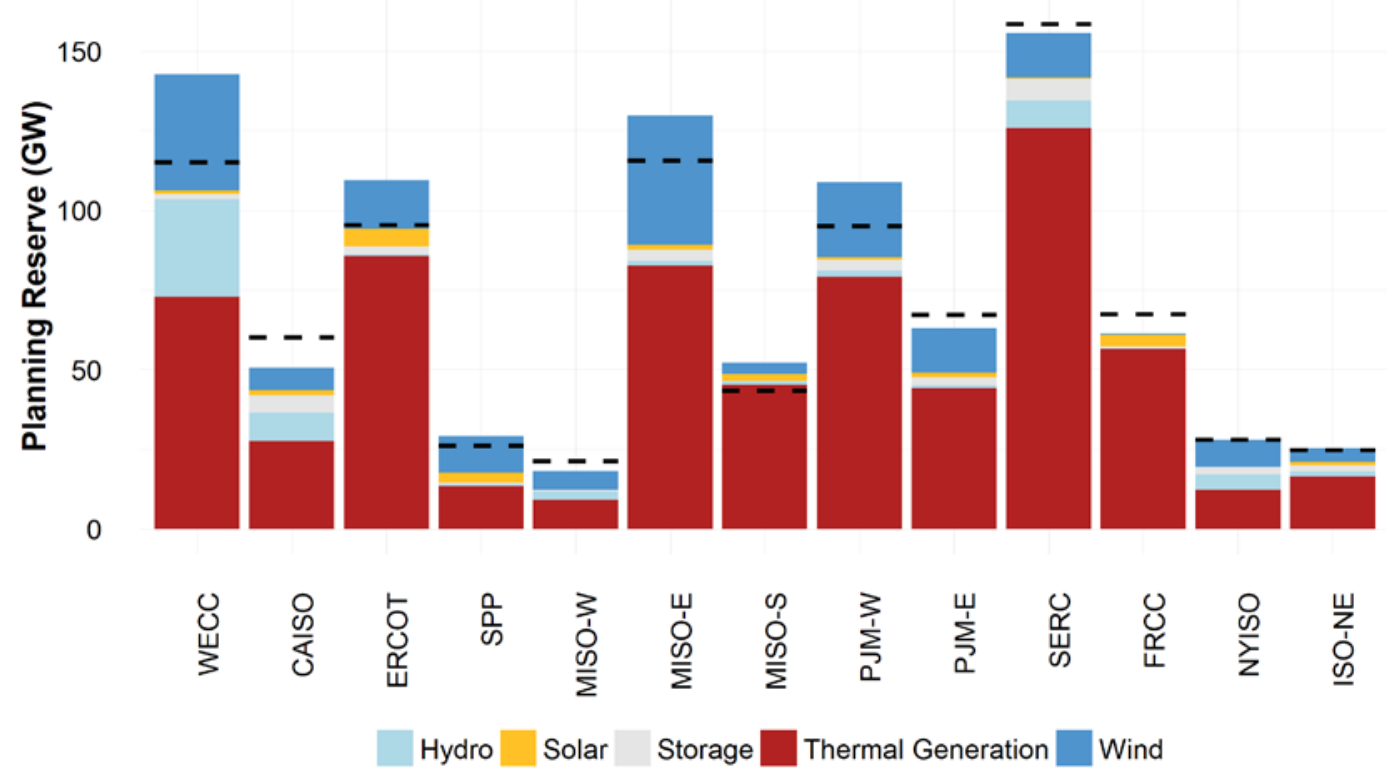

Figure 23. Winter planning reserve in the Low Cost VG scenario

The dashed lines represent the planning reserve requirement for each region. The bars represent the contribution of each resource type to the planning reserve requirement. If the bars are above the dashed line, the excess can be exported to regions that need additional planning reserves. This is comparable to the net firm capacity transfers NERC includes in the LTRA. 
Note that shifting demand patterns that are due to climate change were not in the scope of NARIS; this impact could lead to changing summer and winter peak demand requirements across North America, driven by electric heat and air conditioning.

Figure 24 shows the evolution of summer planning reserve needs in the United States through 2050 (the dashed line), along with the renewable and storage contributions to the planning reserve need (the colored lines). Planning reserve need grows by approximately $22 \%$ relative to 2020 , and the additional planning reserve is met almost entirely by additional renewable generation in all scenarios. The contribution of thermal generation remains similar to 2020 . In the scenario with low-cost storage, storage also plays a significant role (over $200 \mathrm{GW}$ ) and thermal generation plays a smaller role.

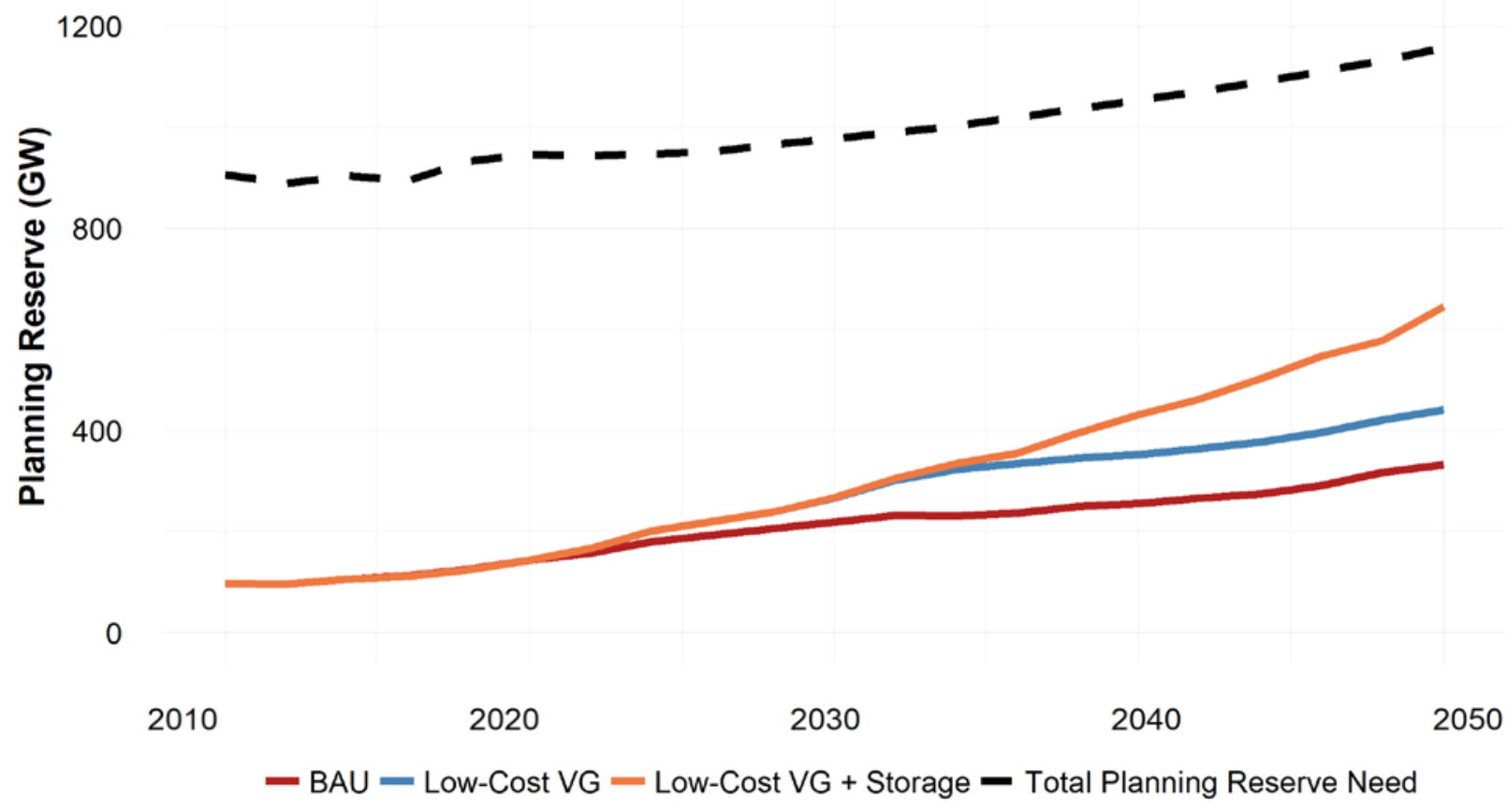

Figure 24. Contribution of renewable generators to summer planning reserve needs in the United States

Capacity contribution to planning reserves from renewables grows in all scenarios in the ReEDS model. Most of the rising peak demand (dashed line) is provided by the capacity credit from new wind and solar. Thermal capacity continues to play a role in resource adequacy to fill the remaining firm capacity needs (the gap between the requirement and the contribution from renewables and storage in each scenario). The Low Cost Storage scenario demonstrates that storage could play a major role in planning reserve contributions in the future.

\subsubsection{Thermal generation operates differently in future scenarios and provides more adequacy than energy.}

Though thermal generation serves a smaller portion of energy needs, it is important in the NARIS scenarios for both energy and adequacy. If other scenarios or sets of assumptions were considered (e.g., technology costs or lower carbon limits), storage or hydropower could potentially fill more of that role. During a small number of hours of the year, thermal generators are producing most of the power to the grid because load is high and/or wind and solar 
generation are low. The thermal generators are helping provide adequacy during those key hours. For many of the rest of the hours of the year, the low-marginal-cost resources (wind, solar, hydropower) are providing most of the energy.

Figure 25 shows the duration curve of gas $\mathrm{CC}$ and gas $\mathrm{CT}$ generation in the three interconnections resulting from the PLEXOS Low Cost VG 2050 scenario. Gas CTs are used primarily for adequacy in all three interconnections, seen by the high utilization exclusively in a few hours of the year at the left edge of the plot. Average capacity factors range from $2 \%$ (Eastern Interconnection) to $10 \%$ (Western Interconnection), comparable to a U.S. average of $11 \%$ in $2019 .{ }^{27}$ Gas CCs have significant utilization in more hours of the year but still see capacity factors of $18 \%-31 \%$, which is substantially lower than the 2019 average of $57 \%$ in the United States. Most coal capacity has retired by 2050 in this scenario, but without any carbon constraints (in the United States), the existing coal does have significant capacity factors (48\% in the Eastern Interconnection and $62 \%$ in the Western Interconnection, with Texas having negligible coal capacity). This is comparable to the 2019 average of $48 \%$. Nuclear generation patterns are not presented here because nuclear is assumed to be online and generating at maximum capacity whenever they are not on outage in the model. The modeling respects minimum generation levels for each generator at each 5-min operating interval. At times, little or no fossil-fueled generators are online. It is assumed for NARIS that frequency support can be provided by nuclear, hydropower, synchronous condensers, and/or advanced inverters; if additional thermal generation is required for frequency support, this would increase curtailment.

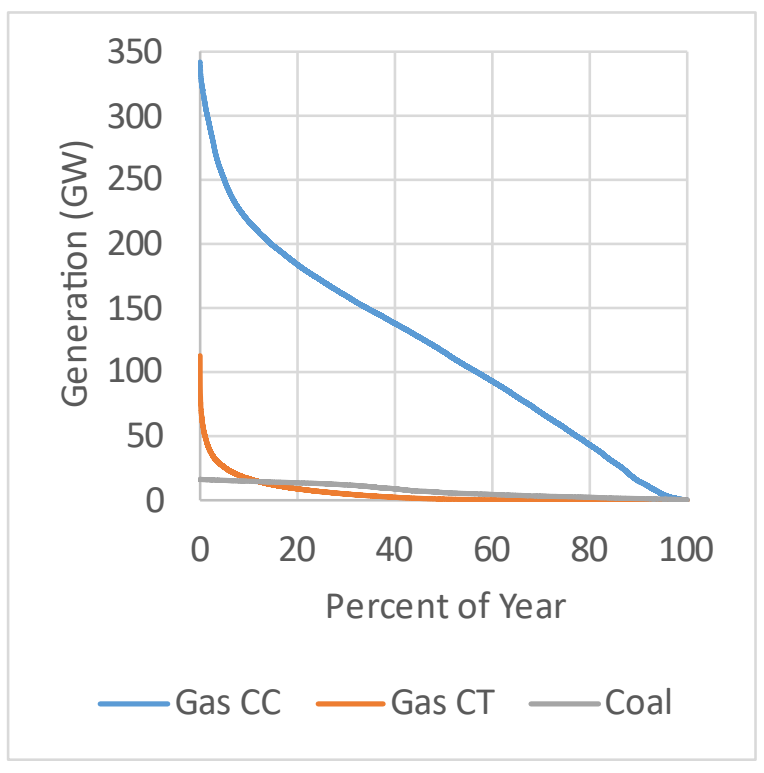

(a) Eastern Interconnection

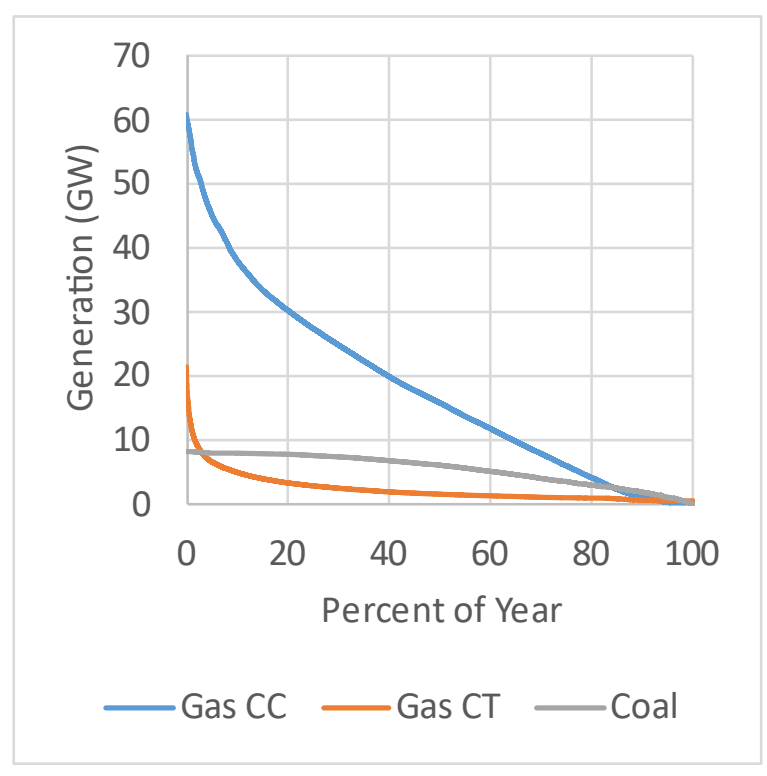

(b) Western Interconnection

\footnotetext{
${ }^{27}$ Capacity factors reported for 2019 are from "Electric Power Monthly," EIA, November 2020, https://www.eia.gov/electricity/monthly/.
} 


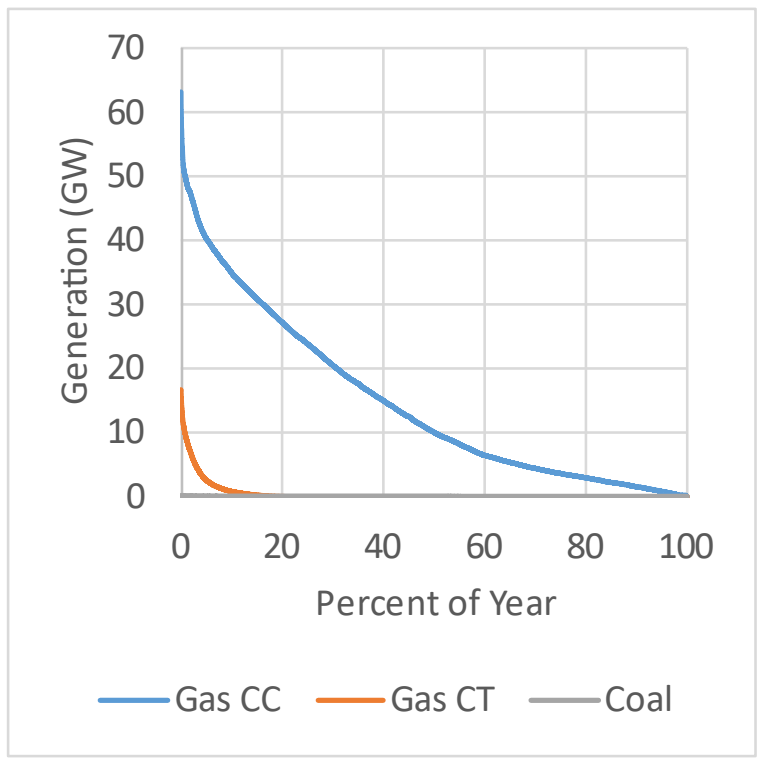

(c) Texas Interconnection

Figure 25. Thermal generation utilization in Low Cost VG scenario in 2050 by interconnection

Figure 26 through Figure 28 summarize the capacity factor of all the plants in the United States in the Low-Cost VG scenario. Most gas CTs have a capacity factor between $0 \%$ and 5\%. Also, a significant number of gas $\mathrm{CC}$ generators with have capacity factors near zero, especially in the Eastern Interconnection and the Texas Interconnection.
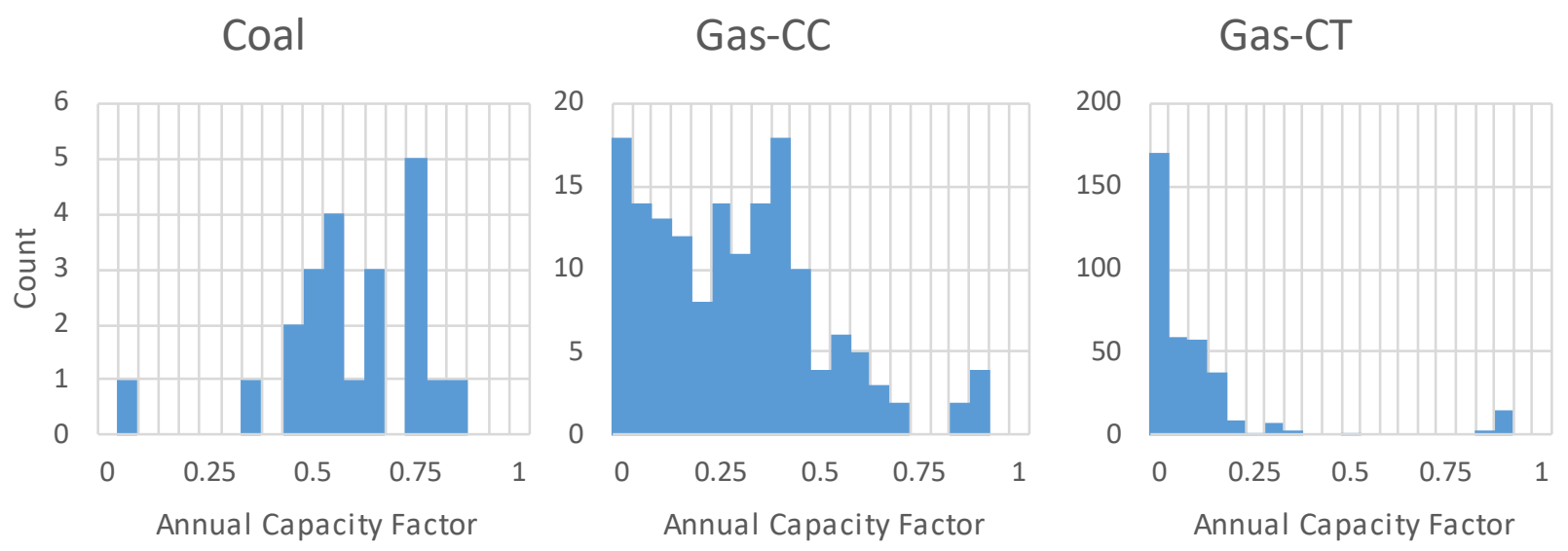

Figure 26. Thermal generation utilization in the U.S. Western Interconnection (Low Cost VG 2050) 

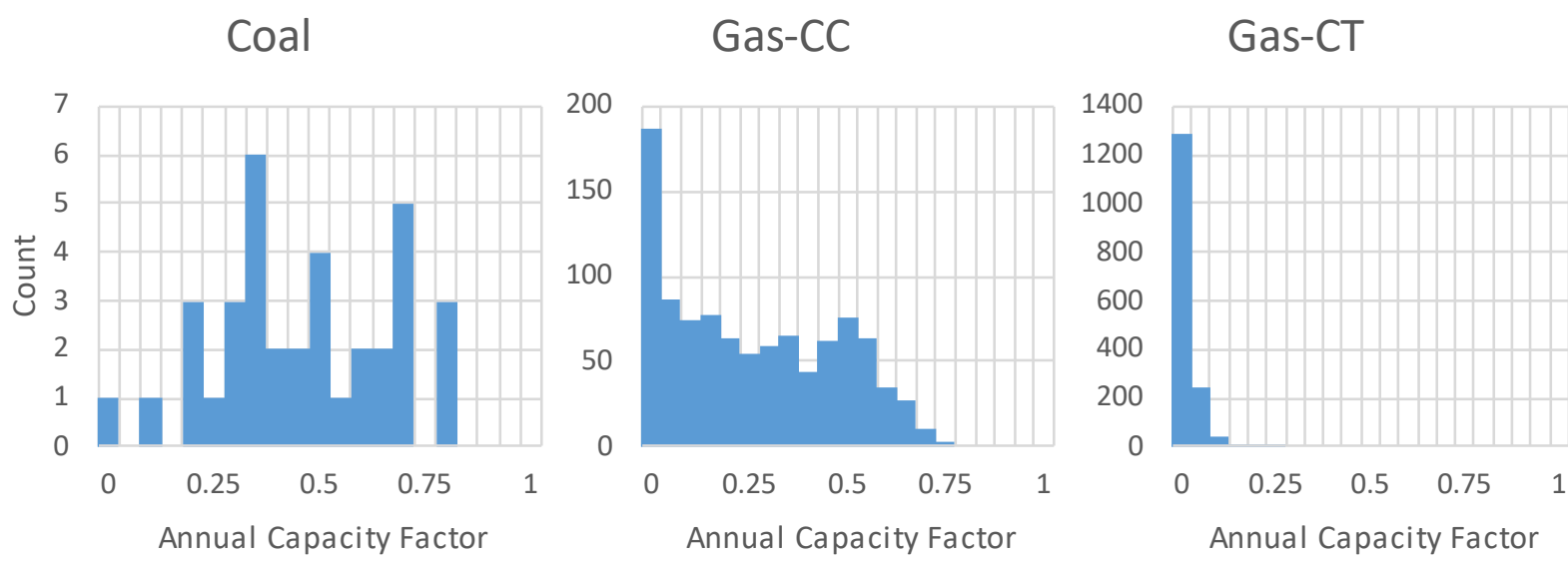

Figure 27. Thermal generation utilization in the U.S. Eastern Interconnection (Low Cost VG 2050)
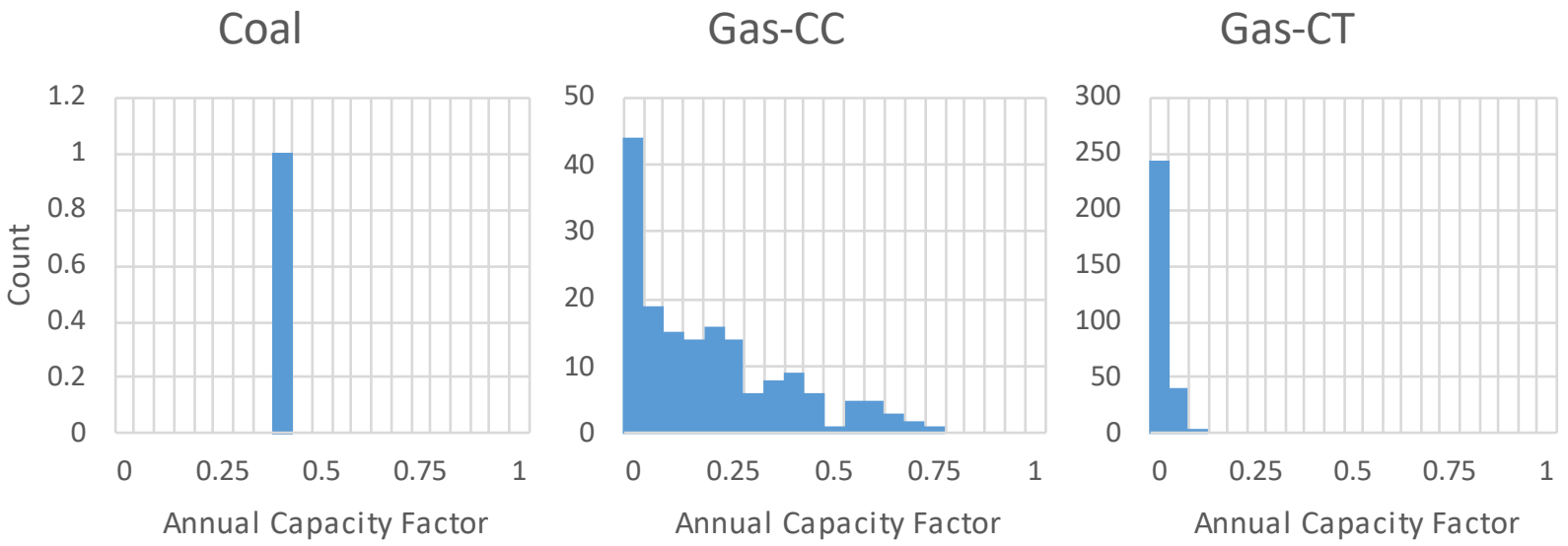

Figure 28. Thermal generation utilization in the Texas Interconnection (Low Cost VG 2050)

Although thermal generators produced less energy in these scenarios than they currently produce, they still have a major role to play in adequacy for the future system studied in these scenarios. Scenarios with higher contributions of wind, solar, and other zero-carbon resources might rely more on storage and demand response and less on coal and gas generation for adequacy. In NARIS, we did not attempt to analyze whether there would be sufficient revenues for these generators to continue operations. Some compensation method (whether based in energy markets, capacity markets, or regulations) would have to exist for these generators to be available. The cost of building these units, however, was considered in the capacity expansion modeling as part of the overall cost optimization.

\subsection{Transmission}

In this section, we discuss some of the transmission-related outcomes of the modeling. In Section 3.3.1, we discuss the value of transmission and results from ReEDS and PRAS, and in Section 3.3.2 we discuss utilization and the results from the PLEXOS modeling. 


\subsubsection{Cooperation and transmission between regions and countries leads to economic and adequacy benefits.}

Figure 29 shows transmission investments by scenario, broken out by whether the additional capacity crosses the Canada-U.S. and Mexico-U.S. borders. From this result, we see that transmission capacity increases with wind and solar contribution. The $\mathrm{CO}^{2}$ Constrained scenario leads to higher transmission investment than the Low Cost VG scenario (despite similar VG contributions) because VG technologies have higher costs in the $\mathrm{CO}_{2}$ Constrained scenario, thus shifting the optimal balance between transmission and VG investment. As a result, VG sited at more-optimal locations in the $\mathrm{CO}_{2}$ Constrained scenario (possibly requiring more transmission), whereas VG can be sited at less-optimal locations closer to load centers in the Low Cost VG scenario. Although the international transmission connections look small in comparison to the increased capacity within the United States, the international expansion is also significant (3-8 GW expansion U.S.-Mexico, 10-20 GW U.S.-Canada). ${ }^{28}$

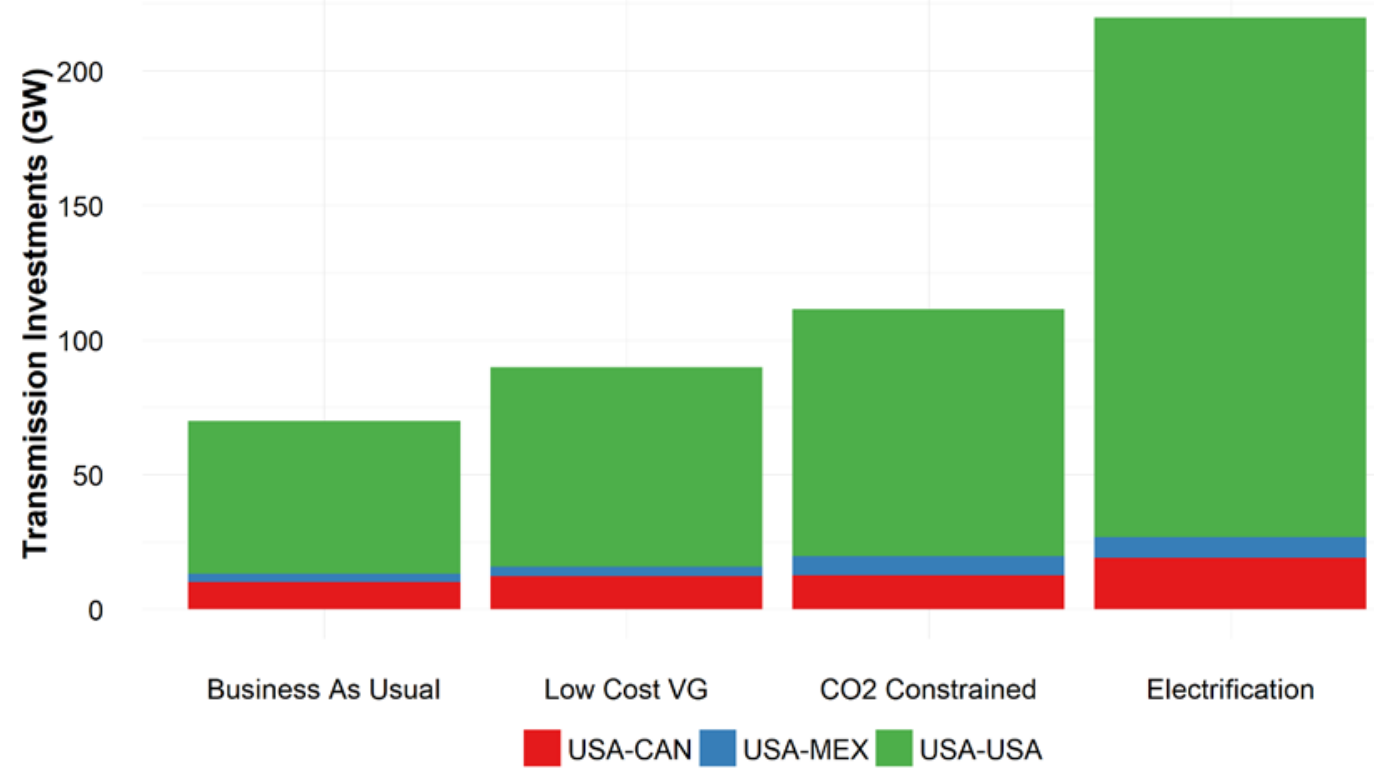

Figure 29 Added transmission capacity in the core scenarios (measured in GW of interface expansion)

Figure 30 shows a map of the transmission expansion in the core scenarios based on the ReEDS generation and transmission co-optimization. In all four cases, the model deploys new transmission infrastructure in regions throughout the United States and North America. Although many of the interfaces are developed in all scenarios, some are developed only in the Electrification scenario, where almost double the new wind capacity is built than in the other scenarios.

\footnotetext{
${ }^{28}$ The expansion values compare to approximately $18 \mathrm{GW}$ of capacity between the United States and Canada in 2020 and 2 GW between the United States and Mexico in 2020, although most of the connection with Mexico does not connect to the interconnection in Mexico (Sistema Eléctrico Nacional).
} 
The transmission expansion in the model is part of a co-optimization of generation and transmission resources. Differences in resource quality or cost assumptions could lead to differences in the optimal build-out of renewable generators and transmission infrastructure both. As seen in Figure 30, however, much of the transmission that is built in the model is robust to a variety of scenarios and the assumptions we varied.
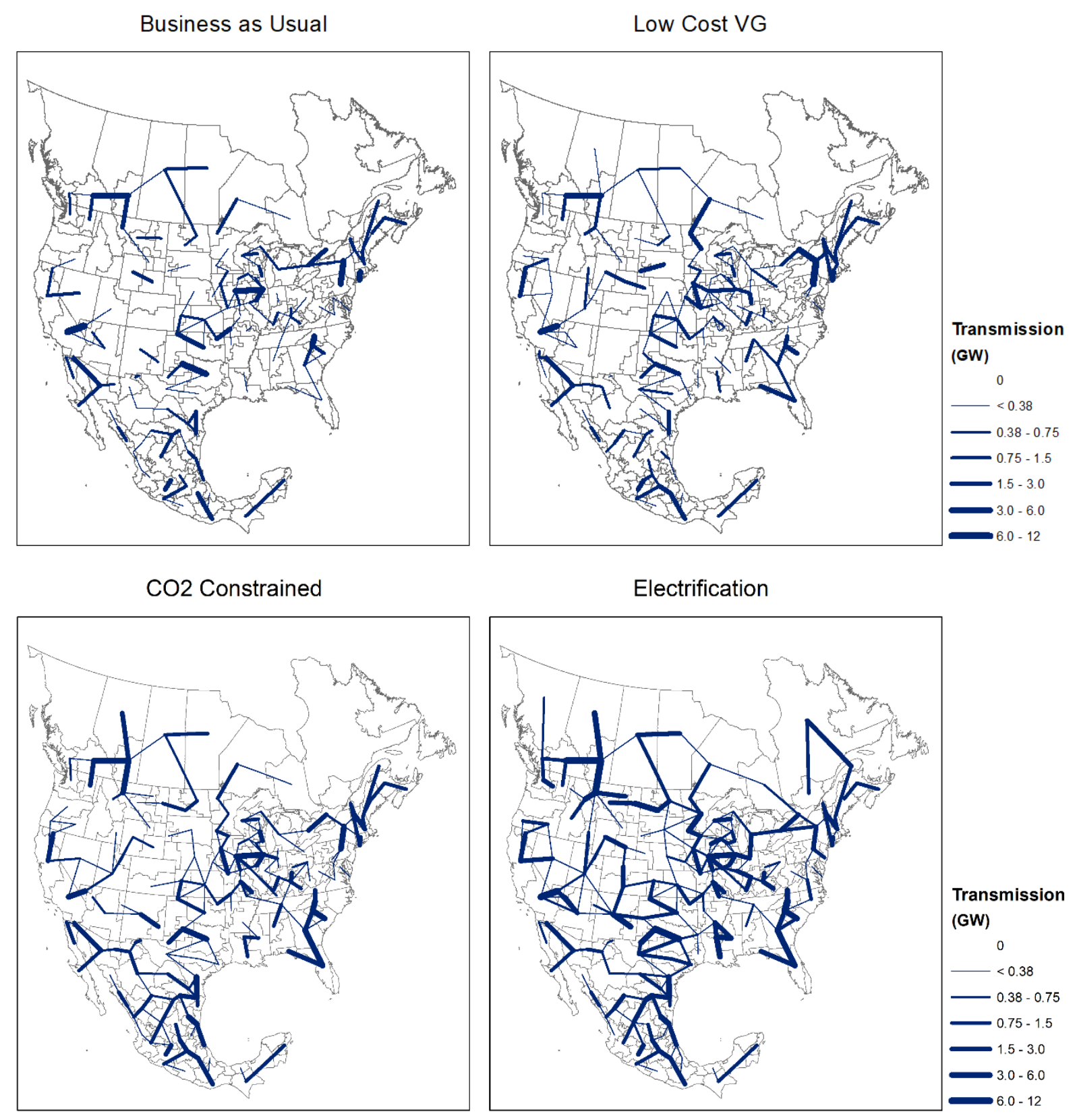

Figure 30. New transmission capacity in the core scenarios

The lines on this map represent transmission interfaces between the zones in the model, and they typically represent aggregated transmission lines. 
To understand the importance of this transmission to costs and other outcomes, we ran the ReEDS model with a variety of limitations on transmission expansion. The difference in total system costs between the constrained and unconstrained scenarios demonstrates the value to the system of the changes. We explored the following changes with scenarios (as identified in Section 1.2):

- International Transmission Expansion: This comparison estimated the value of allowing new international transmission capacity. It did this by comparing each core scenarios with a corresponding scenario that disallows transmission expansion across national boundaries (core scenario versus No Cross-Border Expansion scenarios in Table 2).

- Interregional Transmission Expansion and Coordination: This comparison estimated the value of interregional transmission capacity by comparing a scenario with limited transmission growth and its corresponding core scenario (core scenario versus No CrossBorder Expansion Uncoordinated scenarios in Table 2). The transmission cost increase was included in the optimization but in costs reported here (so that the system costs are directly comparable to the core scenarios) and the scenario represents a very low transmission build-out.

- Interregional Transmission Expansion and Coordination with Macrogrid: This compares the core scenarios with a predesigned macrogrid shown in Figure 32 and described later in this section (Macro Grid versus No Cross-Border Expansion Uncoordinated scenarios in Table 2).

Figure 31 shows the value of enabling each of these transmission assumptions in the model (measured as the reduction in overall system costs in ReEDS). The pattern between scenarios is similar to the overall transmission infrastructure build (Figure 29). The net value of international transmission expansion (mostly between Canada and the United States) is $\$ 10$ billion- $\$ 30$ billion in all the core scenarios except the BAU. ${ }^{29}$ Benefits of increased transmission infrastructure would also occur after 2050 and those are not captured here; this represents the sum of all benefits from 2020 to 2050 in 2018 USD values. The net value of interregional transmission ranges from $\$ 70$ billion to $\$ 180$ billion in the core scenarios, with the higher values corresponding with scenarios with more transmission build and higher wind and solar generation levels. The macrogrid scenarios show that requiring the model to build a macrogrid with 2,700MW HVDC (high-voltage direct current) lines (and allowing additional AC builds) would have overall net value similar to the interregional value when the model optimizes the build (\$60 billon- $\$ 170$ billion versus $\$ 70$ billion- $\$ 180$ billion). Although the net value of the macrogrid is lower than the net value of the optimal interregional expansion in the model in each scenario, benefits from the macrogrid are not well captured in the modeling. The macrogrid benefits that are not fully considered in this modeling include self-contingency, controllability, and dynamic performance benefits.

\footnotetext{
${ }^{29}$ The BAU has nationwide carbon limitations in Canada but only state limitations on carbon in the United States. This could possibly undercut some of the value of transmission expansion, as Canada has limited ability to import anything from the United States in this scenario.
} 


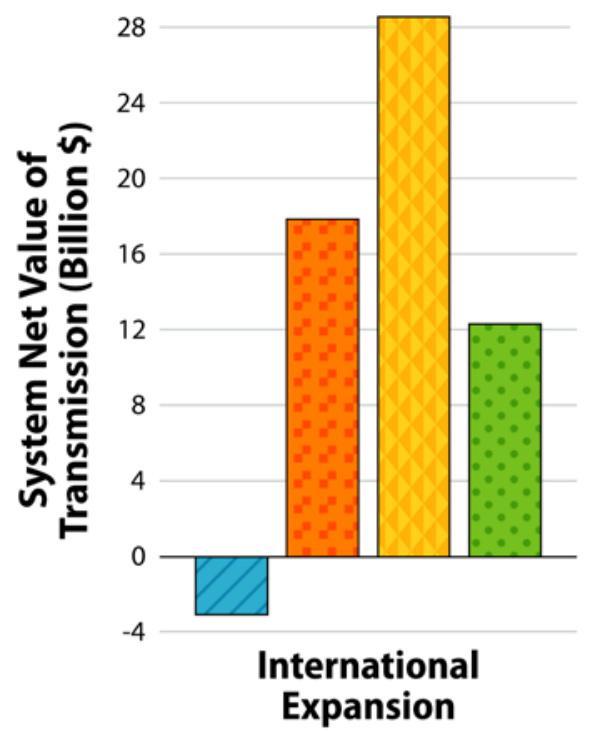

Business As Usual
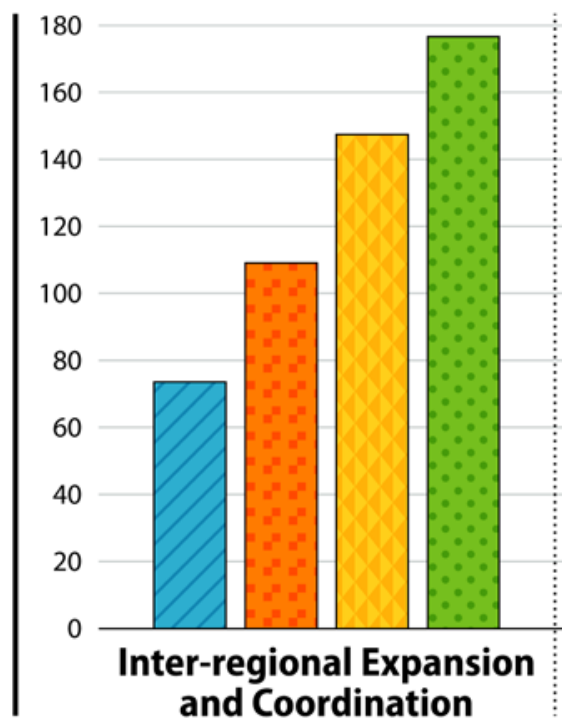

and Coordination

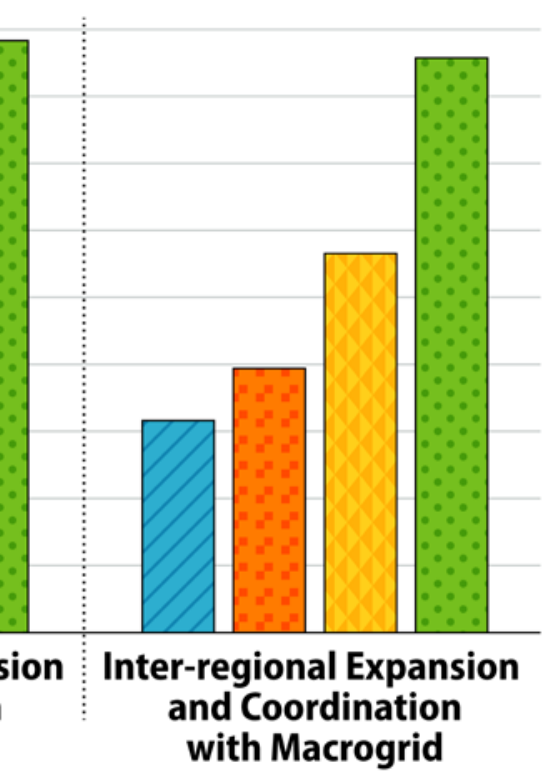

$\mathrm{CO}_{2}$ Constrained

Electrification

Figure 31. Continent-wide net value of transmission expansion

This plot shows the net value of allowing different transmission build assumptions in the model. It shows international transmission expansion worth $\$ 10$ billion- $\$ 30$ billion, interregional expansion (with or without a macrogrid) worth $\$ 60$ billion- $\$ 180$ billion. Note that the macrogrid has additional benefits (e.g., selfcontingency and controllability) not fully captured in this modeling.

Figure 32 shows the macrogrid studied in NARIS, which is a predesigned, HVDC network that spans most of the United States and some of Canada. It expands on the work done in the Interconnections Seam Study ${ }^{30}$ to include a likely high-value branch into Canada, as designed with help from the Technical Review Committee. These model runs might not provide sufficient evidence to conclude that the optimal AC build is better than the HVDC macrogrid (or vice versa), but both scenarios offer more than $\$ 100$ billion in savings than an uncoordinated build (with less transmission expansion).

30 “Interconnections Seam Study,” NREL, https://www.nrel.gov/analysis/seams.html. 


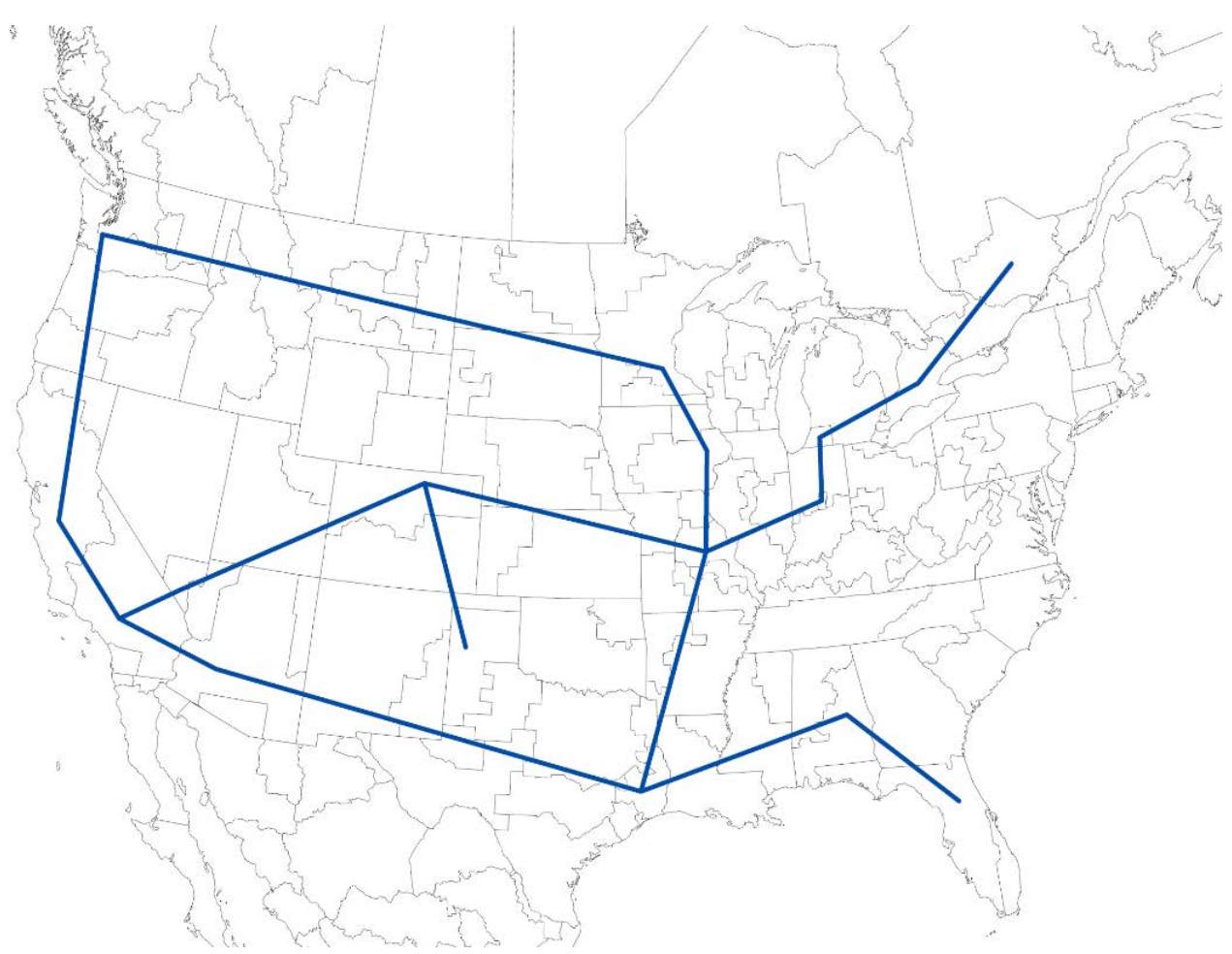

Figure 32. Macrogrid design

Additional macrogrid layouts could be more optimal than this design. Further work could help determine optimal macrogrid layouts for different scenarios, or robust macrogrid layouts.

Figure 33 and Figure 34 show the net and gross trade between the United States and Canada, respectively, through 2050. Net trade between the United States and Canada is highly sensitive to model assumptions, as can be seen from the significant spread. Some scenarios even represent net Canadian imports from the United States. However, the model results are not consistent in suggesting what net Canada exports might look like in 2050. In the NARIS companion report for Canada, ${ }^{31}$ we discuss scenarios we ran that included a significant Canadian net export requirement (100 TWh/year by 2050), and these scenarios were similar in costs to the core scenarios. These specific scenarios are not reflected in the uncertainty bounds of Figure 33.

Gross trade between Canada and the United States (Figure 34) has a more consistent story. Although there is significant spread between the scenarios, it generally increases with continental wind and solar generation levels (which also increase with time). This demonstrates that the importance of energy exchange between the United States and Canada increases in scenarios with higher renewable deployment. In the Low Cost VG scenario, the PLEXOS model showed that despite an average flow between Canada and the United States of 4,700 MW, power flows from the United States to Canada $32 \%$ of the time. Assigning the systemwide benefits to a specific region or country is not possible without knowledge of the contracted and/or market prices.

${ }^{31}$ The North American Renewable Integration Study: A Canadian Perspective. See "North American Renewable Integration Study," NREL, https://www.nrel.gov/analysis/naris.html. 


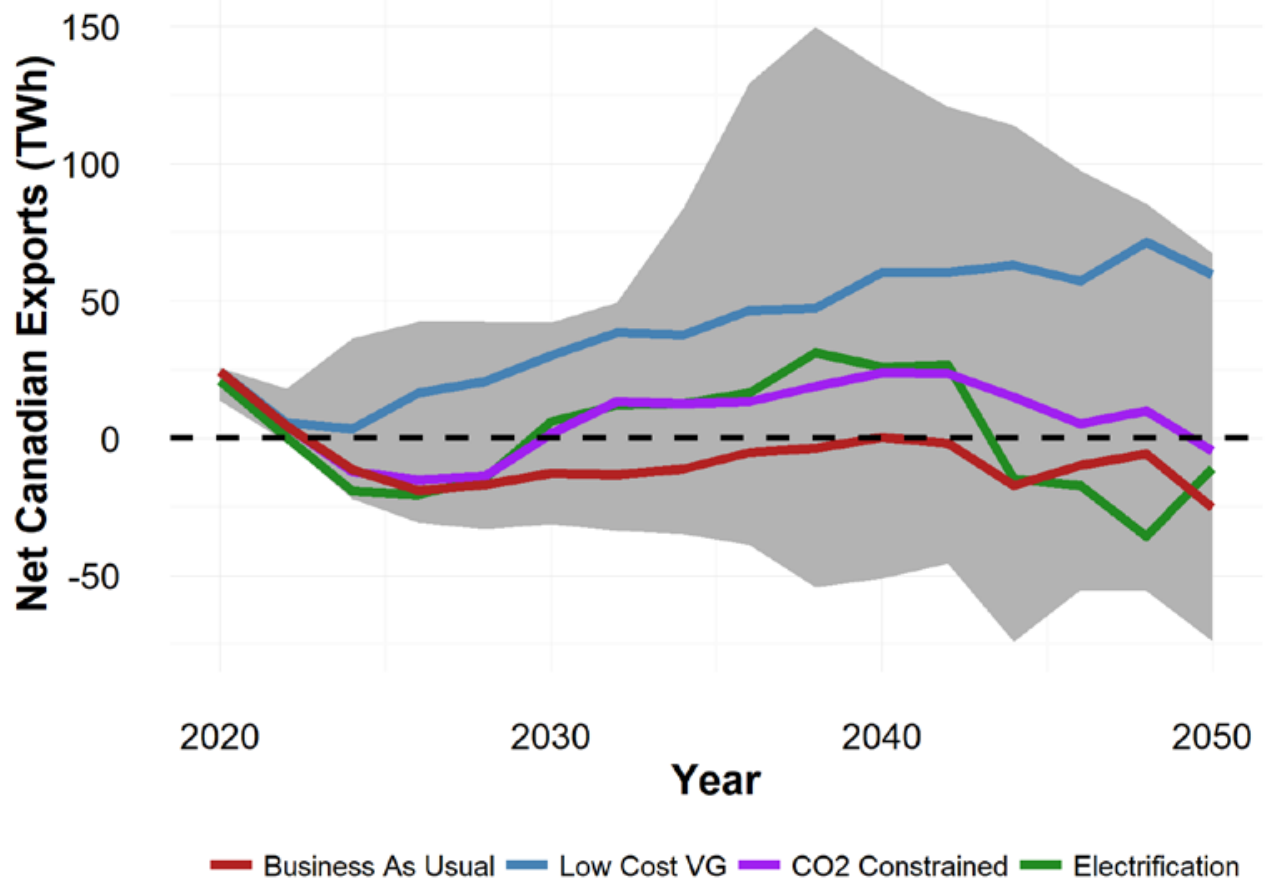

Figure 33. Net United States/Canada trade in all scenarios (core scenarios colored)

The shaded region represents the envelope of all the scenarios that are mentioned in Section 1.2. There is wide variability between the scenarios, and there is no robust conclusion regarding net exports from Canada. In the NARIS

Canadian report, we discuss additional scenarios where Canadian exports were required in the model, and these scenarios showed no significant cost increases.

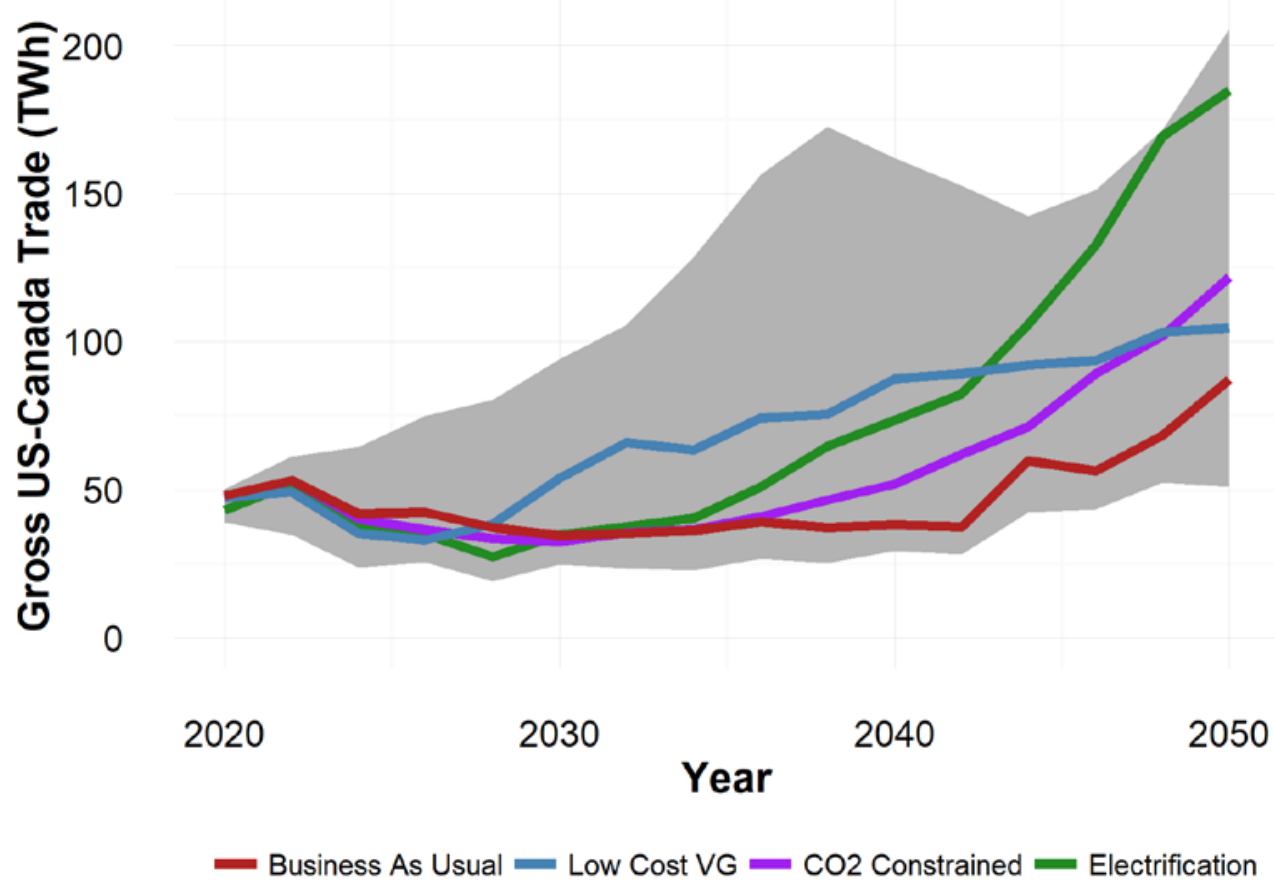

Figure 34. Gross United States/Canada trade in all scenarios (with core scenarios colored)

The shaded region represents all the scenarios that were run for the study, including variations mentioned throughout this report. 
Figure 35 and Figure 36 (page 57) show the net and gross trade between the United States and Mexico, respectively, through 2050. Net trade between the United States and Mexico is highly sensitive to model assumptions, as can be seen from the significant spread. However, gross trade between Mexico and the United States (Figure 36, page 57) has a more consistent story. Although there is significant spread between the scenarios, it generally increases in scenarios with carbon constraints in both countries. This demonstrates that the importance of energy exchange between the United States and Mexico increases in scenarios with higher renewable generation levels.

Transmission is needed for adequacy in the near-term grid, and it is even more important with higher loads and higher renewable deployment in 2050. Using the same random Monte Carlo samples that generated the EUE results discussed in Section 3.1, we computed the maximum utilization of each modeled transmission interface for each scenario in each meteorological year. Maps of these results are presented for selected scenarios in Figure 37 (BAU 2024 with 2010 meteorology) and Figure 38 (Low Cost VG 2050 with 2010 meteorology). The results are highly consistent across meteorological years (not shown here). Maximum utilization increases in the 2050 scenarios from the 2024 scenario, particularly in the Low Cost VG case. Note that as a resource adequacy model, PRAS only utilizes transmission when it is required to avoid unserved load, so the utilization maps indicate transmission requirements for adequacy rather than realistic powerflow. For the rest of the analysis in this section, economic exchanges were considered at every time-step in the modeling.

Though NARIS does demonstrate the value of cooperation and transmission, it does not demonstrate that it is impossible to achieve renewable contribution levels or reliable future grids without extensive new transmission builds. Those scenarios, if feasible, would come at a higher cost. 


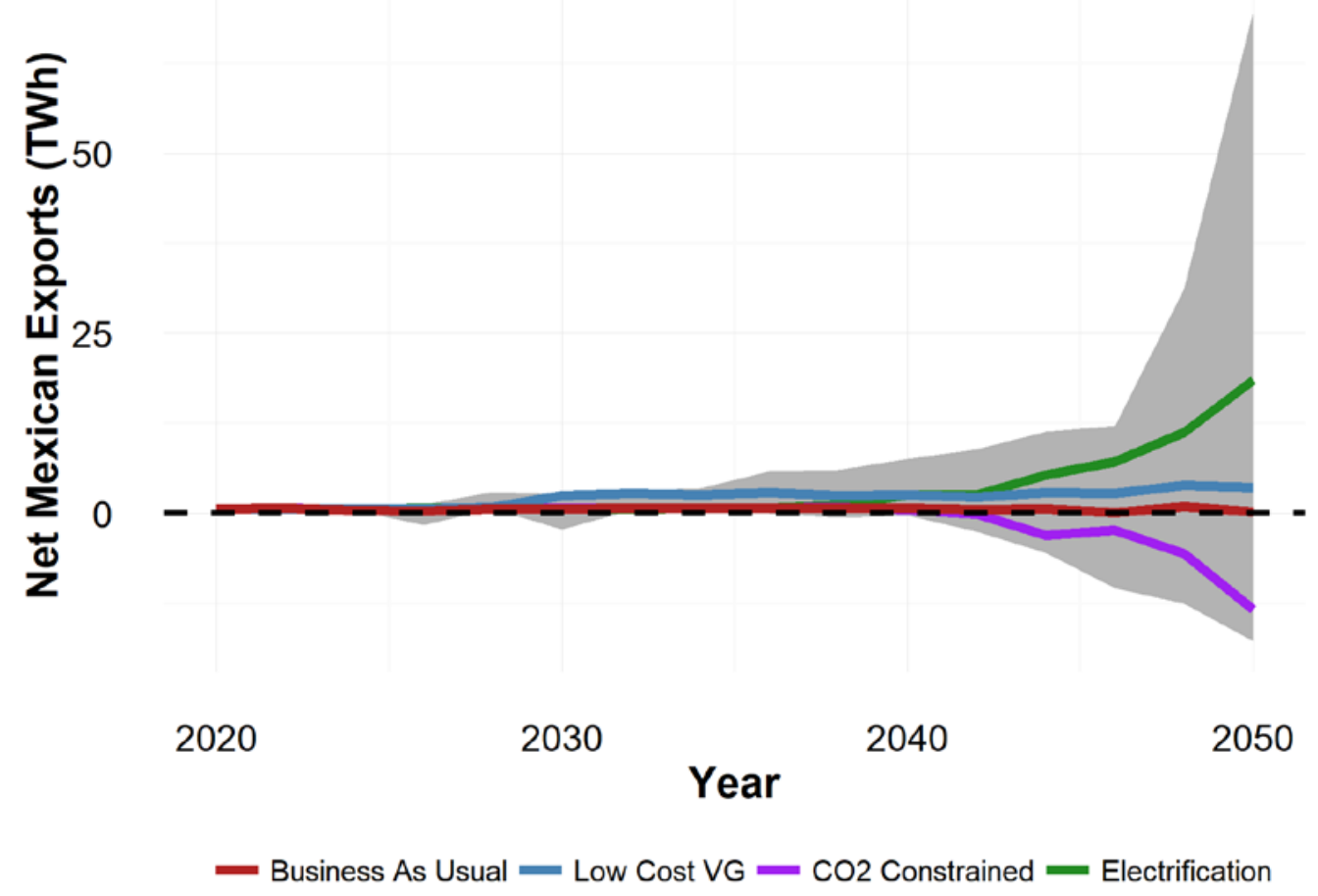

Figure 35 Net U.S./Mexico trade in all scenarios (with core scenarios colored)

The shaded region represents all the scenarios that were run for the study, including variations mentioned throughout this report.
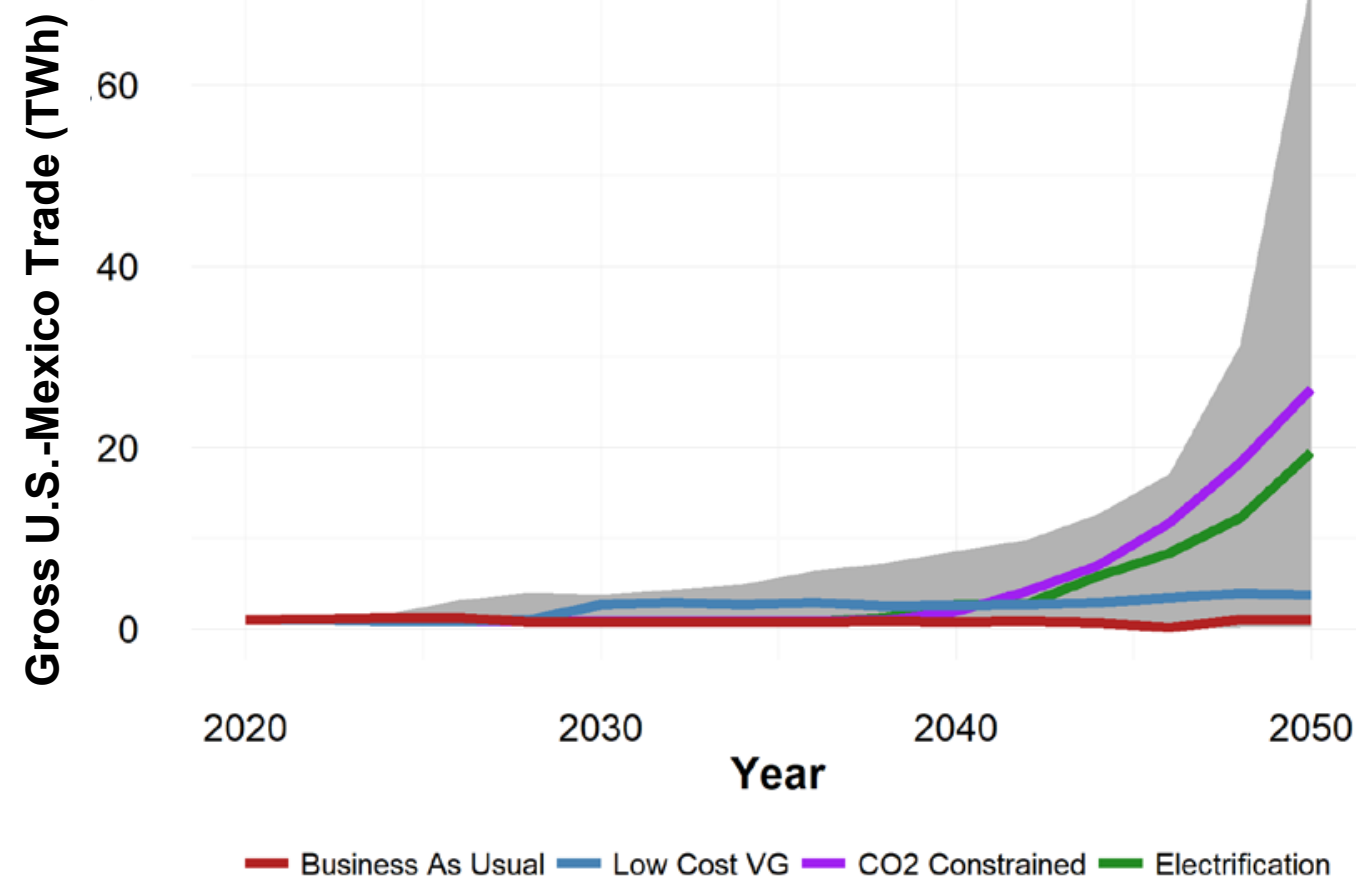

Figure 36 Gross U.S./Mexico trade in all scenarios (with core scenarios colored)

The shaded region represents all the scenarios that were run for the study, including variations mentioned throughout this report. 

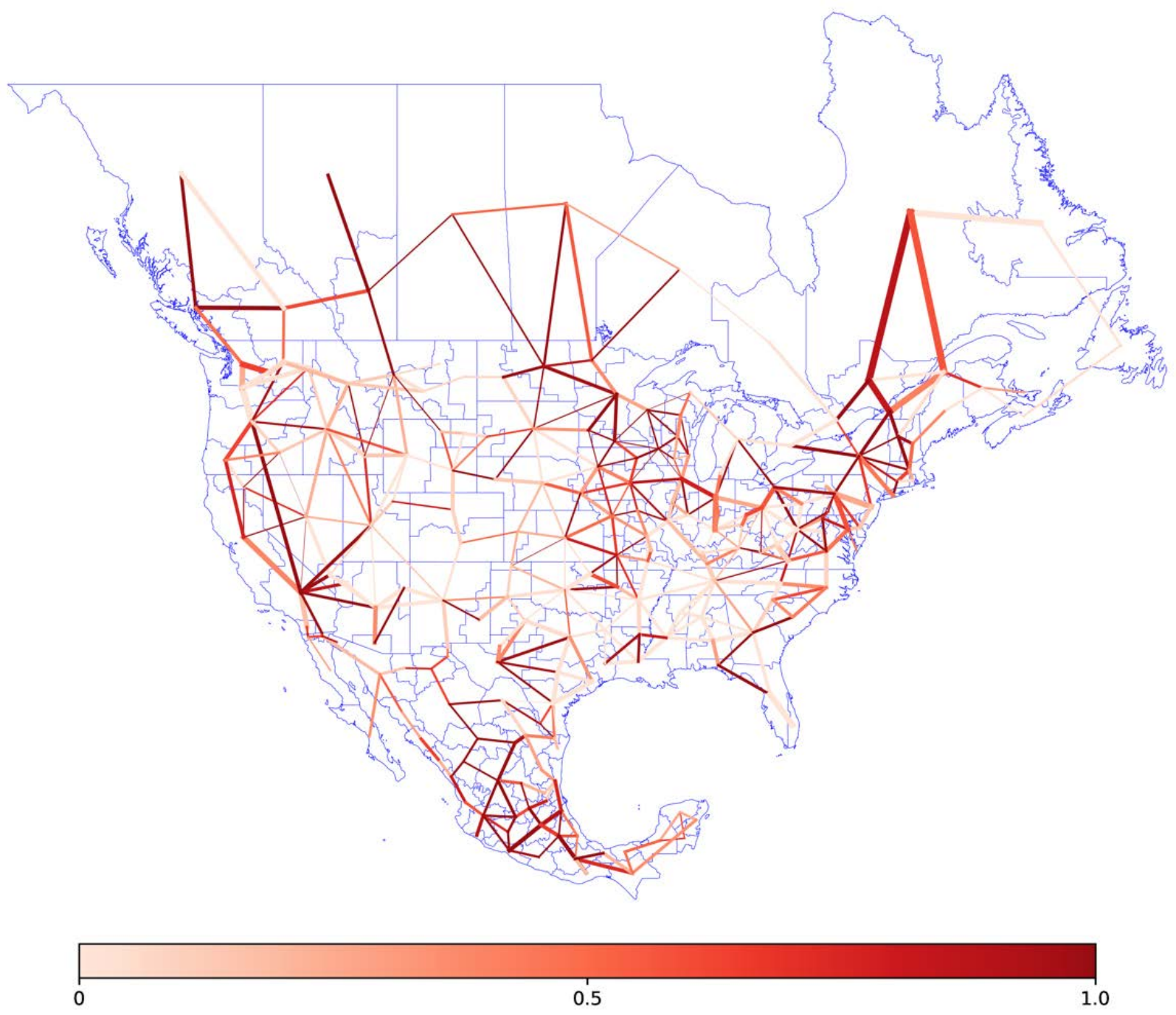

Figure 37. Maximum utilization of paths in the near-term (2024) PRAS adequacy model

The width of the lines represents the capacity of the interface between zones. The color represents the maximum hourly utilization (flow divided by capacity) during the PRAS adequacy analysis for 2010 meteorology; the plot looks similar for other years. This is not an economic dispatch; interfaces are utilized only when it is absolutely needed to serve load. 


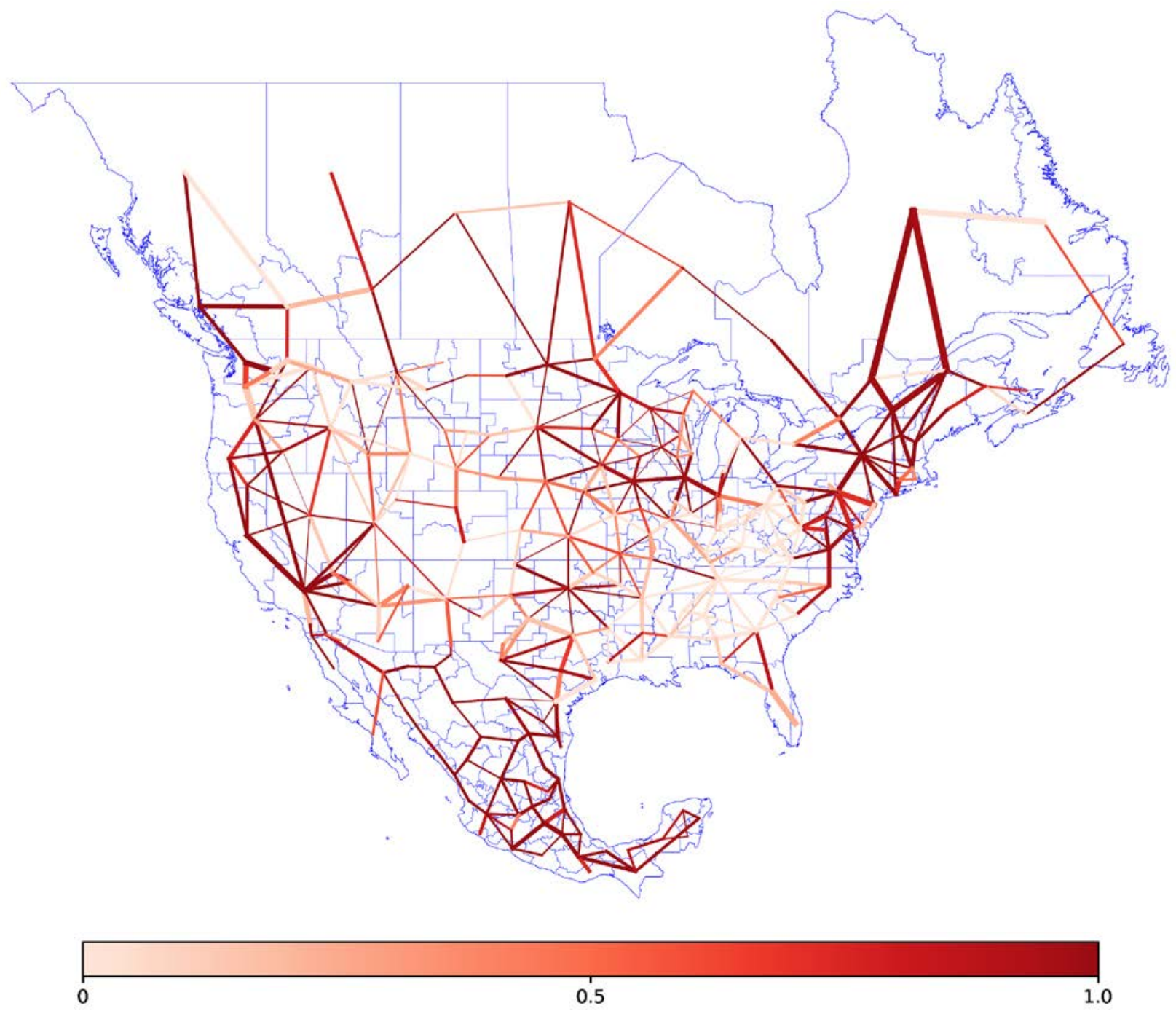

Figure 38. Maximum utilization of paths in the Low Cost VG 2050 scenario in PRAS model

The width of the lines represents the capacity of the interface between zones. The color represents the maximum hourly utilization (flow divided by capacity) during the PRAS adequacy analysis for 2010 meteorology. This is not an economic dispatch; interfaces are utilized only when it is absolutely needed to serve load. 


\subsubsection{Utilization of transmission infrastructure is very high.}

This section describes the utilization of the newly built transmission lines and the interfaces between regions. Figure 39 shows the utilization of lines built by the ReEDS model in the Low Cost VG 2050 scenario. Most lines have annual utilization greater than $90 \%$, demonstrating the high value of the expanded transmission pathways in the Low Cost VG scenario. These lines are operated as DC lines in the PLEXOS modeling, which allows the model to reach higher levels of utilization than $\mathrm{AC}$ (see Section 2.1.3 for a discussion of the overall impact). The utilization rates are very high and are often used bidirectionally.

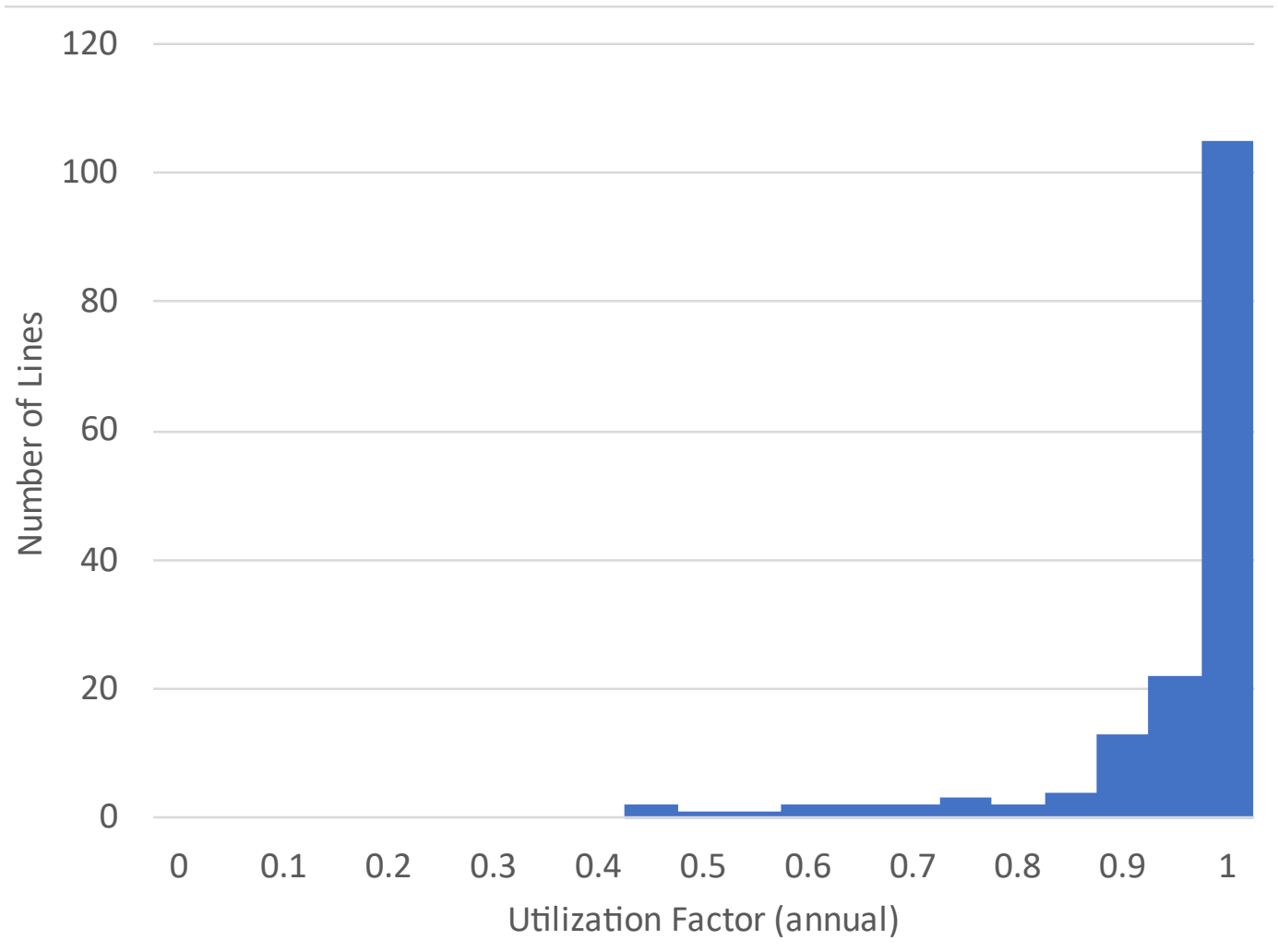

Figure 39. Histogram of total utilization of expansion lines (Low Cost VG 2050)

Figure 40 shows the net interchange between U.S. regions and their neighbors. The biggest net exchanges are from U.S. Southwest to California, the U.S. Northwest to California, the Midcontinent Independent System Operator (MISO) area to the PJM Interconnection (PJM) area, and British Columbia to the U.S. Northwest. Similar to today, California is the largest importer. The total imports into California in the model (95 TWh) are in line with recent years. ${ }^{32}$ Flows from Quebec into the United States are split onto two different interfaces, yet both are significant. The MISO export to PJM is also substantial, which is likely due to the high-quality wind resources in MISO and strong transmission connections with PJM. Many other interfaces have smaller net flows; some of these have large flows in each direction that balance out over the year.

\footnotetext{
${ }^{32}$ EIA data show California imported 71 TWh in 2019, down from an annual average of 89 TWh for 2013-2017.
} 


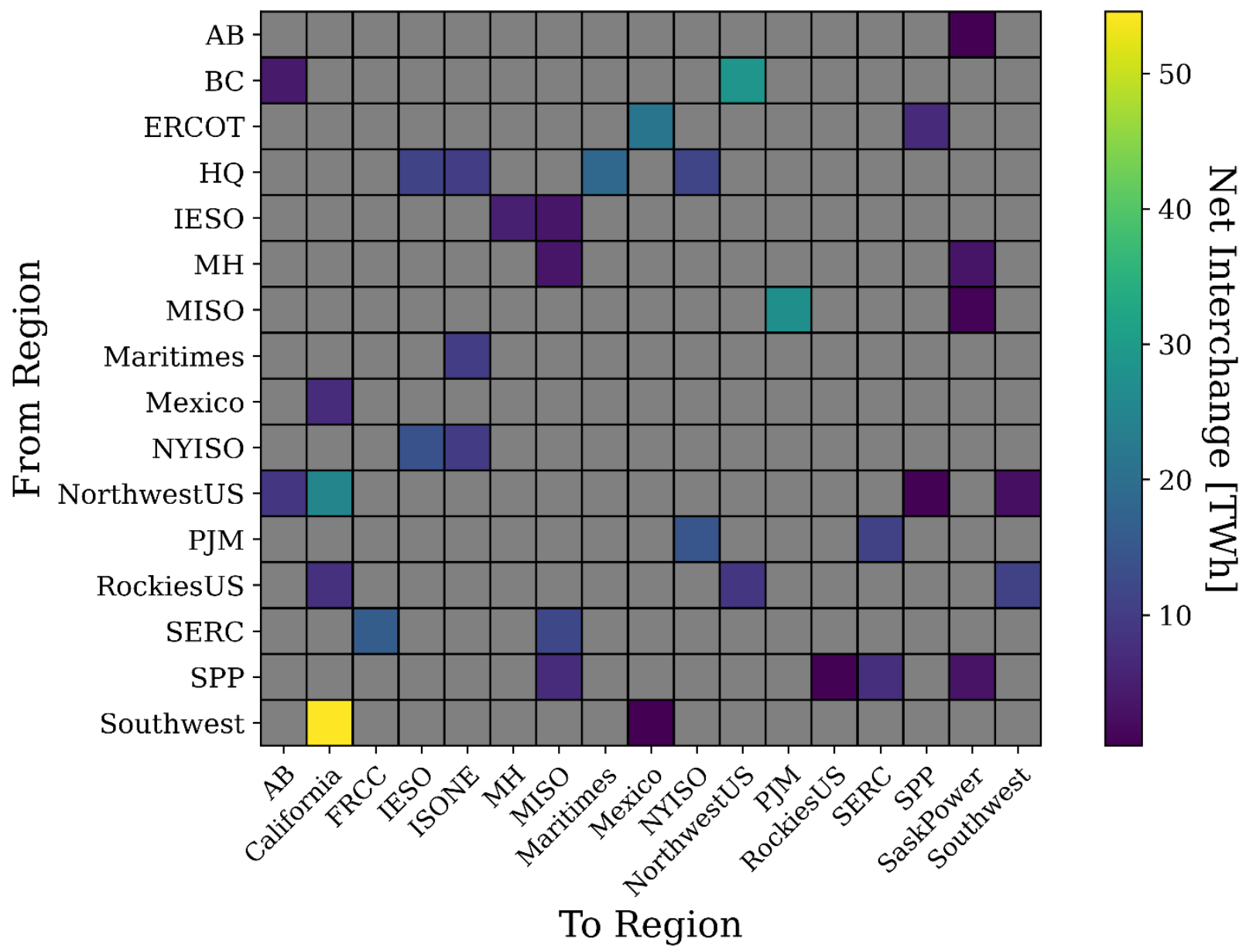

Figure 40. Net interchange between regions and their neighbors over the year (Low Cost VG 2050)

A gray box indicates there is not a connection between the regions (or power is flowing the opposite direction in net).

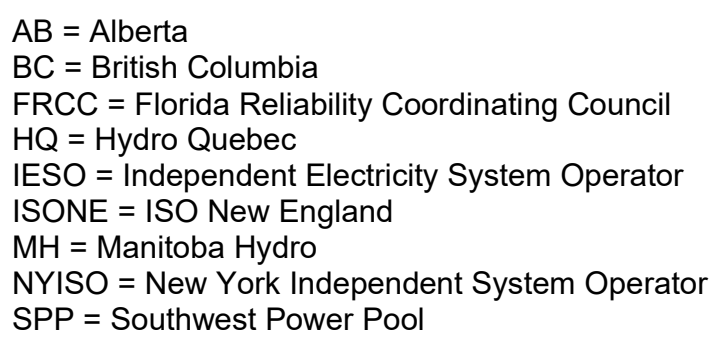

Figure 41 shows the gross interchange patterns between regions. Though many interfaces stand out in both Figure 40 and Figure 41, there are some differences in the figures. Though it is the largest net flow, the flow from the Southwest U.S. to California is not the most significant interface for gross flows, because it flows primarily one way. Other interfaces (particularly between large regions like MISO, SERC, and PJM) flow both directions frequently, and these are more noticeable in gross flow compared to net flow. Gross interchanges are also much larger than net interchanges because of the bidirectional flow on most interfaces, including the MISO/PJM interface. See Figure 42 (page 63) for details about the time series. 


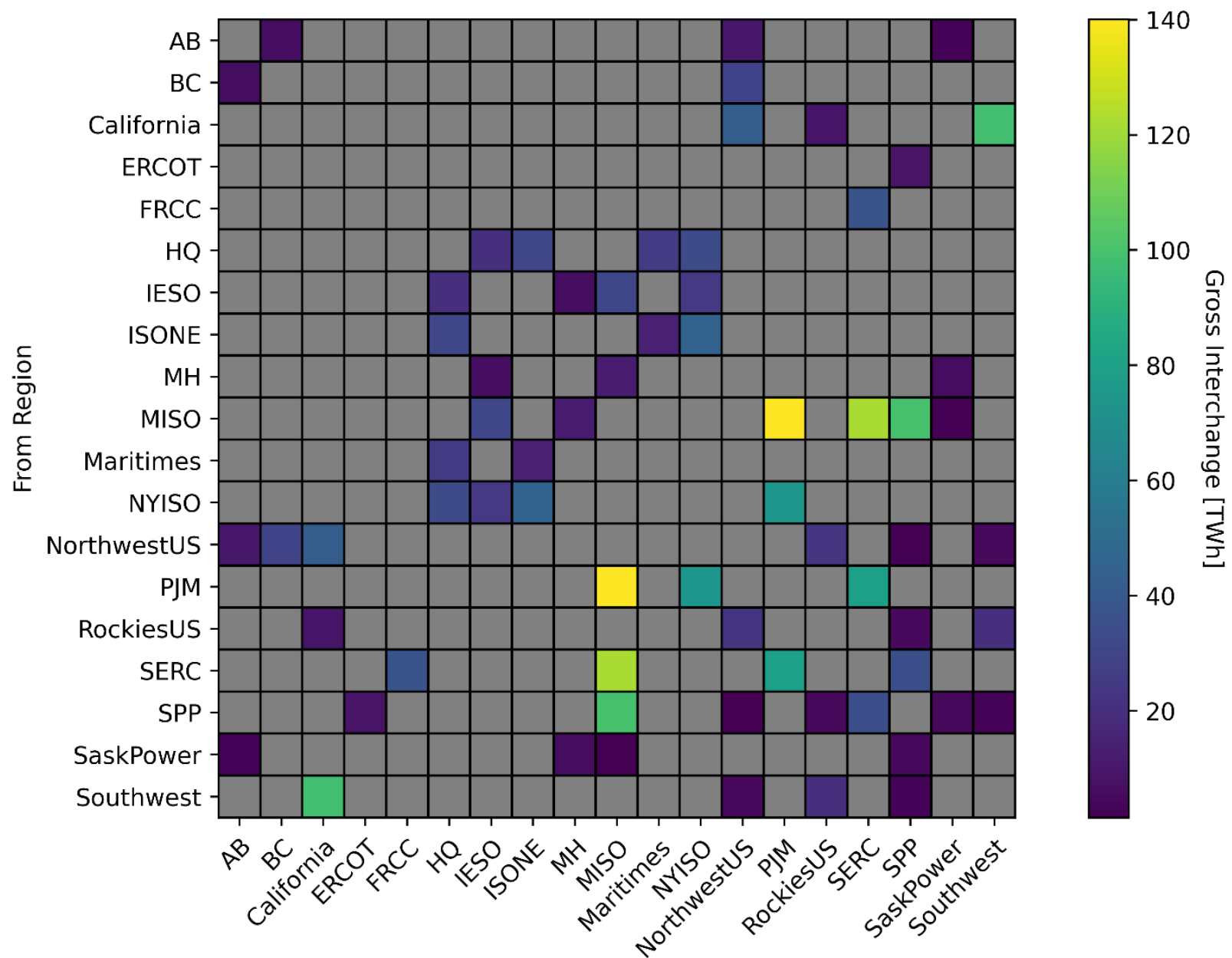

To Region

Figure 41. Gross interchange between regions and their neighbors over the year (Low Cost VG 2050)

Figure 42 shows the duration curve of the flow along major transmission interfaces (including both existing transmission and new builds). Flexibly operating transmission interfaces is useful in these scenarios. Many key interfaces have bidirectional utilization, meaning regions can benefit from cooperation by selling or buying power when the economics (and/or adequacy) are favorable. The PJM-NYISO (New York Independent System Operator) interface is expanded in the capacity expansion model, and the lines are used heavily in both directions. It does not have major net flows (Figure 40) but is heavily used in many hours of the year (Figure 42). In this plot, only the British Columbia to Northwest U.S. interface is used primarily in a single direction. 


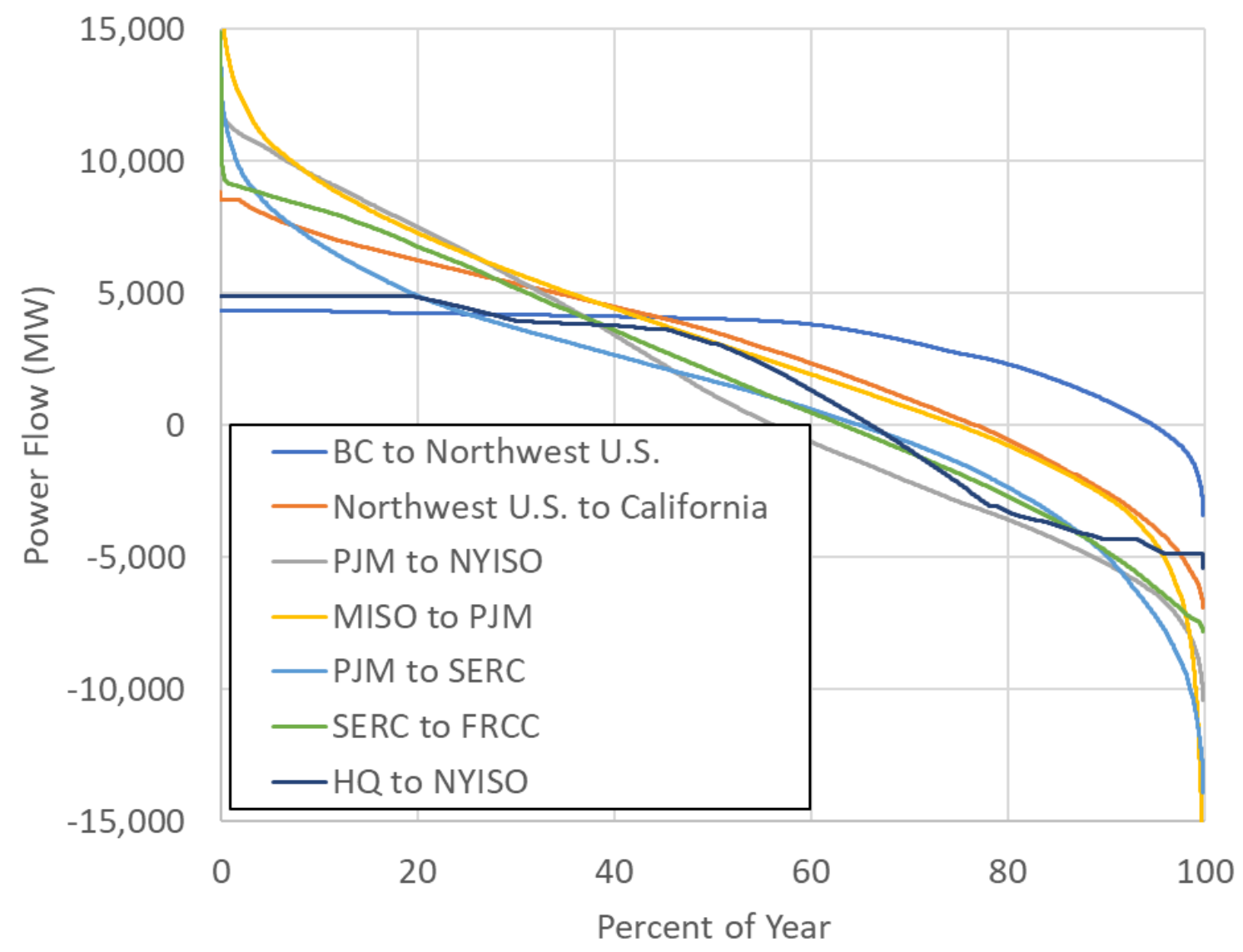

Figure 42. Duration curve of flows along major U.S. interfaces in Low Cost VG 2050

The region name listed first is the source region of the flow and the second name is the destination region. A positive flow means the source region is exporting to the destination region. A negative flow means the destination region is the exporting region.

\subsection{System Flexibility}

This section provides a general overview of flexibility in the scenarios, and the subsequent sections examine specific technologies.

\subsubsection{Operational flexibility comes from transmission, flexible operation of hydropower and thermal resources, storage, and curtailment of wind and solar generation.}

Figure 43 through Figure 45 show the dispatch of the three interconnections during a September week with several very high-load days a few low-load days. This period highlights these sources of flexibility in action. During the peak net load hours in the Eastern Interconnection (mostly around sunset), you see imports, storage, hydropower, and thermal generation all dispatching heavily, with thermal generation comprising more than half of the total generation (up to 59\%). These hours represent the hours in the far left of the thermal generation duration curve in Section 3.2.3 (Figure 26 through Figure 28). By the late morning on September 8, thermal generation represents only $10 \%$ of generation. These are the hours at the far right of the duration curves in Section 3.2.3. Hydropower is also generating significantly less to save power for sunset hours. This flexibility in various technologies helps the grid to balance at high levels of renewable 
contribution. Imports to the Eastern Interconnection are coming mainly from Canada, and the Eastern Interconnections and the Texas Interconnection are not exporting peak load hours (see below). Even during the high-load days, some curtailment of wind and solar generation occurs during midday hours. The curtailment often occurs near peak load in the early afternoon (during high load, high solar output hours), but almost never during the peak net load ${ }^{33}$ hour (sunset each day). There is no unserved energy (load curtailment) in the PLEXOS model.

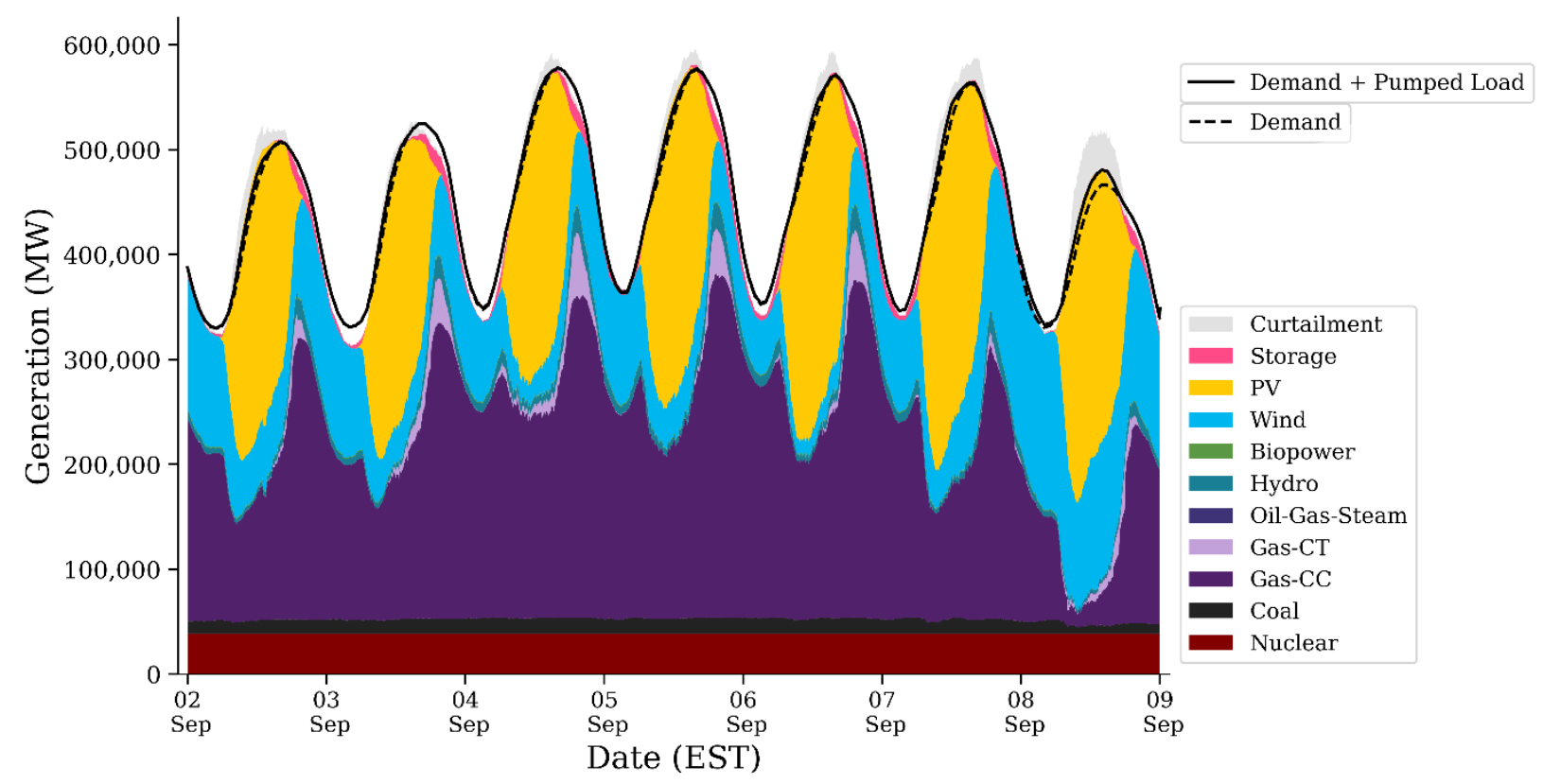

Figure 43. U.S. Eastern Interconnection generation dispatch stack for early September (Low Cost VG 2050)

Figure 44 shows the dispatch in the Western Interconnection during the same period. Many of the same features exist with the Eastern Interconnection but in diferent proportions (e.g., more hydropower). The U.S. portion of the Western Interconnection is importing from the Canadian portion during this period, and hydropower is contributing heavily in peak net load hours (sunset).

\footnotetext{
${ }^{33}$ Net load is the load minus available wind and solar generation.
} 


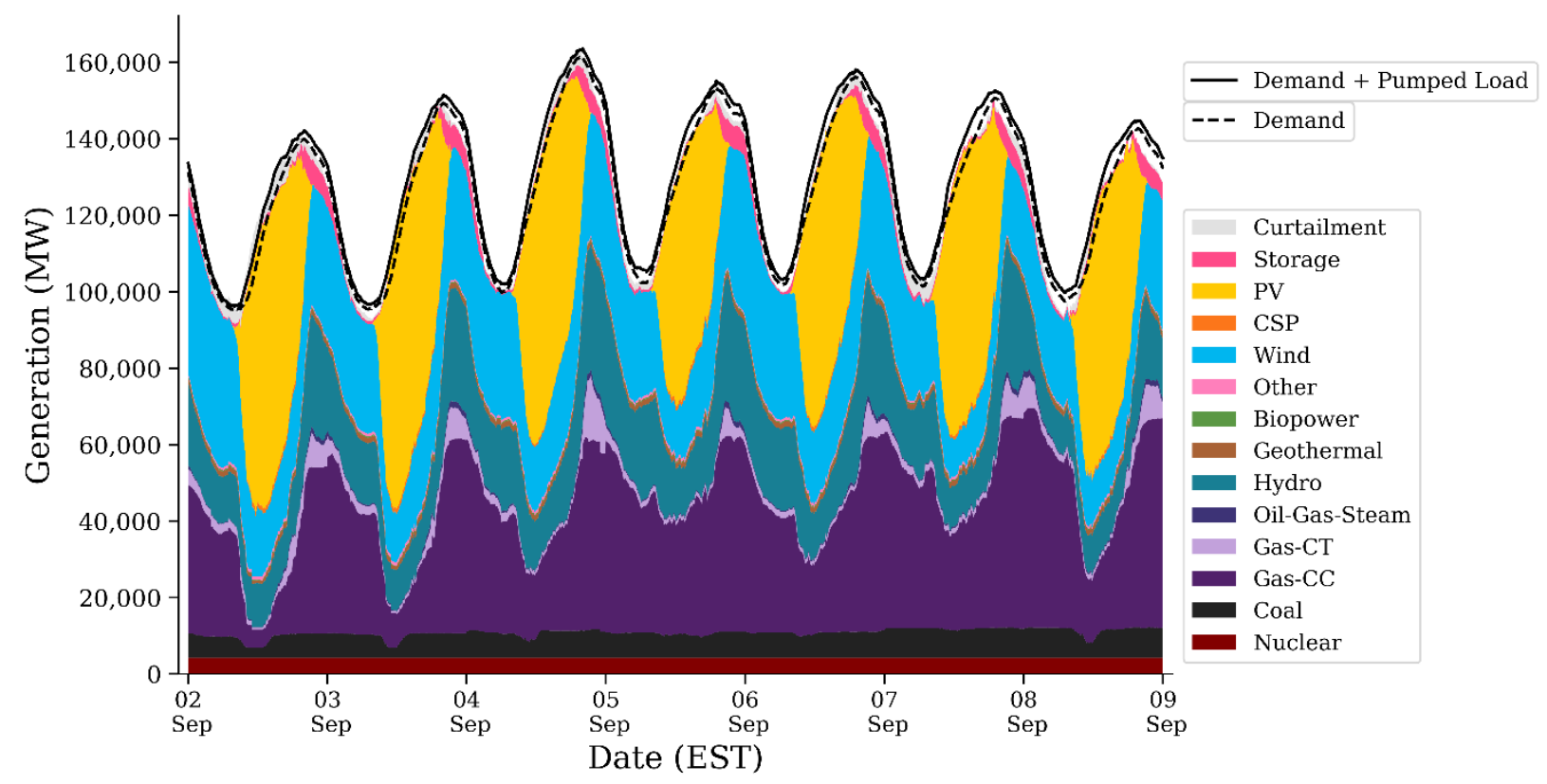

Figure 44. U.S. Western Interconnection generation dispatch stack for early September (Low Cost VG 2050)

Figure 45 shows the Texas Interconnection dispatch during the same week. It has many patterns similar to those in Figure 43 and Figure 44, although curtailment and exporting are seen at night (versus never or during day) and are likely driven by wind and load patterns (i.e., high wind and low load hours). Hydropower plays a minor role in the Texas Interconnection, and the dispatch there is made up entirely of wind, solar, and thermal generators.

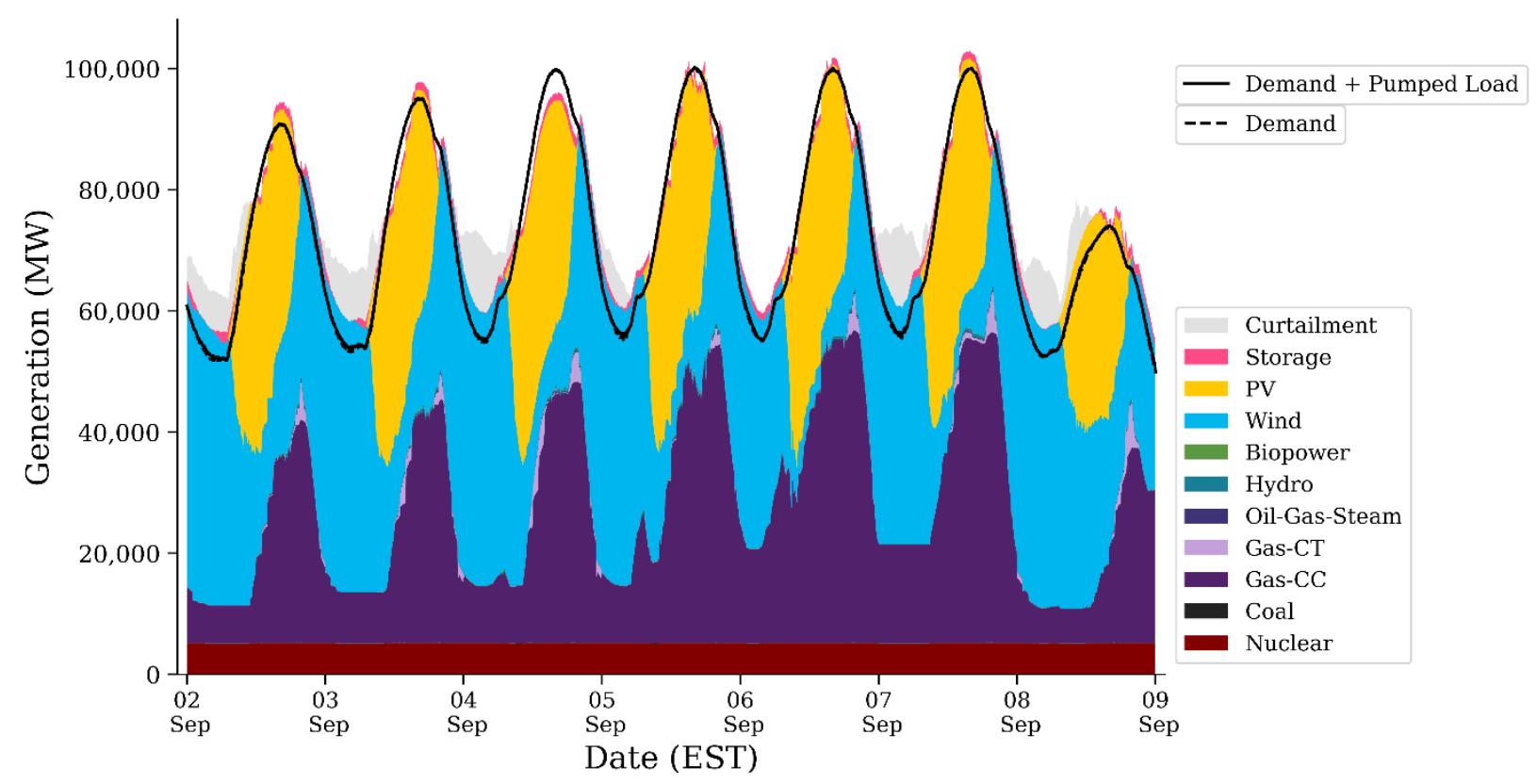

Figure 45. Texas Interconnection generation dispatch stack for early September (LowCost VG 2050) 


\subsubsection{Less than $10 \%$ of potential wind and solar is curtailed.}

Figure 46 shows the duration curve of curtailment in the United States in the Low Cost VG scenario. In total, it represents $9.3 \%$ of the potential wind and solar generation in the United States. The bulk of the curtailment occurs in a small percentage of the hours, but curtailment occurs somewhere in the United States in almost every hour. Curtailment represents a trade-off between capital costs of wind and solar (or transmission and storage) compared to fuel costs of thermal generators.

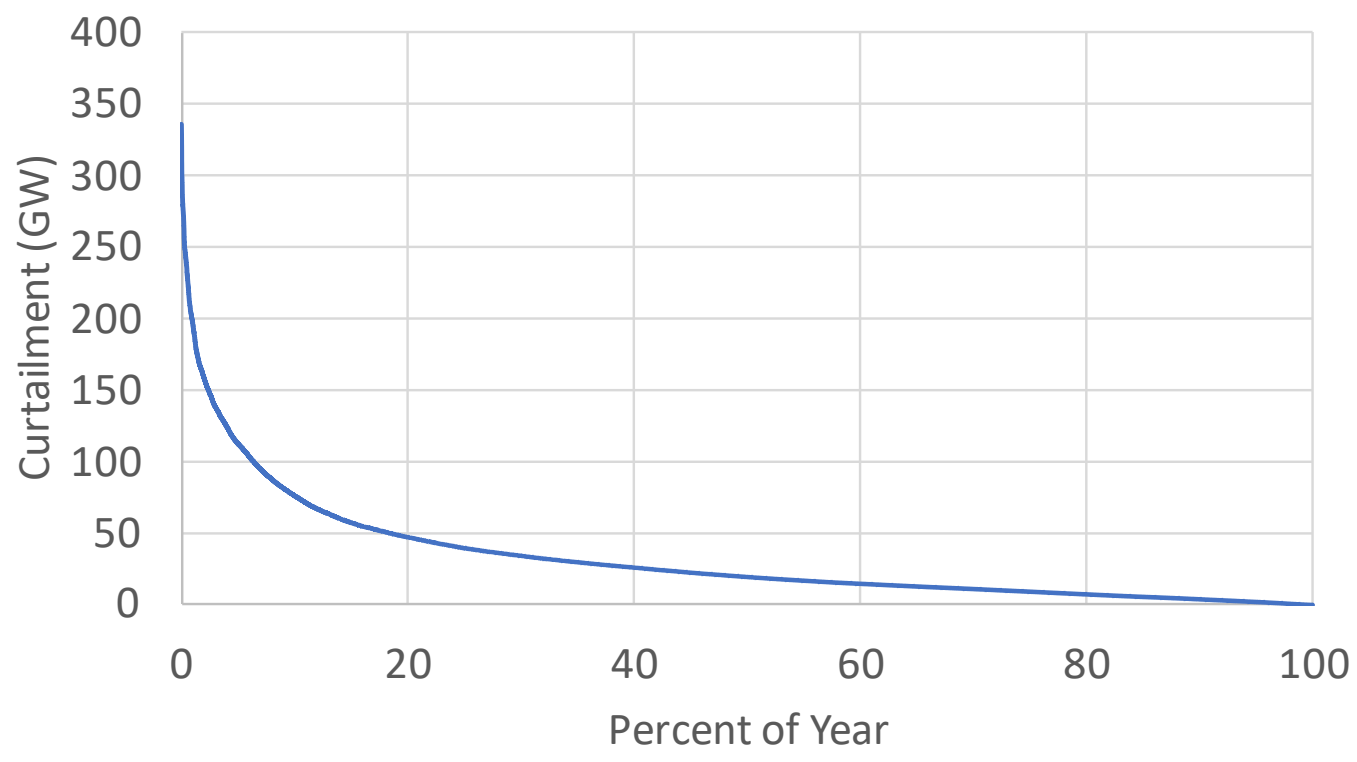

Figure 46. U.S. curtailment duration curve

Figure 47 shows the diurnal and seasonal patterns of curtailment in the United States. Most (but not all) curtailment occurs during the day, following the solar pattern until late afternoon hours, when the curtailment reduces before sunset. Curtailment also peaks in the spring months and is at a minimum in midsummer to late summer. 

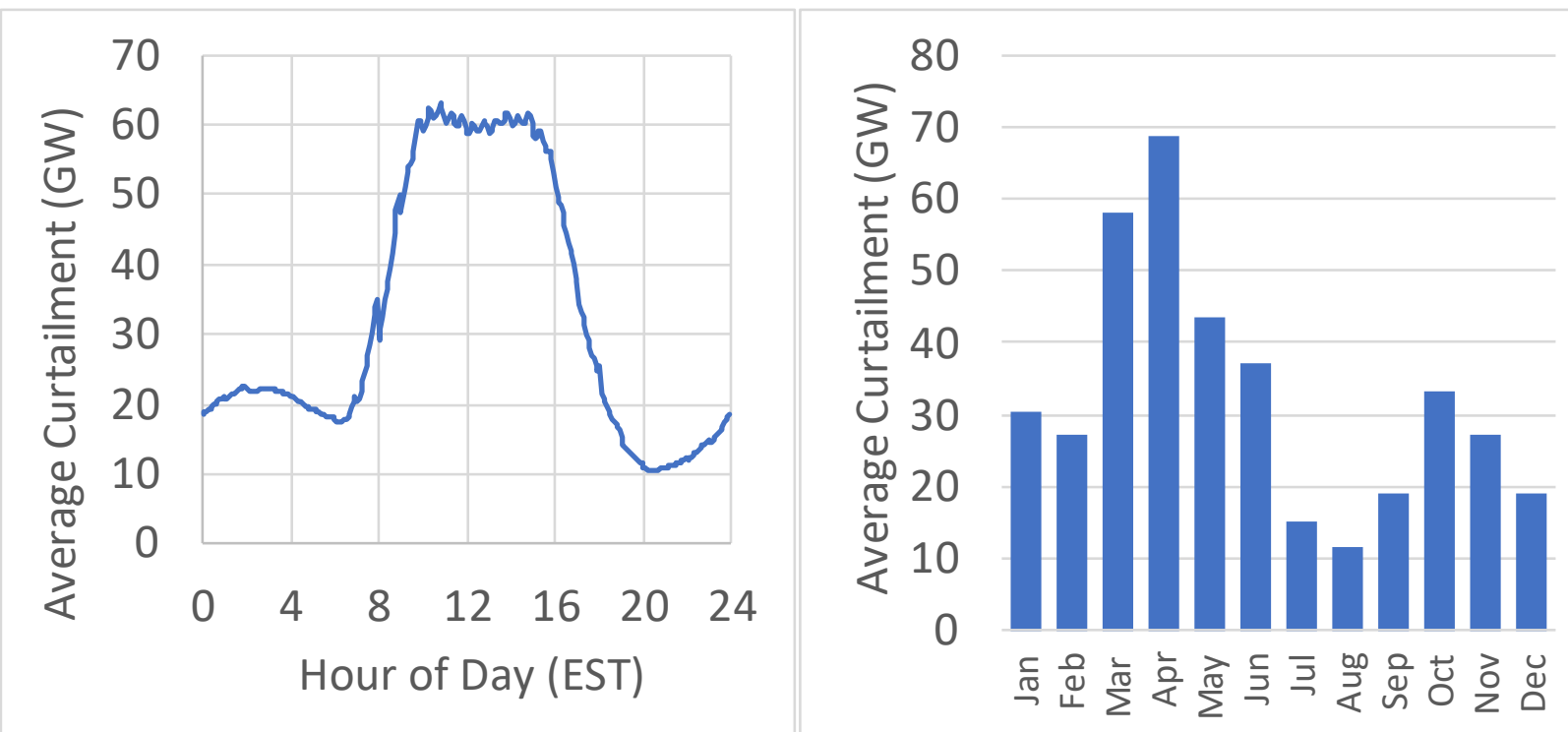

Figure 47. U.S. curtailment duration by hour (left) and month (right)

Figure 48 shows a week of U.S.-wide dispatch during May, a period with lower loads, and high solar and wind generation. Midday hours on May 10 and May 11 show hundreds of gigawatts of curtailment, and the thermal generation (mostly nuclear running flat and gas CCs cycling daily) operates similarly in each day. The curtailment varies widely through the week, but the actual dispatch is fairly consistent. Storage, imports and exports, and hydropower all play key roles, especially regionally, that are explored in Sections 3.3, 3.4, 3.5.

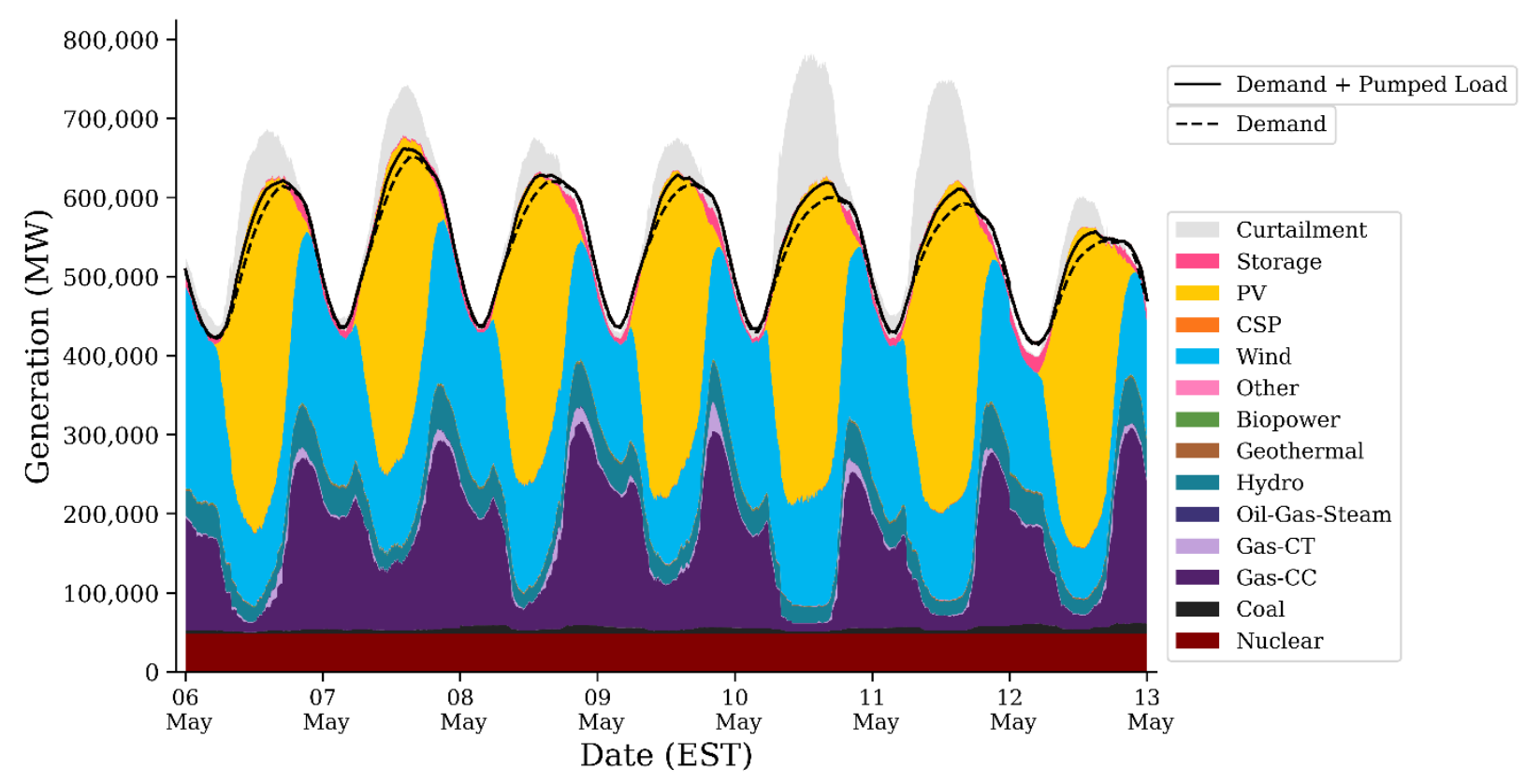

Figure 48. U.S.-wide dispatch stack during a high-curtailment period 


\subsubsection{Hydropower contributes significantly to energy, adequacy, and flexibility.}

Figure 49 through Figure 51 qualitatively demonstrate the contribution of hydropower flexibility. Figure 49 demonstrates hydro's contribution to the adequacy and flexibility during a week in the Western Interconnection that includes low-load and high-load days. At the peak net load, hydro capacity is contributing more than $30 \mathrm{GW}$ toward the $120 \mathrm{GW}$ net load peak, even in the fall, when overall energy available for hydropower is low. Earlier in the week, when net load peaks are much lower, the hydropower generators are holding back energy for higher load days. This demonstrates the potential for flexible hydropower to generate most when needs are high and least when needs are low in the future grid. ${ }^{34}$

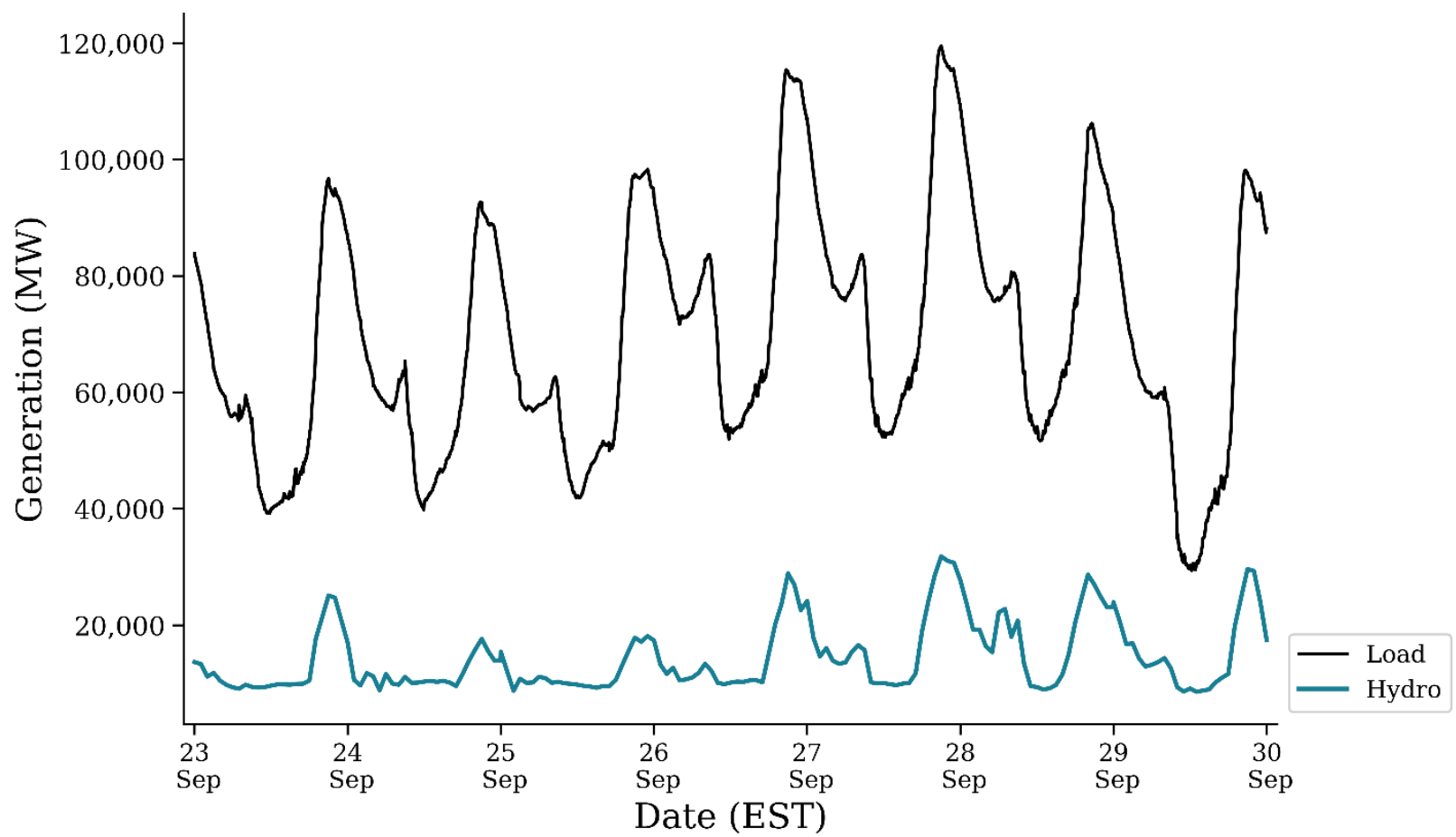

Figure 49. U.S. Western Interconnection hydropower and net load during a week with both highand low-load days in September in the Low Cost VG 2050 scenario

Although average generation is low during this example of a week in September, the peak generation is much higher and contributes toward adequacy in the high-value periods.

Figure 50 shows the hydropower and net load again during a period in May with high curtailment (the same period shown in the dispatch stack in Figure 48). Average hydropower output is higher during this period despite lower loads than September. This demonstrates some of the seasonal limitations on hydropower flexibility based on the model assumptions (see Section 2.2.3). Some generators throughout the continent (e.g., Quebec) might have some interseasonal flexibility that is not considered here, but these seasonal limitations represent a real constraint on hydropower flexibility for many generators.

\footnotetext{
34 This implies some ability to forecast these higher-load days in advance, although the model simplifications in the multiday dispatch prevent an unrealistic amount of information being available in the optimization.
} 
The hydropower follows diurnal load patterns well in both weeks. In the model dispatch, hydropower contributes during both the larger peaks in net load (which is sunset in Figure 49 and Figure 50) and the smaller peaks that sometimes occur during hours around sunrise. The Eastern Interconnection hydropower dispatch shows some similar patterns, but hydropower makes up a much smaller fraction of the load overall.

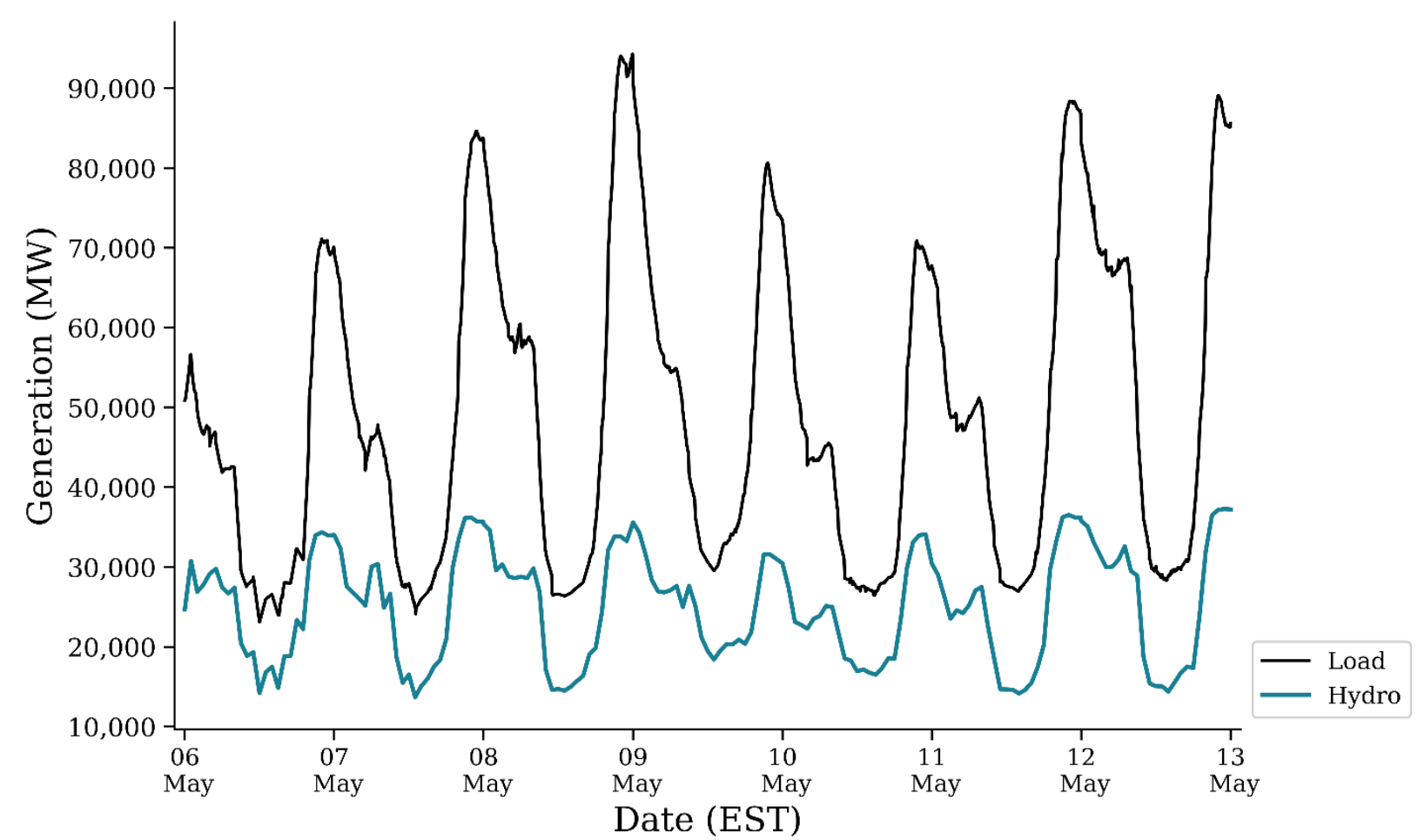

\section{Figure 50 U.S. Western Interconnection hydropower generation and net load during a week with high curtailment}

Average generation is significantly higher than during the September week, although the net loads are lower. This seasonal challenge demonstrates a constraint on flexibility, although the hydropower still follows the daily load pattern well, helping contribute in higher-value hours and reduce generation in hours when curtailment is happening the most.

Figure 51 shows the total U.S. net load versus total U.S. hydropower generation for the year. The strong correlation indicates that even with the modeled limitations to flexibility, hydropower generally can contribute substantially when energy production has the most value to the grid (high net load) and reduce generation when it has the least (low net load). 


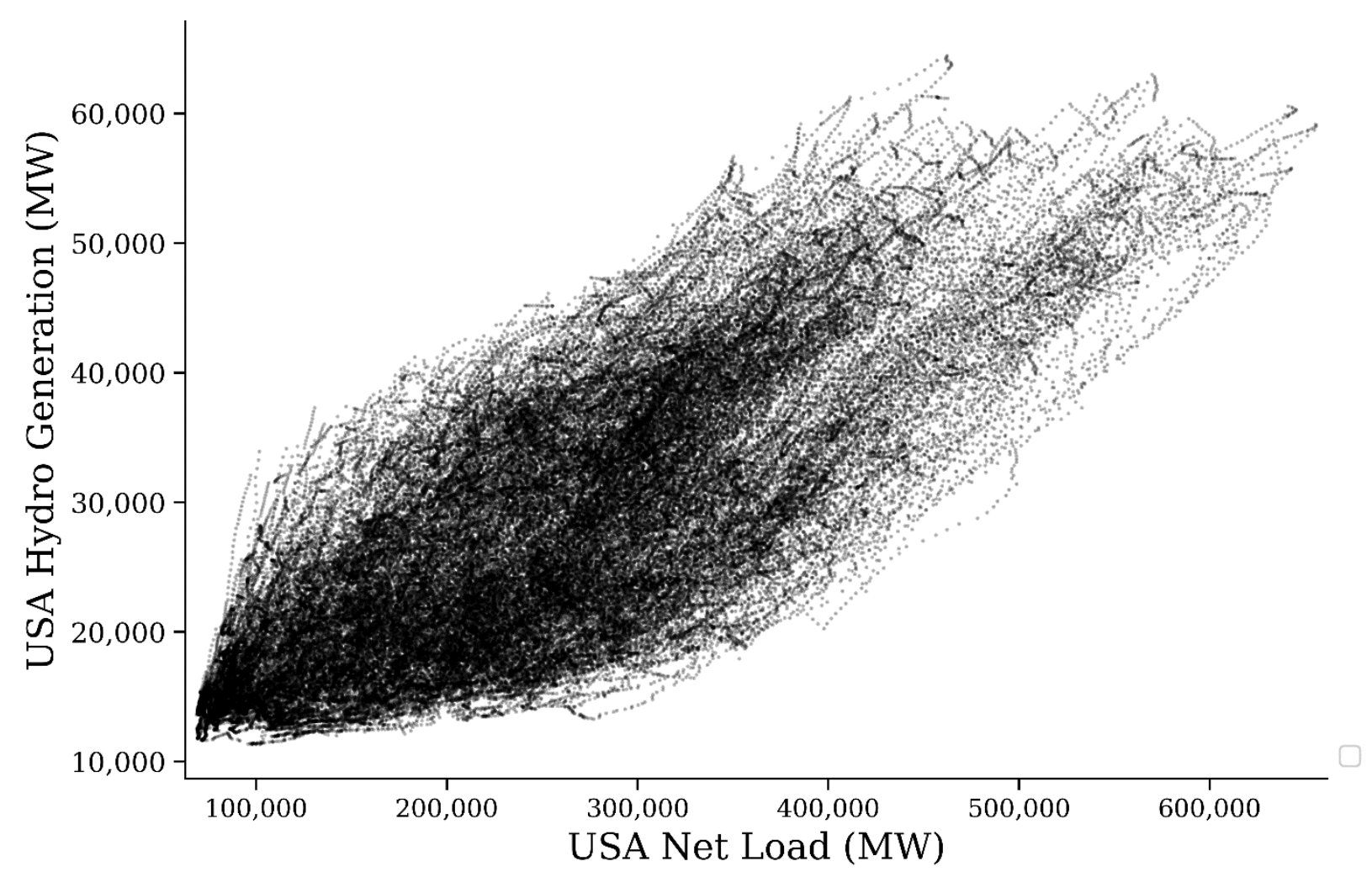

Figure 51 Total U.S. generation versus total U.S. net load for the entire year

Each dot represents a 5-minute interval in the PLEXOS model. The strong correlation indicates that hydropower is following net load patterns well and contributing to adequacy in high-value hours, and is helping reduce curtailment of wind and solar by generating less in low net load hours.

\subsubsection{Hydropower flexibility reduces system costs by more than $\$ 2$ billion per year.}

The previous section qualitatively demonstrates some of the value hydropower brings to the system, including generation during times of peak demands and the ability to turn down at other times. To explore these values in quantitatively, we ran the unit commitment and dispatch model again assuming heavily constrained hydropower operations. By comparing the cases, we can understand the value and benefits of hydropower flexibility to this future scenario (Low-Cost VG 2050).

The Low-Cost VG scenario assumed hydropower flexibility intended to represent today's levels of flexibility. The constrained case assumed operations at all hydropower plants (not just run-ofriver) have no flexibility (i.e., they have constant output, with the constant output varying monthly or daily based on water flows). Run-of-river plants were modeled with the same time series assumptions (historical flows) in both cases. This case was not intended to represent a realistic future, but to help estimate the benefits that the flexibility of hydropower provides compared to a hypothetical resource that cannot follow load. The key caveat for this valuation is that it is based on the amount of flexibility allowed in the model (see Section 2.2.3). Future work could further refine the representation of hydropower within the model and disaggregate the types of flexibility (e.g., determine how much benefit is from interday versus intraday flexibility). 
Table 10 shows some of the impacts of hydropower flexibility on key metrics in the Low-Cost 2050 production cost modeling. Today's approximate level of hydropower flexibility-compared to a completely inflexible hydropower fleet - could reduce annual operating (production) costs by $3.0 \%$, curtailment by 0.6 percentage points, fossil-fueled generation by $1.6 \%$, and emissions by $1.3 \%$.

Table 10. Benefits of Hydropower Flexibility

\begin{tabular}{|l|l|}
\hline Metric & Impact \\
\hline Cost & $\begin{array}{l}\text { Today's level of hydropower flexibility reduces annual operating costs by } \$ 2.3 \text { billion, } \\
\text { which represents 3.0\% of the system production costs. }\end{array}$ \\
\hline Curtailment & $\begin{array}{l}\text { The flexibility of hydropower to turn down in periods of curtailment and generate more } \\
\text { in periods of need reduces curtailment from } 9.9 \% \text { to } 9.2 \% .^{\text {a }}\end{array}$ \\
\hline Generation & $\begin{array}{l}\text { The reduction in curtailment leads to a reduction in generation from fossil-fueled units } \\
\text { of 22 TWh (1.6\%); this includes an increase in coal generation of } 4 \text { TWh and a } \\
\text { decrease in gas of } 26 \text { TWh. }\end{array}$ \\
\hline Emissions & Increased flexibility reduces emissions in this scenario by $1.3 \%$. \\
\hline
\end{tabular}

These values are based on a comparison of the 5-minute dispatch model runs from the Low-Cost VG scenario with runs from an identical scenario with all hydropower flexibility disabled (i.e., dispatchable hydropower generators are assumed to have flat output levels for each month). U.S. and Canadian hydropower was included in the sensitivity, so results presented are aggregated for the continent.

a Curtailment reported here is a U.S. and Canada average, because the sensitivity was done for all U.S. and Canada hydropower.

${ }^{\mathrm{b}}$ Because the dispatch of generators is a cost optimization, increased flexibility will lead to selecting lowercost resources (in this case, coal because of fuel costs)

Figure 52 shows the annual pattern of daily cost reductions from hydropower flexibility. It is smoothed to limit the visibility of interday energy shifting. Although the reasons for the value likely vary by season, the overall value is similar between seasons. Curtailment is likely a strong driver of this value; the highest curtailment in the model and the highest monthly value of hydropower flexibility both occur in April. The lowest curtailment occurs in July and August, as does the lowest monthly value of hydropower flexibility. In high curtailment periods, like the spring, the value comes primarily from avoided curtailment. In low curtailment periods, it comes from a variety of sources, including substituting higher-cost peak generation with lower-cost resources.

From a hydrology perspective, the high-value periods do coincide with low-water times of the year for these modeling assumptions (see Section 2.2.3 for hydropower output by week). This might be due to the ability to shift power more easily when the quantity of water does not require generators to regularly run near capacity. More study of different hydrological conditions mixed with flexibility changes would help address this question. 


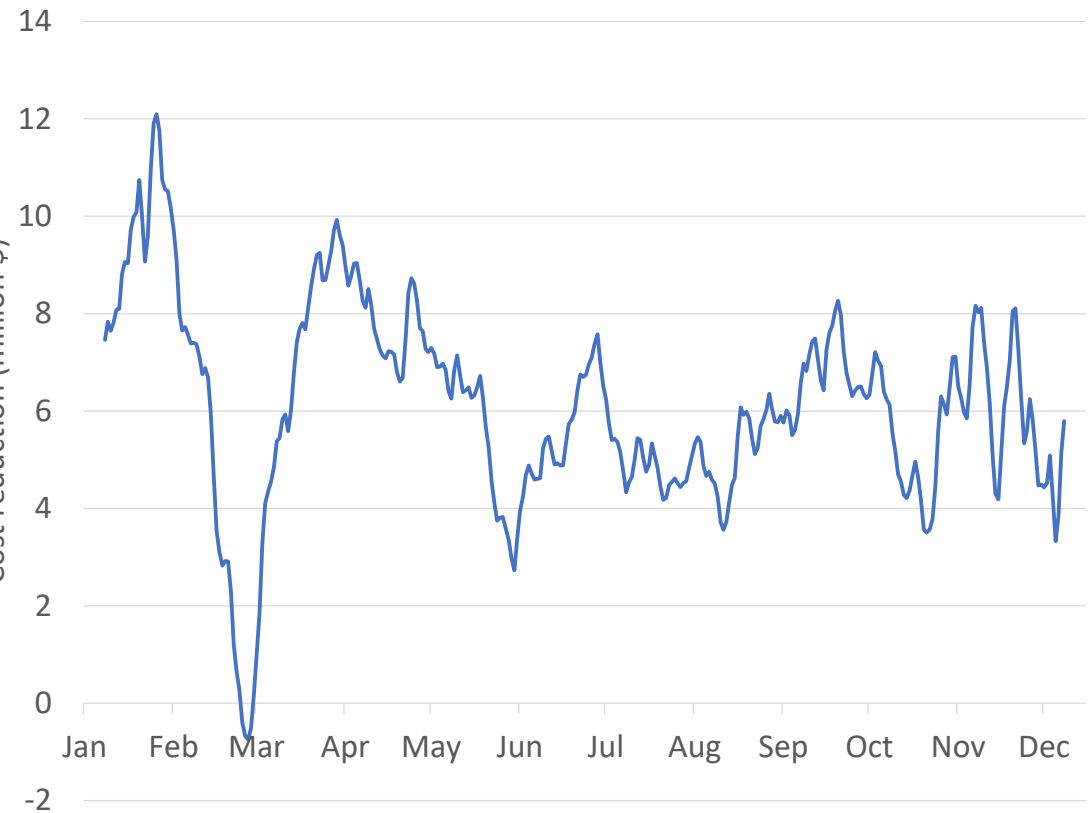

Figure 52. Daily cost reduction from hydropower flexibility

This figure shows the smoothed, daily hydropower flexibility cost reduction, which averages $\$ 6.3$ million per day. It does not substantially vary by season, except a period in early March when the model shifts energy to another time if it is feasible to do so. The smoothing is a 30-day filter, to limit the impacts of daily variability due to substantially more or less energy generation from hydropower.

The above analysis is based on a typical hydropower year for all regions. We also reran the model with a 5\% increase (wet) and a 5\% decrease (dry) in energy availability at hydropower generators to see the different impacts (no changes were made to the capacity of the generators). The Dry case leads to an increase in production costs of $\$ 1.1$ billion. Most ( $27 \mathrm{TWh}$ ) of the approximately $35 \mathrm{TWh}$ generation needed to make up for the reduced hydropower generation came from gas CCs, and $5 \mathrm{TWh}$ came from reduced curtailment at wind and solar generators In the Wet case, production costs decrease by $\$ 0.9$ billion. The additional curtailment from wet conditions is slightly higher than the reduction from wet conditions, and the 7 TWh additional wind and solar curtailment represents approximately $20 \%$ of the additional available hydropower energy.

Table 11. Impacts of Different Water Conditions

\begin{tabular}{|c|c|c|c|}
\hline Metric & Dry & Typical & Wet \\
\hline $\begin{array}{l}\text { Cost, } \$ \text { billion } \\
\text { (change from Typical) }\end{array}$ & $\begin{array}{l}\$ 78.5 \text { billion } \\
(+\$ 1.1 \text { billion })\end{array}$ & $\$ 77.4$ billion & $\begin{array}{c}\$ 76.5 \text { billion } \\
\text { (- } \$ 0.9 \text { billion })\end{array}$ \\
\hline $\begin{array}{l}\text { Gas CT, TWh } \\
\text { (change from Typical) }\end{array}$ & $\begin{array}{c}95 \\
(+1)\end{array}$ & 94 & $\begin{array}{c}93 \\
(-1)\end{array}$ \\
\hline $\begin{array}{l}\text { Gas CC, TWh } \\
\text { (change from Typical) }\end{array}$ & $\begin{array}{l}1,584 \\
(+27)\end{array}$ & 1,557 & $\begin{array}{l}1,534 \\
(-23)\end{array}$ \\
\hline $\begin{array}{l}\text { Wind and Solar } \\
\text { (TWh difference) }\end{array}$ & $\begin{array}{l}3,492 \\
(+5)\end{array}$ & 3,487 & $\begin{array}{c}3,480 \\
(-7)\end{array}$ \\
\hline
\end{tabular}

These values are based on comparing the 5-minute dispatch model runs from the Typical case to a Wet (5\% additional energy from hydropower in every month) and Dry (5\% reduction in energy). 


\title{
3.4.5 Hundreds of gigawatts of storage could be installed if costs came down significantly.
}

In this section, we discuss the impacts of running the ReEDS model with the 2018 ATB LowCost assumptions for storage, compared to the Mid-Cost assumptions that were used for the core cases. In the core nonelectrification scenarios (BAU, Low-Cost VG, and $\mathrm{CO}_{2}$ Constrained), storage capacity in 2050 is $30 \mathrm{GW}-55 \mathrm{GW}$. In the Electrification scenario, storage capacity is noticeably higher at $130 \mathrm{GW}$. Figure 53 shows the change in capacity in the core scenarios assuming low-cost storage (based on the 2018 ATB). In the nonelectrification scenarios, storage capacity is approximately $200 \mathrm{GW}$ higher by 2050 . In the electrification scenario, there is approximately $350 \mathrm{GW}$ of additional storage by 2050 . The existing pumped-storage hydropower was modeled in all scenarios and included as storage (not hydropower) in all plots; the new builds in the core and Low Cost Storage scenarios are primarily batteries with 4 hours of storage capacity.

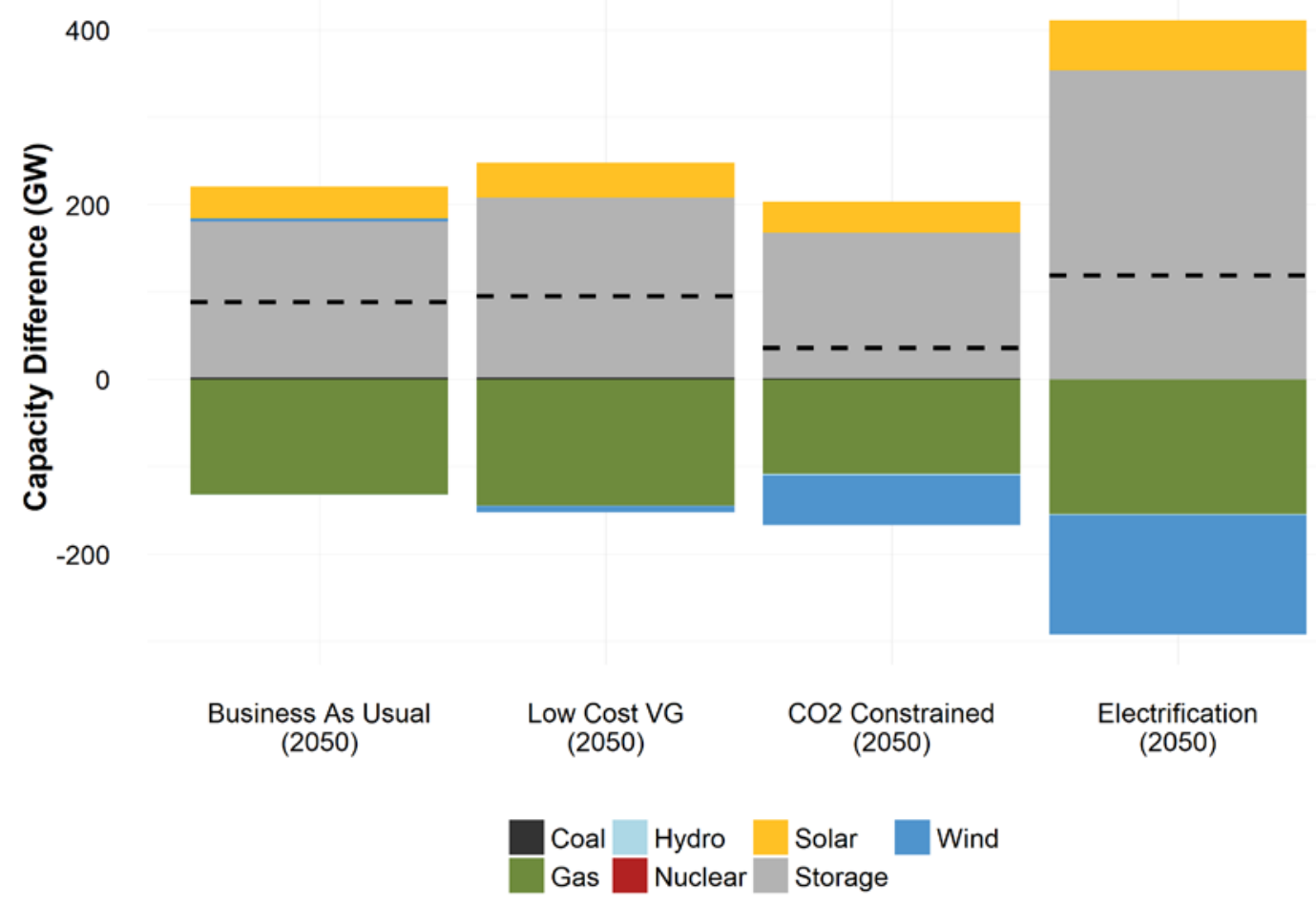

Figure 53. Change in 2050 capacity for core scenarios with lower-cost storage availability

\begin{abstract}
Each core scenario was modeled with standard (2018 NREL ATB Mid Cost) assumptions for storage costs. As a sensitivity, each core scenario was also modeled with lower storage cost trajectories through 2050. The difference between each sensitivity and each core scenario is presented here. The dashed line represents the net capacity impact for each scenario and sensitivity pairing. For all scenarios, the total capacity is higher in the Low Cost Storage cases.
\end{abstract}

The importance of the contribution of storage to adequacy in these low-cost storage scenarios is shown in Section 3.2.2, where the contribution of renewables plus storage to planning reserve is seen to be hundreds of GW higher in the low-cost storage cases because of the high storage deployment. Deployment of thermal generation (a mixture of gas CCs and CTs) is also several hundred GW less in the low-cost storage scenarios because of the adequacy provided by the storage. 


\subsection{Scenario Comparisons}

In this section, we compare some of the key outcomes of the scenarios, including costs, emissions, distributed generation, and the impacts of electrification.

\subsubsection{Emissions drop substantially in all scenarios.}

Figure 54 shows the emissions trajectory through 2050 in the core scenarios. Existing state renewable portfolio standards and clean energy standards drive $\mathrm{CO}_{2}$ reductions through 2028 . The carbon limits in the model ( $80 \%$ reduction by 2050 in the $\mathrm{CO}_{2}$ Constrained and Electrification cases) are binding starting in the late 2020s. Emissions reductions from the electrification of additional energy end uses in the Electrification scenarios are not considered in this plot, so the Electrification scenario could be part of much larger emissions reduction in the overall energy system. In the Electrification Futures Study, nonelectric sector emissions reductions that were enabled by the newly electrified end uses were approximately 1,500 million metric tons per year in 2050, which is more than the electric sector emissions reductions shown here in any of the scenarios between 2020 and 2050. Between 2030 and 2040, the Low-Cost VG trajectory has significantly lower emissions than the $\mathrm{CO}_{2}$ Constrained. However, they are nearly identical by 2050 .

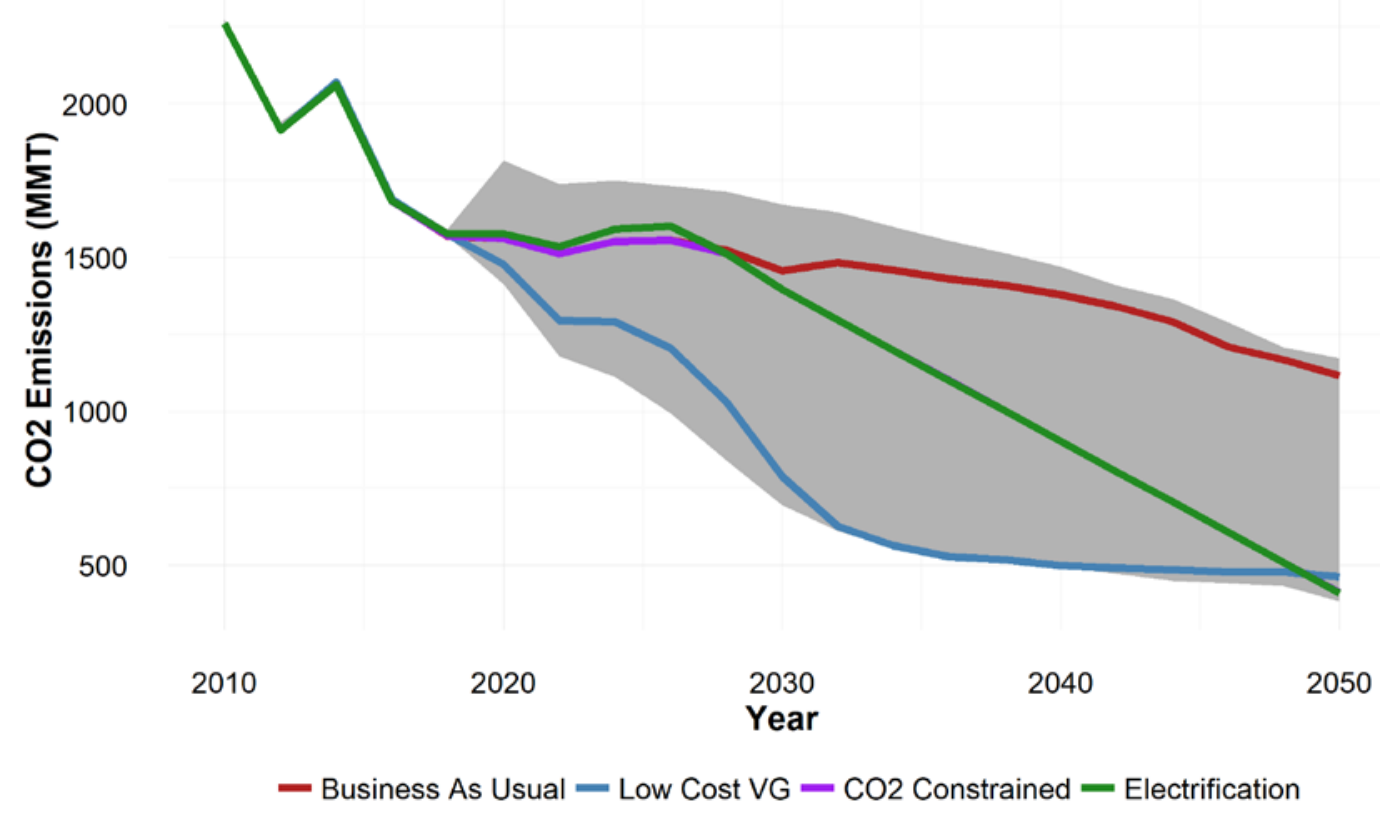

Figure 54. U.S. $\mathrm{CO}_{2}$ trajectory through 2050 in the core scenarios

The emissions reductions from the electrification of energy end uses (e.g., transportation and heating) in the Electrification scenario are not considered in this plot. The $\mathrm{CO}_{2}$ Constrained and Electrification scenarios follow an identical trajectory after 2028 because of binding carbon constraints. 


\subsubsection{Distributed generation is likely to play a significant role in generation; costs strongly impact adoption.}

The dGen modeling results for the United States are primarily drawn from the results of the 2018 Standard Scenarios Report (Cole et al. 2018). This analysis examines the geographic distribution of DPV deployment across the United States over three cost scenarios as explained in Section 2.1.2.

The installed cost of distributed solar PV is the most significant factor affecting cumulative solar adoption. Based on the three ATB cost projections described in Section 2.1.2, Figure 55 displays dGen's cumulative DPV deployment forecast by scenario. In the High Cost scenario, adoption climbs slowly from $28.2 \mathrm{GW}$ in 2030 to 32.3 in 2050 . This slow growth is unsurprising, as the cost of solar remains consistent at 2018 levels in the High Cost scenario, leading to a stagnant market once the least-cost agents have adopted. In the Mid-Cost scenario, adoption increases to $57.3 \mathrm{GW}$ in 2030 and $116.2 \mathrm{GW}$ in 2050 . Despite this growth, adoption is still concentrated in the residential sector $(91.9 \mathrm{GW})$. In the Low Cost scenario, some $83.1 \mathrm{GW}$ are adopted by 2030 and this grows to $232.6 \mathrm{GW}$ by 2050 . In this scenario, the commercial sector sees significant growth (55.9 GW by 2050) as payback periods are achieved that can compete with the generally lower-cost electricity purchased by commercial businesses.

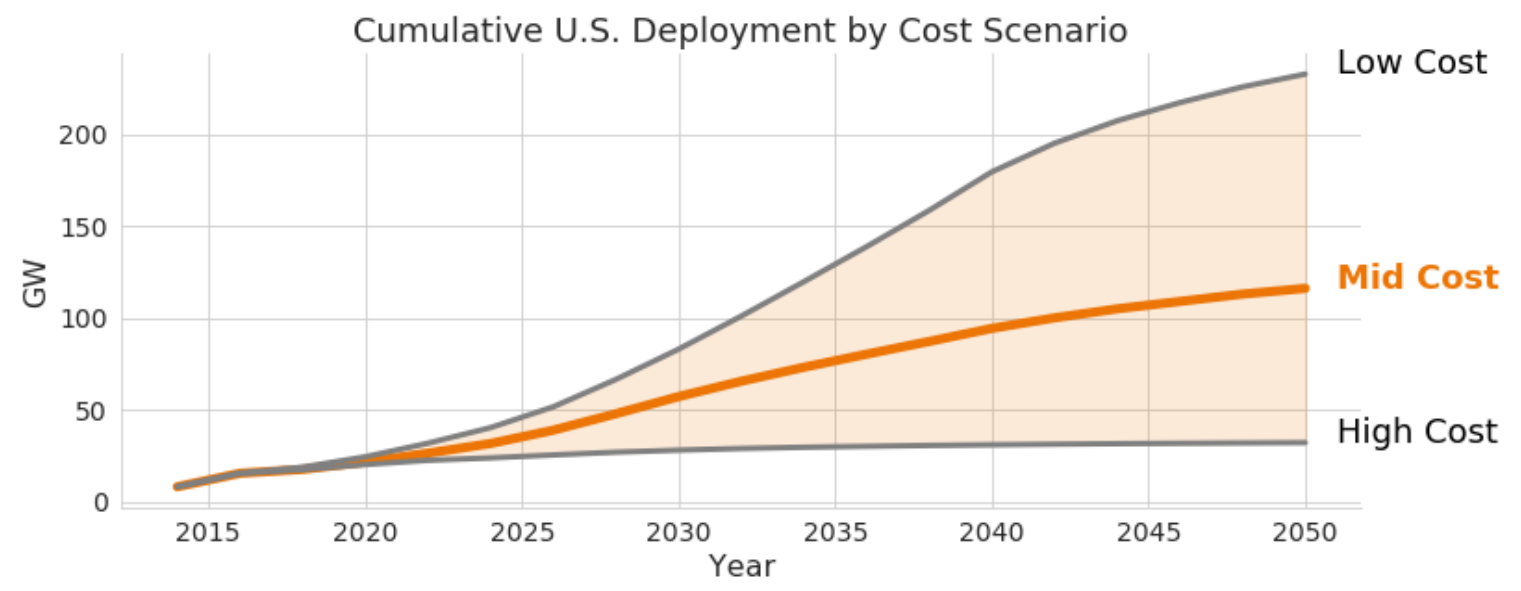

Figure 55. Cumulative U.S. DPV deployment by cost scenario

Differences in adoption levels between geographies can also be explained by policies (including tariffs such as NEM, subsidies, and other incentives) and resource quality (as measured by global horizontal solar irradiance). Resource quality influences the differences in the capacity factor that comparable PV systems would be able to produce, as displayed in the solar resource map included in Figure 1. The differences from policies and resource are explored in Table 12 (page 76) and Figure 56 (page 77).

Table 12 provides a heat map of the temporal and geographic trends of adoption within U.S. regions. Adoption is considerably concentrated in only a few regions, with $24 \%$ of 2050 adoption concentrated in only two regions, and 51\% concentrated in the top five regions (for the Mid Cost NEM scenario). The coasts dominate rooftop solar adoption, including the service areas for system operators in the Middle Atlantic (PJM), Florida (Florida Reliability Coordinating Council, or FRCC), the Southeast (SERC-E), and California. Some of this is likely due in part to higher resource quality in these areas (e.g., Florida versus New York). Also, strong state policy 
support or comparatively expensive retail electricity costs boost adoption in New England (ISO$\mathrm{NE}$ ), which otherwise has lower solar resource quality. Table 12 also shows the impact of extending NEM policies that do not have a legislated end date (the net metering cases), compared to assuming all regions transition to a tariff where electricity sold to the grid is compensated at wholesale rates (net billing).

Table 12. Cumulative Adoption (GW) in $\mathbf{2 0 5 0}$ by Region for Cost and Policy Sensitivities

\begin{tabular}{|l|c|c|c|c|}
\hline \multirow{2}{*}{ Region } & \multicolumn{2}{|c|}{ Low Cost } & \multicolumn{2}{c|}{ Mid Cost } \\
\cline { 2 - 5 } & $\begin{array}{c}\text { Net } \\
\text { Metering }\end{array}$ & Net Billinga & $\begin{array}{c}\text { Net } \\
\text { Metering }\end{array}$ & Net Billing $^{\text {a }}$ \\
\hline PJM-E & 26.7 & 19.4 & 14.1 & 8.2 \\
\hline FRCC & 28.1 & 10.3 & 14.1 & 3.7 \\
\hline SERC-E & 19.0 & 13.8 & 12.2 & 5.8 \\
\hline CA & 22.0 & 22.1 & 10.8 & 10.8 \\
\hline ISO-NE & 14.0 & 10.3 & 8.5 & 4.8 \\
\hline PJM-W & 18.0 & 13.6 & 8.5 & 4.5 \\
\hline MISO-E & 17.6 & 9.8 & 8.5 & 3.0 \\
\hline NWPP-NW & 11.9 & 8.5 & 6.6 & 2.9 \\
\hline SPPc & 13.1 & 7.1 & 5.5 & 1.9 \\
\hline MISO-S & 10.3 & 6.1 & 4.9 & 1.5 \\
\hline ERCOT & 14.7 & 14.7 & 4.7 & 4.7 \\
\hline SRSG & 6.8 & 5.5 & 3.6 & 2.7 \\
\hline MISO-W & 8.4 & 2.8 & 3.5 & 0.8 \\
\hline RMRG & 4.6 & 1.7 & 2.6 & 0.8 \\
\hline NYISO & 5.2 & 5.2 & 2.5 & 2.5 \\
\hline NWPP-S & 3.7 & 3.2 & 2.4 & 2.1 \\
\hline SERC-SE & 5.0 & 3.8 & 2.0 & 1.2 \\
\hline SERC-N & 3.2 & 3.1 & 1.2 & 1.0 \\
\hline Total & 233 & 161 & 116 & 63 \\
\hline
\end{tabular}

a Net metering assumes state NEM policies that do not have a legislated end date are extended, while net billing assumes all regions use a policy that compensates customers at wholesale rates for power sold back to the grid.

${ }^{b}$ NPP-NW = Northwest Power Pool-Northwest; NPP-S = Northwest Power Pool-South

c SPP $=$ Southwest Power Pool

d SRSG = Southwest Reserve Sharing Group

${ }^{\mathrm{e}} \mathrm{RMRG}=$ Rocky Mountain Reserve Group

Figure 56 is a county-level map of the United States indicating the projected cumulative DPV installed capacity by the year 2040 from dGen's Mid Cost scenario (with net metering). The scenario shown in Figure 56 assumes policies such as incentives or NEM programs will continue until current statues expire (as of November 2018). These policies likely explain some of the adoption in Northeastern U.S. states such as New York, Pennsylvania, and Massachusetts, which are expected to see substantial growth through 2040. On the other hand, states like Florida, and Arizona see high levels of adoption likely because of high solar resource availability. California 
and North Carolina both benefit from both a favorable policy regime and substantial solar resource availability.

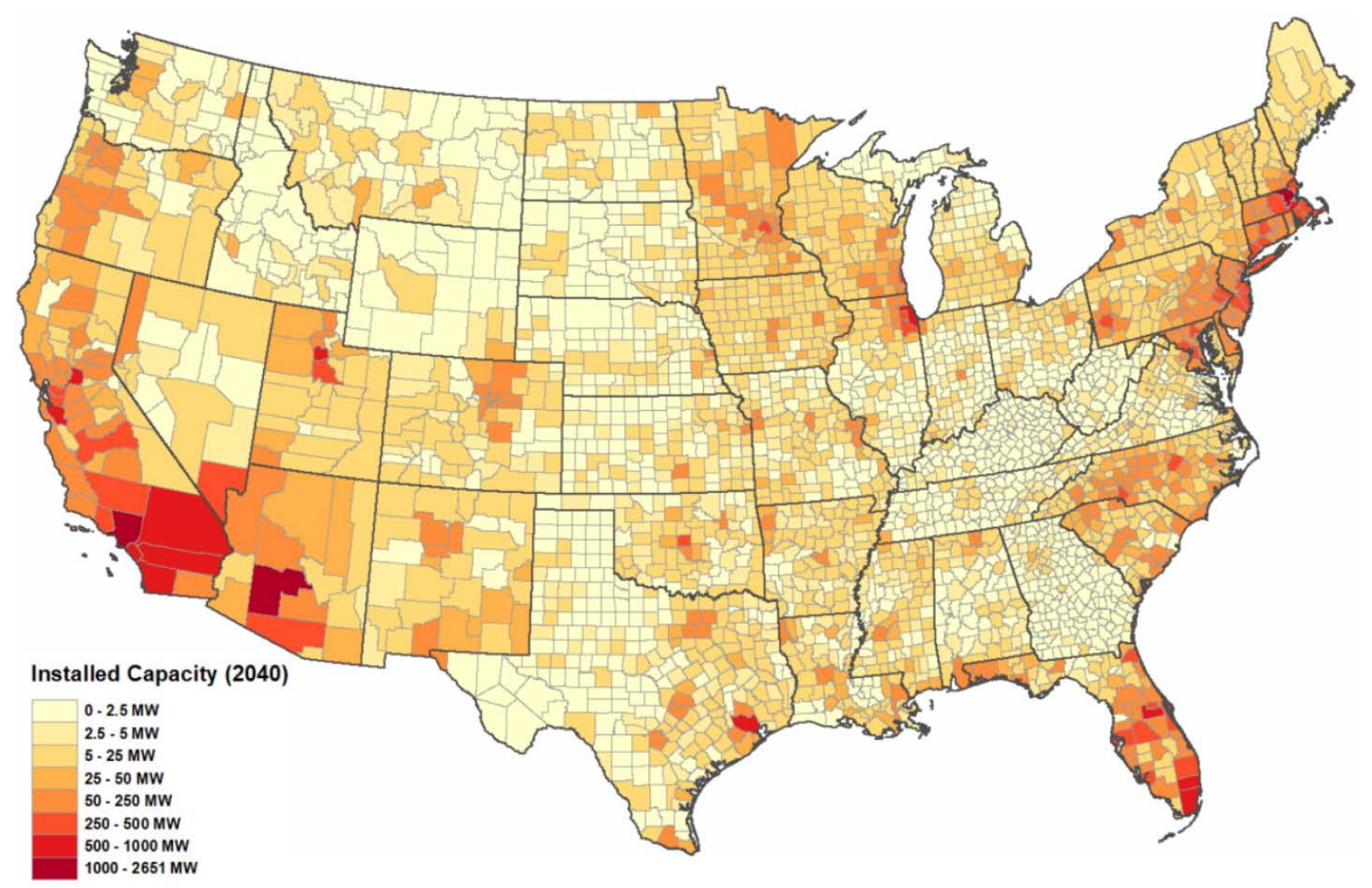

Figure 56. Projected DPV installed capacity (Mid Cost Scenario) by county

Across all geographies, solar resource adoption is temporally linked to factors such as the (increasing) cost of electricity and the (decreasing) installed technology cost of solar. Figure 57 shows a distribution of retail electricity consumption in North America by sector and cost (average $\$ / \mathrm{kWh}$ inclusive of all fees paid by dGen agents). In the United States, the residential sector forms a normal curve with a mean electricity cost of around $\$ 0.11 / \mathrm{kWh}$ in 2018 dollars. Commercial agents in the model pay somewhat less on average, although there is some bifurcation with bookends between $\$ 0.03 / \mathrm{kWh}$ and $\$ 0.15 / \mathrm{kWh}$. Industrial agents pay substantially less on average, which indicates residential and commercial agents provide some level of cross-subsidization to support industry within the United States through retail rates. This pattern makes the economics of rooftop solar PV adoption more favorable among the residential sector by potentially offering a lower-cost source of electricity as the cost of solar decreases (installed costs per kilowatt were displayed earlier in Figure 9). All these rates are adjusted into the future based on electricity cost projections in the ReEDS model in the iterative process described in Section 2.1.2. 


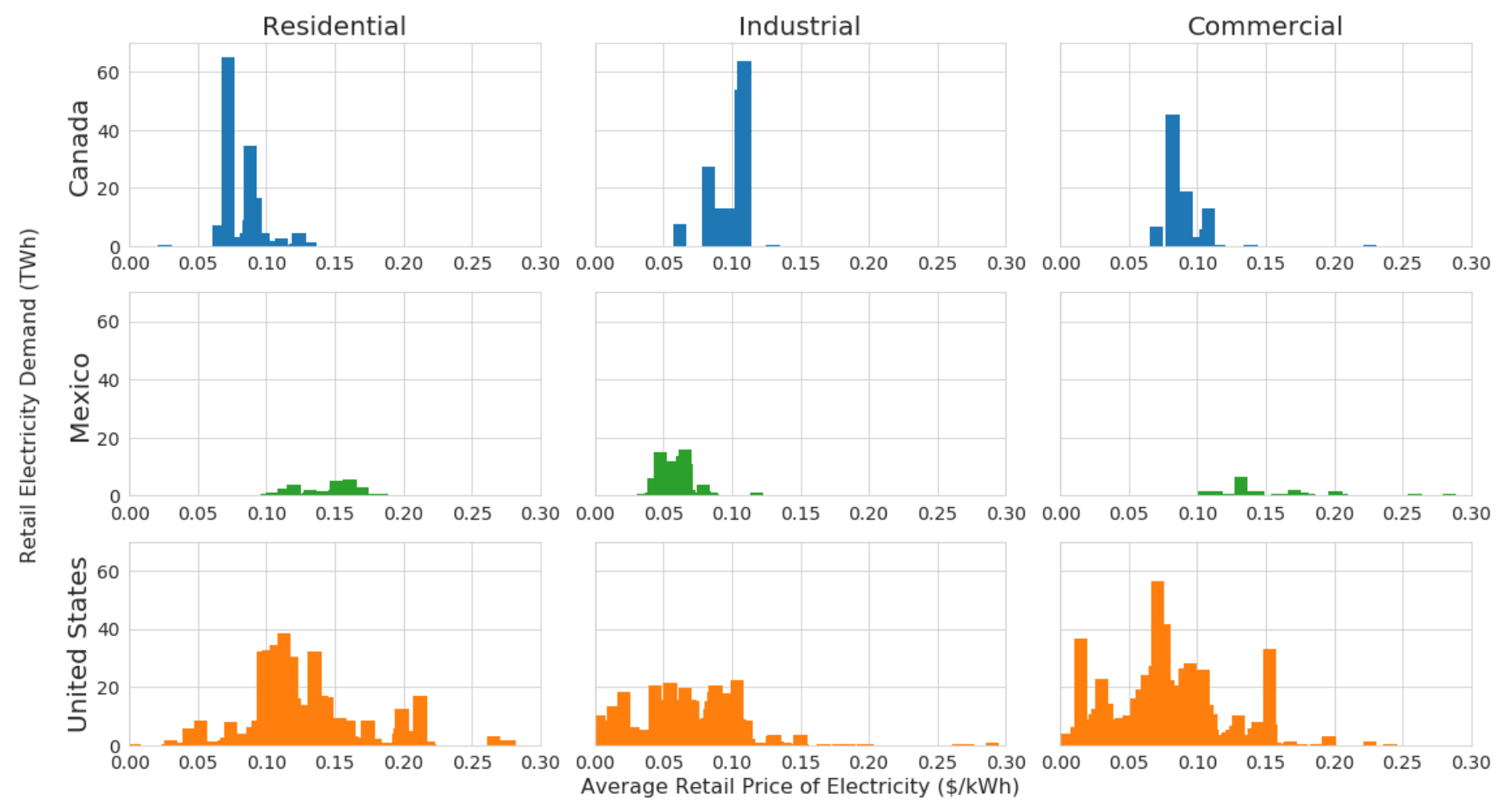

Figure 57. Histograms of average retail cost of electricity $(\$ / k W h)$ across United States by sector

Histogram bins are weighted based on total load, with rates based on the total charges (including, for example, any metering charges or demand charges) divided by total load. Data were populated in the Utility Rate Database (OpenEl, https://openei.org/wiki/Utility Rate Database); see the database for individual sources.

As the cost of electricity increases (modeled as an escalation within dGen, based on iteration with the ReEDS model) and the cost of solar decreases (in the Mid-Cost and Low-Cost scenarios of the ATB), the payback period of adopting DPV decreases. The payback period indicates the number of years of system operation needed to pay for financed system cost through retail electricity bill savings. Because of their higher average electricity cost in the United States, the residential sector achieves lower payback periods than other sectors as displayed in Figure 58 averaging 8.3 years across the United States in 2050 compared with 14.4 in the commercial sector and 15.5 in the industrial sector. As with adoption, payback periods vary greatly by geography. SERC-E which covers Georgia offers the lowest payback periods modeled by dGen of 5.8 years by 2050 in the Mid-Cost Scenario. NYISO contains average payback periods of 21.1 years. Though there is a trend in the results for greater adoption per capita in areas with low payback periods, other influences such as peer effects favor some regions over others. 


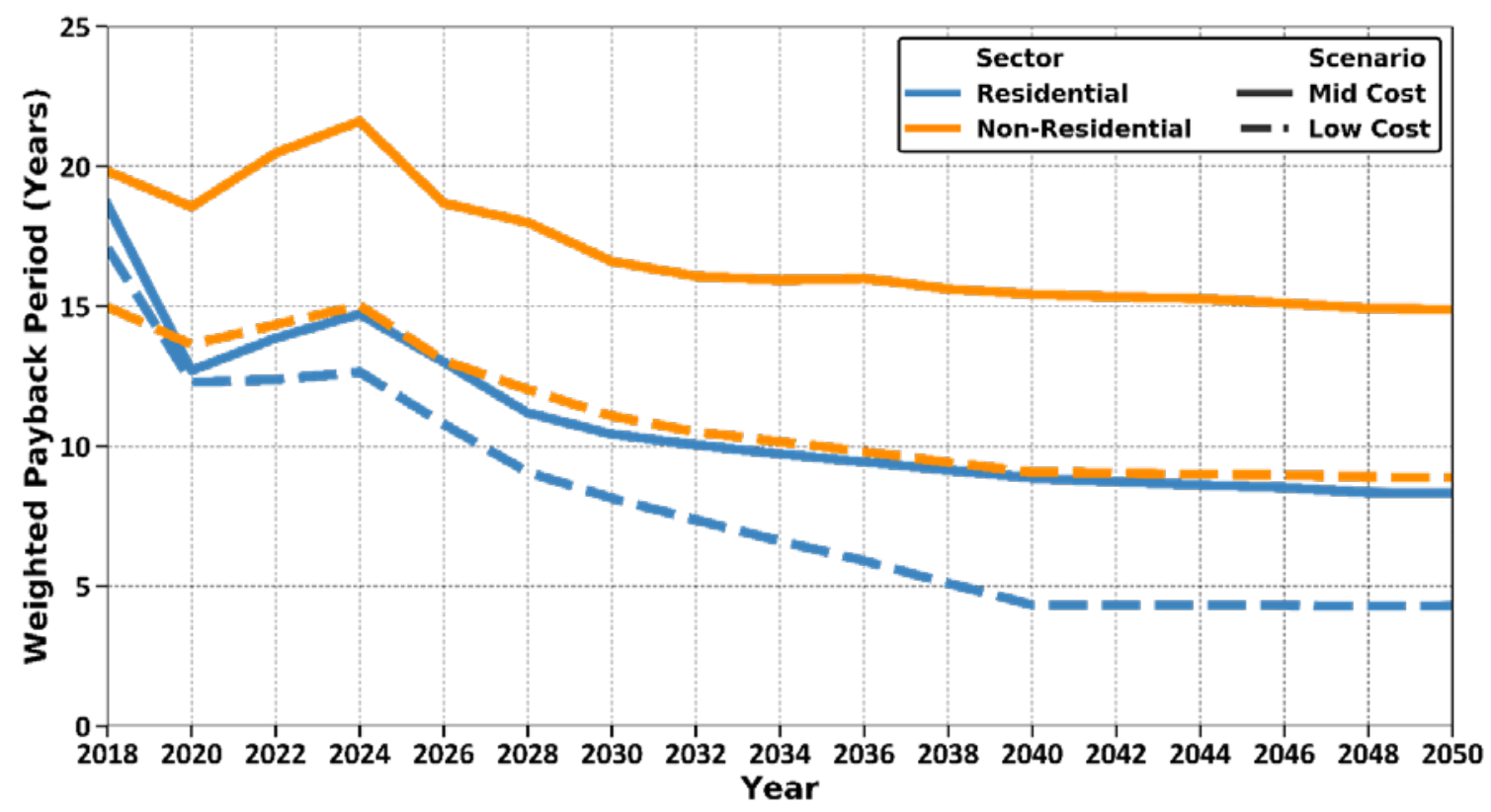

Figure 58. DPV payback periods by year across sectors and scenarios

In conclusion, dGen forecasts $63 \mathrm{GW}-233 \mathrm{GW}$ of DPV adoption by 2050 (depending on assumed costs and tariff structures), with the Mid Cost scenario forecasting $116 \mathrm{GW}$ for the net metering case assumptions. Cost is seen to be the most significant factor in determining adoption rates, and factors such as policy regime and resource availability lead to a concentration of adoption in a few regions with lower payback periods for solar PV. The distributed PV adoption is allowed to contribute toward planning reserve and adequacy in the ReEDS and PRAS modeling (respectively), based on the same methods as used for other wind and solar technologies.

The Mid and Low Costs scenarios in dGen (with Net Billing assumptions) were used as inputs for the ReEDS modeling in the NARIS scenarios (Low Cost dGen was used for Low Cost VG scenario, and the Mid Cost dGen was used for all others). Note that there is substantial uncertainty between the cost trajectories.

\subsubsection{Total costs are more sensitive to electrification and assumptions about wind and solar costs than carbon limits.}

Figure 59 shows the total system costs of the core scenarios through 2050. Comparisons of scenarios depend on several key assumptions - the most important of which are likely the assumed cost of wind and solar generation and the assumed price of natural gas. Based on the standard (2018 ATB) cost assumptions, the carbon constraint (80\% reduction from the U.S. grid compared to 2005) leads to a $6 \%$ increase in costs. The $\mathrm{CO}_{2}$ Constrained scenario reduces cumulative continental emissions by 10.5 billion metric tons at an average cost of $\$ 39$ per metric ton over the 30-year time horizon.

Low-cost wind and solar assumptions lead to overall cost reductions of $16 \%$ over the BAU with even lower carbon emissions (through 2050) than the $\mathrm{CO}_{2}$ Constrained scenario. Although the exact values are sensitive to assumptions, the low-cost wind and solar trajectories consistently lead to higher deployments of wind and solar in NARIS, both in the final scenarios presented here and previous iterations with different cost trajectory assumptions. 


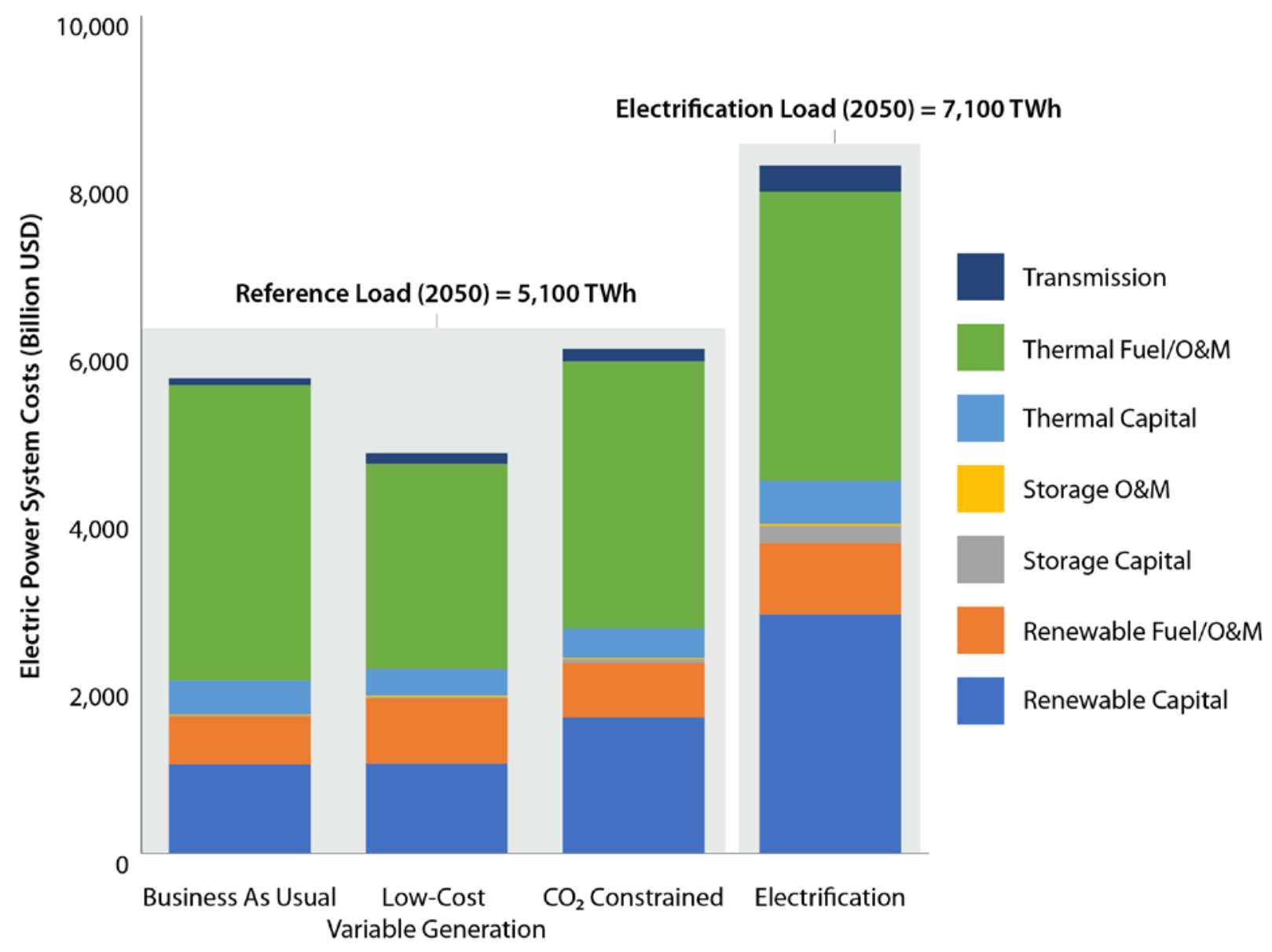

Figure 59. Total U.S. system costs for the core scenarios

The Electrification scenario costs include only electric sector costs and represent a large difference in 2050 demand (2050 annual demand is noted on figure); this does not consider the savings from reducing energy use in other sectors.

\subsubsection{Widespread electrification requires approximately doubling infrastructure investment from other core scenarios; further research is needed.}

Most of the scenarios in this study assumed load growth consistent with default assumptions that assume minimal newly electrified loads in 2050 (see Section 2.2.2). To understand how key conclusions from the study could change under a high-electrification scenario, we applied the load profiles created for the High Electrification scenario in the Electrification Futures Study for the United States to produce scenarios that assumed higher electrification of existing energy uses, such as transportation and building heating. We used the EnergyPATHWAYS model (using a slightly simpler methodology than the EnergyPATHWAYS used for the Electrification Futures Study) for Canada and Mexico.

EnergyPATHWAYS is a comprehensive energy accounting and analysis framework specifically designed to examine the large-scale energy system transformations. It has been used in more than a dozen national and subnational studies to calculate the impacts of energy system decisions into the future in terms of infrastructure, emissions, and cost impacts to energy consumers and the economy more broadly. 
Projections of future energy service are based on projections of variables that correlate with energy services, such as population. These explanatory variables are referred to as service demand drivers and are exogenous inputs to the EnergyPATHWAYS model. Often a chain of explanatory variables are used to determine service demand in a single subsector. For instance, residential space heating demand is based on residential square footage, which is based on the number of households, which is based on total population. Creation of hourly electricity profiles involves the additional step of multiplying annual final energy by a unitized shape representing the portion of electricity demand that occurs in each hour of the year.

Figure 60 and Figure 61 show the projected load growth from electrification through time and by province respectively. Electrification could add $38 \%$ to U.S. load in 2050, with transportation comprising the largest share of the new demands. Generally regional distribution of electrification load growth is similar to regional distribution of load, although some regions will see significant changes to the patterns of electricity load growth. For example, regions in the Northeastern United States could shift from summer peaking to winter peaking (see Figure 61).

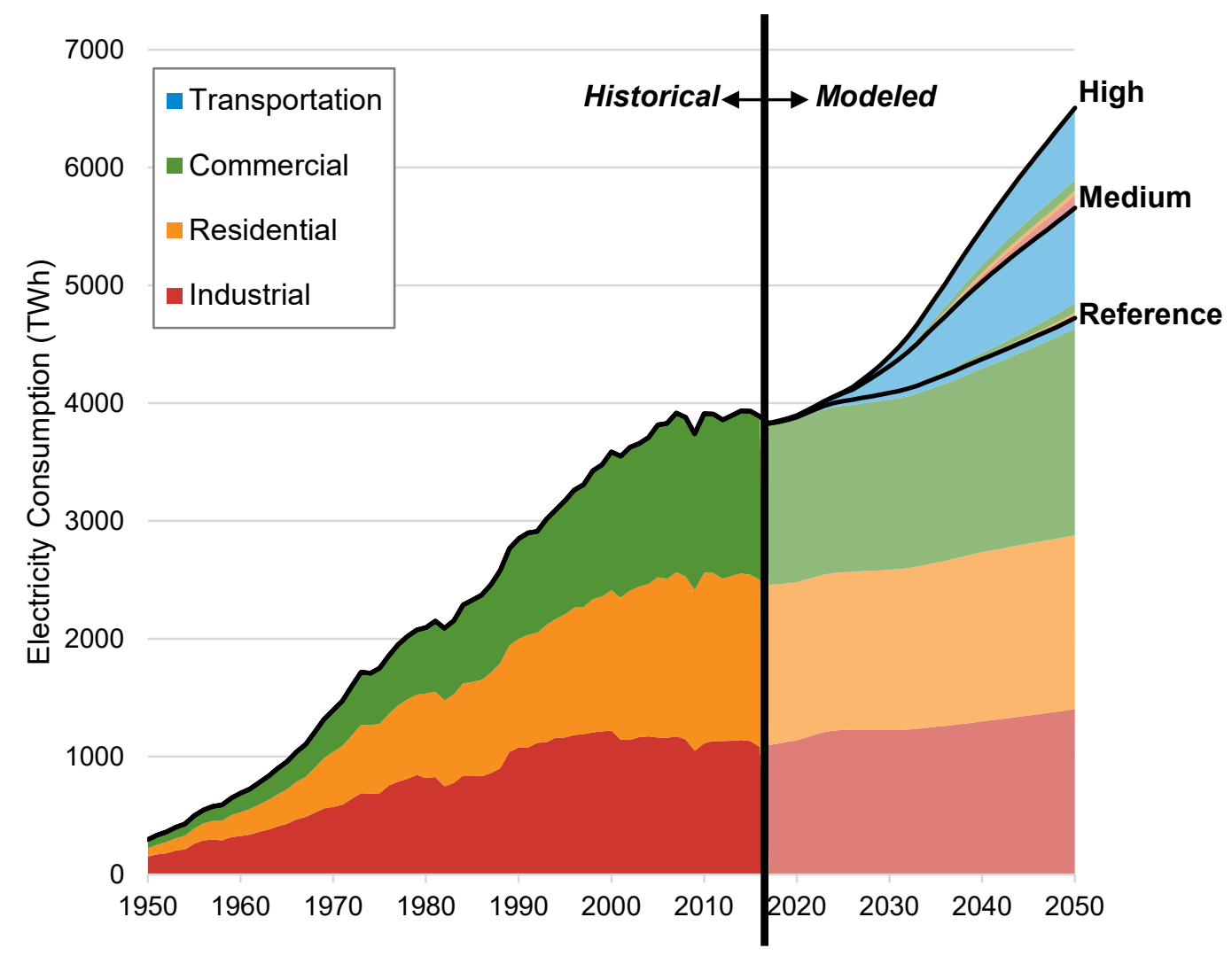

Figure 60. Load growth due to additional electrification in the Electrification scenario

The total load growth from electrification, shown here by sector, represents a $38 \%$ increase over the reference case in 2050. Source: Electrification Futures Study (Mai et al. 2018). 

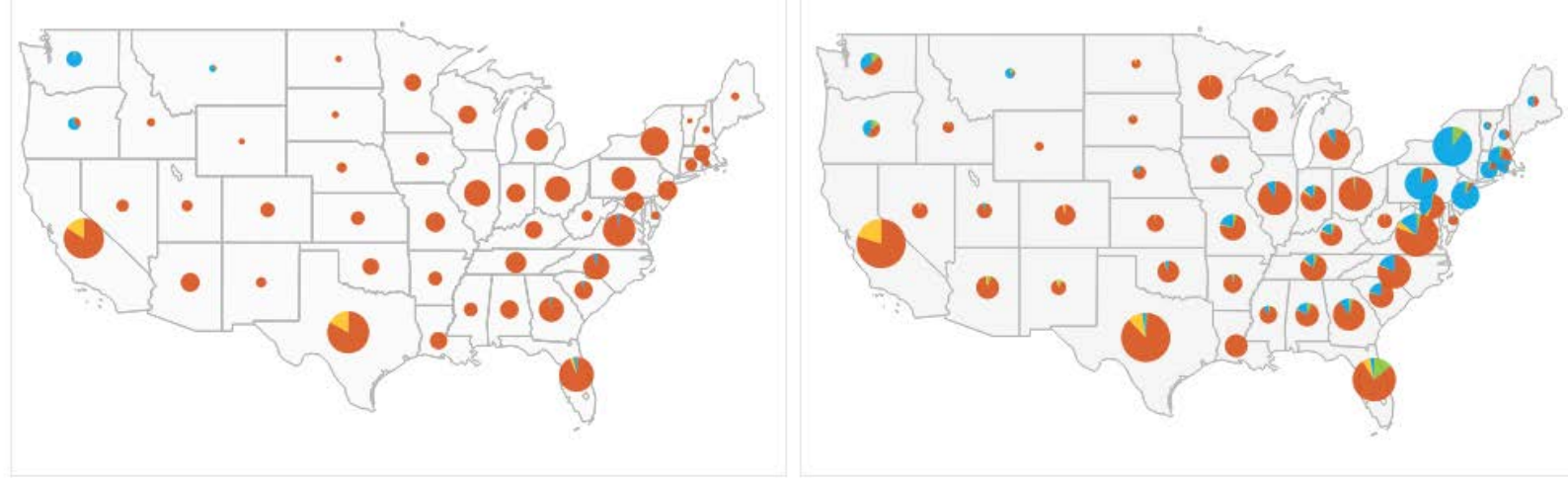

Season

Spring Fall

Summer Winter
Peak Load (GWh)

$\begin{array}{rrrr}1 & & 40 & \\ 20 & 60 & ( \\ 0 & 80\end{array}$

Figure 61. Electrification by state in 2050

The size of a pie charts corresponds with total electricity demand (GW) during the top demand hour. The pie wedges show the seasonal distribution of the top 100 hours with the highest demand by state. Seasons are defined along monthly groupings: summer includes June, July, and August; fall includes September, October, and November; winter includes December, January, and February; and spring includes March, April, and May. Data shown, including 2015 data, are based on modeled estimates from the Electrification Futures Study.

Figure 62 (page 83) shows the generation (left) and transmission (right) infrastructure built in the Electrification scenario versus the $\mathrm{CO}_{2}$ Constrained scenario, which is the next closest scenario in terms of infrastructure built in the model. Wind and solar development, and transmission development, are approximately double in the Electrification scenario. Though the benefits of electrification (possibly including both economics and emissions) might justify the investment, the quantity of infrastructure development is notable when compared to the other scenarios. 


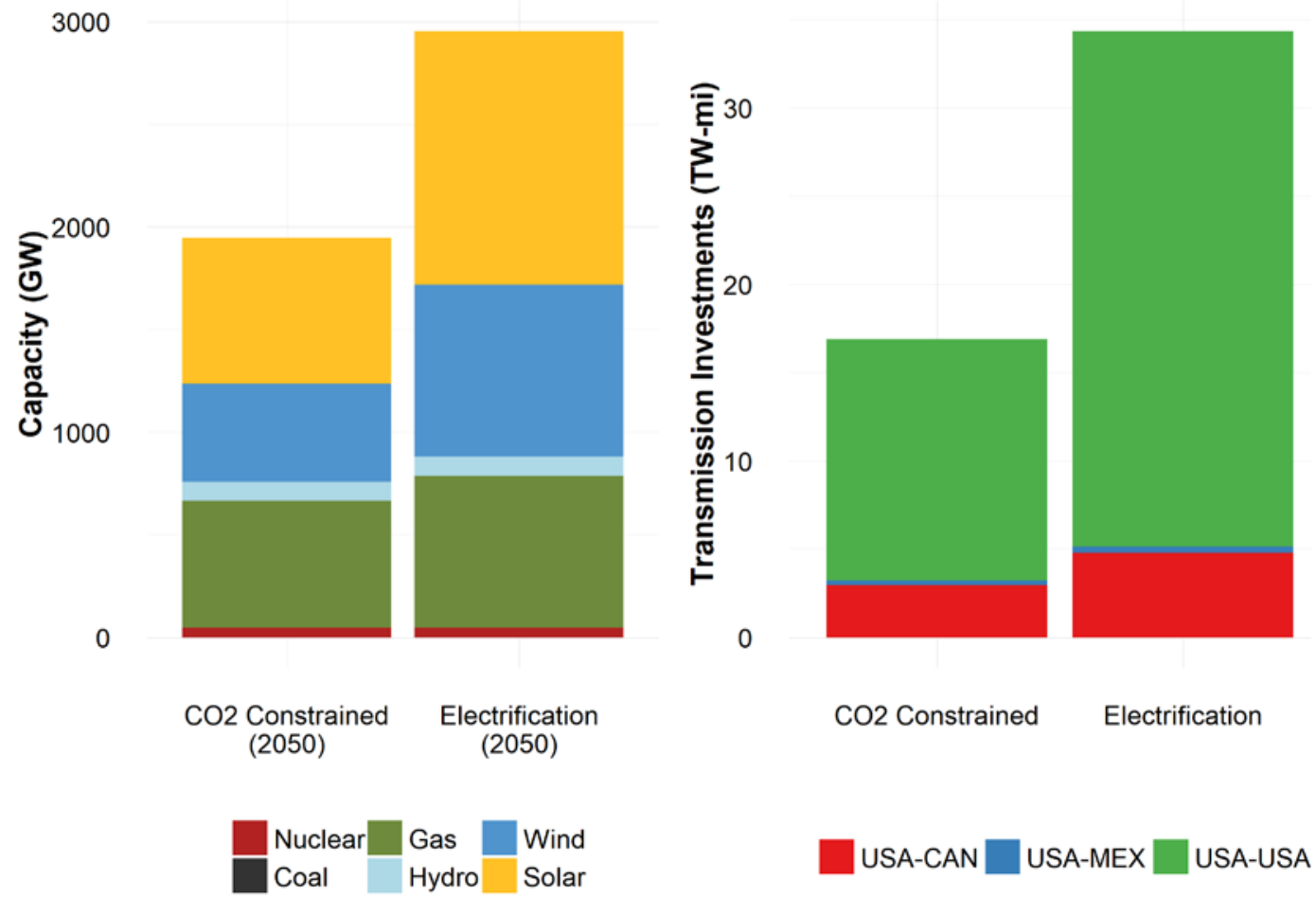

Figure 62. Generation capacity difference in 2050 (left) and total new transmission builds (right) between $\mathrm{CO}_{2}$ Constrained and Electrification scenarios

The ReEDS model results for the Electrification scenario look similar to those for other scenarios in many respects, with one very substantial difference: the amount of infrastructure built in the Electrification scenario is much larger because of higher loads.

These results are from the ReEDS model; PLEXOS and PRAS were not run on any scenarios that included electrification. Studying demand flexibility in PLEXOS and PRAS could lead to conclusions that reduce infrastructure needs (due to lower planning reserve requirements if peak demands are more flexible) or increase infrastructure needs (if nodal powerflow analysis demonstrates that more intrazonal transmission is needed).

Outside of the general infrastructure builds and costs (which occur due to shifting infrastructure and costs to the electricity sector), the results from the Electrification scenario do not conflict with other scenarios on any key findings (including findings related to transmission value, exports, achieving low-carbon targets, and others). Methods recently developed for the Electrification Futures Study and other studies could help improve methods for treatment of these new, potentially flexible loads. In future work, the value of load flexibility can be addressed. 


\subsubsection{Using better information during unit commitment reduces costs and curtailment.}

There is significant uncertainty about both (1) what the quality of wind and solar forecasts will look like in 2050 and (2) when commitment decisions will be made in regions both with and without ISOs. To address this uncertainty, we made three different types of forecasts and ran the PLEXOS unit commitment and dispatch modeling with each in the geographically decomposed method described in Section 2.1.3. Forecast data are described in Section 2.2.1.

A system operator in the 2050 grid could use better information during unit commitment in two ways:

- Improvements in Wind and Solar Forecasting: Advanced site-specific forecasting techniques were not specifically applied for NARIS, but such techniques could help achieve better information for use by operators in unit commitment.

- Shorter-Term Commitment Horizons: Though system operators today make many unit commitment decisions in the day-ahead time-frame, the U.S. grid in the NARIS 2050 scenarios consists mostly of generators that do not need commitment decisions to be made 24 hours in advance. Improved information could be used during unit commitment by performing operational commitment closer to real-time and repeating the process regularly. Such a "rolling" unit commitment method, in combination with generators that are flexible enough to adjust, could incorporate better information.

The model runs presented in Table 13 do not assume any specific rolling commitment horizon or forecasting technique; they use improved forecast information (from "blending" with real-time actual generation) to understand the potential benefit of using better information during unit commitment. Improving forecast error from $10 \%$ average MAE to $5 \%-0 \%$ reduces production costs by approximately $\$ 1$ billion (1\%) per step and reduces curtailment by approximately one percentage point per step.

Table 13. Continent-Wide Cost Impacts of Forecast Quality Used During Unit Commitment

\begin{tabular}{|l|l|l|l|}
\hline Forecast & $\begin{array}{l}\text { Annual Production } \\
\text { Cost Increase (\$) }\end{array}$ & $\begin{array}{l}\text { Annual Production } \\
\text { Cost Increase (\%) }\end{array}$ & $\begin{array}{l}\text { Total Wind and Solar } \\
\text { Curtailment (\%) }\end{array}$ \\
\hline Perfect forecasts & N/A & N/A & $9.1 \%$ \\
\hline $\begin{array}{l}\text { Forecast with 5\% continental } \\
\text { MAE (hours-ahead) }\end{array}$ & $\$ 800$ million & $1.1 \%$ & $10.4 \%$ \\
\hline $\begin{array}{l}\text { Forecast with 10\% } \\
\text { continental MAE (day- } \\
\text { ahead) }\end{array}$ & \$2 billion & $2.8 \%$ & $11.1 \%$ \\
\hline
\end{tabular}

Forecasts were created using day-ahead model runs from the ECMWF model, time synchronous with the 2012 meteorology presented in this report for dispatch. The forecast with $5 \%$ plant-averaged MAE is used in other sections of this report. Note that these sensitivities are based on a penultimate hourly version of the model, and absolute numbers may not be consistent with other sections. 


\section{Discussion and Future Work}

This report represents the findings of NARIS from a U.S. perspective. However, the overarching conclusions are nearly identical across the continent. ${ }^{35}$ Key NARIS learnings for the United States include:

- Supply can balance with demand in a variety of scenarios, with high contributions coming from renewable resources continentally. This was demonstrated through unit commitment and dispatch modeling with nodal transmission representation for 1 year of meteorological data and 7 years of historical meteorology for the Monte Carlo resource adequacy modeling.

- Thermal generators (i.e., nuclear, coal, and gas) do not produce as much energy in the NARIS scenarios in 2050 as actual thermal generators produce today, but significant thermal capacity remains in the NARIS scenarios to serve capacity adequacy needs of the system. This result is economic from a system cost perspective, but more study is needed to understand the market implications. Increased transmission and storage could also fulfill some of these system roles, and they could be optimal depending on cost and emissions limit assumptions.

- Transmission helps enable economics and reliability (via resource adequacy) in the NARIS scenarios. Transmission expansion and cooperation between countries can save the system tens of billions of dollars, while transmission and cooperation between regions can save hundreds of billions of dollars.

- Flexibility to accommodate the variability in the system can come from flexible operation of hydropower and thermal generators, transmission, storage, curtailment, and other technologies and practices.

Key assumptions and limitations of the study, which are listed in Section $\square$, include that:

- The ReEDS model used to create the transmission and generation expansion scenarios performs a cost optimization. Though this helps illuminate potential low-cost pathways to a reliable grid, it should not be read as a blueprint for the continent or any specific region.

- We ran scenarios with various assumptions about wind and solar costs, storage costs, natural gas prices, and other assumptions, and many of the conclusions in this report are robust to these assumptions. However, we represented only a small fraction of the infinite possibilities of combinations of all potential grid conditions in 2050.

- Although we addressed the adequacy portion of reliability, we did not address voltage or frequency stability in any detail in this work.

- Much of the work is based on meteorological conditions from 2007 through 2013. If these years are not representative of typical conditions in the future, or of certain types of extreme events, there could be gaps in our analysis. Climate change has the potential to lead to meteorological conditions different than what we have studied here.

\footnotetext{
${ }^{35}$ For our report of the NARIS findings from a Canadian perspective, see The North American Renewable Integration Study: A Canadian Perspective, which is available at "North American Renewable Integration Study," NREL, https://www.nrel.gov/analysis/naris.html.
} 
More study is needed to understand some of the key caveats and questions that remain after this work, including about:

- Market Implications: The optimizations in our sequence of models led to very different future operation for thermal generators (particularly natural gas combined cycle units) compared to their current operation. Existing market structures might not create sufficient revenue for these generators.

- Extreme Events: The NARIS scenarios were analyzed with state-of-the-art tools for data development and modeling. A variety of extreme meteorological events were considered in the 7 years studied (e.g., storms, heat waves, and polar vortex events). More-detailed analysis of how various technologies perform in extreme events (e.g., wind performance in a hurricane) could improve our understanding of grid reliability with today's infrastructure or the infrastructure of the future.

- Transmission: More-detailed transmission and power flow modeling could help us better understand the feasibility of the NARIS scenarios, and the costs and benefits of new transmission investments.

- Demand: The uncertainty of electricity demand patterns in the long-term future is significant due to climate change and electrification of other sectors. Building off the Electrification Futures Study, electrification-focused studies can also help refine and quantify the benefits of electrification to other sectors and understand the potential flexibility of new demands. For this study, the more detailed models (production cost and Monte Carlo resource adequacy) were not run on the Electrification scenario.

- Evolving Technologies: Technology cost improvements in NARIS sensitivities for storage and distributed generation led to significant increases in their deployment (hundreds of GW for each). Ongoing cost reductions for offshore wind in North America would likely lead to significant deployment increases. Other technology breakthroughs, including long-duration storage, carbon capture, geothermal, and concentrating solar power, could possibly lead to similar deployment expectations. Although the key conclusions in this report may be unaffected by these changes, there may be different conclusions or more efficient (or robust) ways to maintain a reliable low-carbon grid with emerging technologies over the coming decades. 


\section{References}

ABB. 2018. "Velocity Suite." https://www.hitachiabb-powergrids.com/us/en/offering/productand-system/energy-planning-trading/market-intelligence-services/velocity-suite.

Barrows, Clayton, Brendan McBennett, Josh Novacheck, Devon Sigler, Jessica Lau, and Aaron Bloom. 2019. "Multi-Operator Production Cost Modeling." IEEE Transactions on Power Systems 34(6): 4429-4427. https://doi.org/10.1109/TPWRS.2019.2918849.

Bass, Frank M. 1969. "A New Product Growth for Model Consumer Durables." Management Science 15(5): 215-227. https://doi.org/10.1287/mnsc.15.5.215.

Bloom, Aaron, Aaron Townsend, David Palchak, Joshua Novacheck, Jack King, Clayton Barrows, Eduardo Ibanez, et al. 2016. Eastern Renewable Generation Integration Study. Golden, CO: National Renewable Energy Laboratory. NREL/TP-6A20-64472. https://doi.org/10.2172/1318192.

Bloom, Aaron, J. Novacheck, G. Brinkman, J.D. McCalley, A.L. Figueroa-Acevedo, A. Jahabani-Ardakani, H. Nosair, J. Casparay, D. Osborn, J. Lau. "The Value of Increased HVDC Capacity Between Eastern and Western U.S. Grids: The Interconnections Seam Study." Submitted to IEEE Transactions on Power Systems.

Brinkman, Gregory. 2015. Renewable Electricity Futures: Operational Analysis of the Western Interconnection at Very High Renewable Penetrations. Golden, CO: National Renewable Energy Laboratory. NREL/TP-6A20-64467. https://doi.org/10.2172/1225515.

Carvalho, D., A. Rocha, M. Gómez-Gesteira, and C. Silva Santos. 2014. "WRF Wind Simulation and Wind Energy Production Estimates Forced by Different Reanalyses: Comparison with Observed Data for Portugal." Applied Energy 117: 116-126.

https://doi.org/10.1016/j.apenergy.2013.12.001.

Cohen, Stuart, Jon Becker, Dave Bielen, Maxwell Brown, Wesley Cole, Kelly Eurek, Will Frazier, et al. 2019. Regional Energy Deployment System (ReEDS) Model Documentation: Version 2018. Golden, CO: National Renewable Energy Laboratory. NREL/TP-6A20-72023. https://doi.org/10.2172/1505935.

Cole, Wesley, Will Frazier, Paul Donohoo-Vallett, Trieu Mai, and Paritosh Das. 2018. 2018 Standard Scenarios Report: A U.S. Electricity Sector Outlook. Golden, CO: National Renewable Energy Laboratory. NREL/TP-6A20-71913. https://doi.org/10.2172/1481848.

DNV GL. 2014. Integrating Renewable Energy in Europe: Final Report. Bonn, Germany: DNV GL - Energy. 9011-700.

https://ec.europa.eu/energy/sites/ener/files/documents/201406_report_renewables_integration_eu rope.pdf. 
Dobbs, Alex. Tarek Elgindy, Bri-Mathias Hodge, and Anthony Florita. 2017. "Short-Term Solar Forecasting Performance of Popular Machine Learning Algorithms: Preprint." Presented at the International Workshop on the Integration of Solar Power into Power Systems (Solar Integration Workshop), Berlin, Germany, October 24-26, 2017. NREL/CP-5D00-70030. https://www.nrel.gov/docs/fy18osti/70030.pdf.

DOE (U.S. Department of Energy). 2016. Hydropower Vision: A New Chapter for America's 1st Renewable Electricity Source. DOE/GO-102016-4869. https://doi.org/10.2172/1502612.

Dong, Changgui, and Benjamin Sigrin. 2019. "Using Willingness to Pay to Forecast the Adoption of Solar Photovoltaics: A 'Parameterization + Calibration' Approach." Energy Policy 129: 100-110. https://doi.org/10.1016/j.enpol.2019.02.017.

Draxl, Caroline, Andrew Clifton, Bri-Mathias Hodge, and Jim McCaa. 2015. "The Wind Integration National Dataset (WIND) Toolkit.” Applied Energy 151(1): 355-366. http://dx.doi.org/10.1016/j.apenergy.2015.03.121.

Draxl, C., B.M. Hodge, K. Orwig, W. Jones, K. Searight, D. Getman, S. Harrold, et al. 2013. Advancements in Wind Integration Study Data Modeling: The Wind Integration National Dataset (WIND) Toolkit. Golden, CO: National Renewable Energy Laboratory. NREL/CP-5D0060269. https://www.nrel.gov/docs/fy14osti/60269.pdf.

EIA (U.S. Energy Information Administration). 2018. Annual Energy Outlook 2018 with Projections to 2050. https://www.eia.gov/outlooks/archive/aeo18/pdf/AEO2018.pdf..

EIPC (Eastern Interconnect Planning Collaborative). 2015. Phase 2 Report: DOE Draft: Parts 27 Interregional Transmission Development and Analysis for Three Stakeholder Selected Scenarios. Eastern Interconnect Planning Collaborative.

Eurek, Kelly, Wesley Cole, David Bielen, Nate Blair, Stuart Cohen, Bethany Frew, Jonathan Ho, et al. 2016. Regional Energy Deployment System (ReEDS) Model Documentation: Version 2016. Golden, CO: National Renewable Energy Laboratory. TP-6A20-67067.

https://doi.org/10.2172/1332909.

Frazier, A. Will, Wesley Cole, Paul Denholm, Daniel Greer, and Pieter Gagnon. 2020. "Assessing the Potential of Battery Storage as a Peaking Capacity Resource in the United States," Applied Energy 275: 115385. https://doi.org/10.1016/j.apenergy.2020.115385.

Gagnon, Pieter, Robert Margolis, Jennifer Melius, Caleb Phillips, and Ryan Elmore. 2016. Rooftop Solar Photovoltaic Technical Potential in the United States: A Detailed Assessment. Golden, CO: National Renewable Energy Laboratory. NREL/TP-6A20-65298. https://doi.org/10.2172/1236153.

Garcia-Diez, M., J. Fernandez, L. Fita, L., M. Menendez, F.J. Mendez, and J.M. Gutierrez. 2012. "Using WRF to Generate High Resolution Offshore Wind Climatologies." Proceedings: $8^{\circ}$ Congreso Internacional AEC, Salamanca, Spain, September 2012. http://www.meteo.unican.es/en/node/73063. 
GE Energy. 2010. Western Wind and Solar Integration Study. Prepared for the National Renewable Energy Laboratory by GE Energy. Golden, CO: National Renewable Energy Laboratory. NREL/SR-550-47434. https://doi.org/10.2172/981991.

GE Energy Consulting. 2016. Pan-Canadian Wind Integration Study (PCWIS): Section 1: Summary Report. Prepared for Canadian Wind Energy Association (CanWEA) by GE Energy Consulting. October 14, 2016. https://canwea.ca/wp-content/uploads/2016/07/pcwis-section01summaryreport.pdf.

Government of Canada. 2016. Canada's Mid-Century Long-Term Low-Greenhouse Gas Development Strategy. Gatineau, Quebec: Environment and Climate Change Canada. https://unfccc.int/files/focus/long-term_strategies/application/pdf/canadas_mid-century_longterm strategy.pdf.

Heard, B. P., B. W. Brook, T. M. L. Wigley, and C. J. A. Bradshaw. 2017. "Burden of Proof: A Comprehensive Review of the Feasibility of 100\% Renewable-Electricity Systems." Renewable and Sustainable Energy Reviews 76 (September 1, 2017): 1122-1133. https://doi.org/10.1016/j.rser.2017.03.114.

Ji-Hang, Li, Zhen-Hai Guo, Wang Hui-Jun. 2014. "Analysis of Wind Power Assessment Based on the WRF Model." Atmospheric and Oceanic Science Letters 7(2): 126-131. https://doi.org/10.3878/j.issn.1674-2834.13.0078.

Lew, D., G. Brinkman, E. Ibanez, A. Florita, M. Heaney, B. M. Hodge, M. Hummon, et al. 2013. Western Wind and Solar Integration Study Phase 2. Golden, CO: National Renewable Energy Laboratory. NREL/TP-5500-55588. https://dx.doi.org/10.2172/1095399.

Liu, Shucheng. 2014. "Direct Testimony of Dr. Shucheng Liu on Behalf of the California Independent System Operator Corporation.” Rulemaking 13-12-010 for California Public Utilities Commission.

Lundquist, J.K., A. Purkayastha, C. St. Martin, and R. Newsom. 2014. Estimating the Wind Resource in Uttarakhand: Comparison of Dynamic Downscaling with Doppler Lidar Wind Measurements. Golden, CO: National Renewable Energy Laboratory. NREL/TP-5000-61103. https://doi.org/10.2172/1126840.

MacDonald, Alexander E., Christopher T. M. Clack, Anneliese Alexander, Adam Dunbar, James Wilczak, and Yuanfu Xie. 2016. "Future Cost-Competitive Electricity Systems and Their Impact on US CO 2 Emissions." Nature Climate Change 6(5): 526-531. https://doi.org/10.1038/nclimate2921.

Maclaurin, Galen, Nick Grue, Anthony Lopez, and Donna Heimiller. 2019. The Renewable Energy Potential (ReV) Model: A Geospatial Platform for Technical Potential and Supply Curve Modeling. Golden, CO: National Renewable Energy Laboratory. NREL/TP-6A20-73067. https://doi.org/10.2172/1563140. 
Mai, Trieu, Paige Jadun, Jeffrey Logan, Colin McMillan, Matteo Muratori, Daniel Steinberg, Laura Vimmerstedt, et al. 2018. Electrification Futures Study: Scenarios of Electric Technology Adoption and Power Consumption for the United States. Golden, CO: National Renewable Energy Laboratory. NREL/TP-6A20-71500. https://doi.org/10.2172/1459351.

Miller, N.W., M. Shao, S. Pajic, and R. D'Aquila. 2014. Western Wind and Solar Integration Study Phase 3: Frequency Response and Transient Stability. Golden, CO: National Renewable Energy Laboratory. NREL/SR-5D00-62906. https://doi.org/10.2172/1167065.

NEB (National Energy Board). 2017. Canada's Energy Future 2017: Energy Supply and Demand Projections to 2040. https://doi.org/10.35002/sqvz-gs91.

NERC (North American Electric Reliability Corporation). 2020. 2020 Long-Term Reliability Assessment. https://www.nerc.com/pa/RAPA/ra/Reliability\%20Assessments\%20DL/NERC LTRA 2020.pdf.

- 2018. 2018 Long-Term Reliability Assessment. https://www.nerc.com/pa/RAPA/ra/Reliability\%20Assessments\%20DL/NERC_LTRA_2018 12 202018.pdf.

Novacheck, Joshua, Greg Brinkman, and Gian Porro. 2018. Operational Analysis of the Eastern Interconnection at Very High Renewable Penetrations. Golden, CO: National Renewable Energy Laboratory. NREL/TP-6A20-71465. https://doi.org/10.2172/1476255.

Rossol, Michael, Gregory Brinkman, Grant Buster, Paul Denholm, Joshua Novacheck, and Gord Stephen. 2019. "An Analysis of Thermal Plant Flexibility Using a National Generator Performance Database.” Environmental Science \& Technology 53(22): 13486-13494. https://doi.org/10.1021/acs.est.9b04522.

Rossol, Michael, Grant Buster, and Mike Bannister. 2021. "The Renewable Energy Potential Model (reV)." https://github.com/NREL/reV.

Schlag, Nick, Arne Olson, Elaine Hart, Ana Mileva, Ryan Jones, Carlo Brancucci MartinezAnido, Bri-Mathias Hodge, et al. 2015. Western Interconnection Flexibility Assessment:

Final Report. San Francisco, CA: Energy and Environmental Economics, Inc.

https://www.ethree.com/wpcontent/uploads/2017/02/WECC_Flexibility_Assessment_Report_2016-01-11-1.pdf.

SEMARNAT-INECC. 2016. Mexico's Climate Change Mid-Century Strategy. Mexico City, Mexico: Ministry of Environment and Natural Resources (SEMARNAT), and National Institute of Ecology and Climate Change (INECC). https://unfccc.int/files/focus/longterm_strategies/application/pdf/mexico_mcs_final_cop22nov16_red.pdf.

SENER (Secretaría de Energía). 2018. "Programa de Desarrollo del Sistema Eléctrico Nacional 2018-2032." Mexico City, Mexico: La Secretaría de Energía. https://www.gob.mx/sener/acciones-y-programas/programa-de-desarrollo-del-sistema-electriconacional-33462. 
Sigrin, Ben, and Easan Drury. 2014. "Diffusion into New Markets: Economic Returns Required by Households to Adopt Rooftop Photovoltaics." Energy Market Prediction: Papers from the 2014 AAAI Fall Symposium.

https://www.aaai.org/ocs/index.php/FSS/FSS14/paper/viewFile/9222/9123

Sigrin, Ben, and Meghan Mooney. 2018. Rooftop Solar Technical Potential for Low-toModerate Income Households in the United States. Golden, CO: National Renewable Energy Laboratory. NREL/TP-6A20-70901. https://doi.org/10.2172/1434891.

Skamarock, William C., Joseph B. Klemp, Jimy Dudhia, David O. Gill, Dale M. Barker, Michael G. Duda, Xiang-Yu Huang, Wei Wang, and Jordan G. Powers. 2008. A Description of the Advanced Research WRF Version 3. Boulder, CO: National Center for Atmospheric Research. NCAR Tech Notes-475+STR. http://dx.doi.org/10.5065/D68S4MVH.

Stephen, Gord. 2021. Probabilistic Resource Adequacy Suite (PRAS) v0.6 Model Documentation. Golden, CO: National Renewable Energy Laboratory. NREL/TP-5C00- 79698. https://www.nrel.gov/docs/fy21osti/79698.pdf.

Uría-Martínez, Rocío, Megan M. Johnson, Patrick W. O’Connor, Nicole M. Samu, Adam M. Witt, Hoyt Battey, Timothy Welch, Marisol Bonnet, and Sarah Wagoner. 2018. 2017 Hydropower Market Report. Oak Ridge, TN: Oak Ridge National Laboratory. OE/EE1737. https://doi.org/10.2172/1513459.

White House, The. 2016. United States Mid-Century Strategy for Deep Decarbonization. November 2016. https://unfccc.int/files/focus/longterm_strategies/application/pdf/mid_century strategy report-final_red.pdf. 


\section{BNREL}

National Renewable Energy Laboratory

15013 Denver West Parkway, Golden, CO 80401

303-275-3000 • www.nrel.gov

NREL prints on paper that contains recycled content.
NREL is a national laboratory of the U.S. Department of Energy

Office of Energy Efficiency and Renewable Energy

Operated by the Alliance for Sustainable Energy, LLC

NREL/TP-6A20-79224 • June 2021 